\title{
OUT OF THE SQUARE: ENGAGING COMMUNITIES THROUGH URBAN GATHERING SPACES
}

\author{
by Michèle Curtis
}

A thesis submitted to the Faculty of Graduate and Postdoctoral Affairs

In partial fulfillment of the requirements for the degree of

\section{MASTER OF ARCHITECTURE}

In Azrieli School of Architecture

\author{
Carleton University \\ Ottawa, Ontario
}

(C) 2017 Michèle Curtis 



\begin{abstract}
Supporting and strengthening Indigenous culture is a prerequisite for Indigenous peoples adjusting to an urban environment. Maintaining a strong sense of identity and remaining engaged in the Indigenous community is an essential and self-validating pursuit. 'This thesis proposes gathering spaces for different cultural groups in Montreal in order to facilitate community engagement and to invigorate cultural identity, with a focus on Indigenous culture.

For over twenty years Cabot Square in Montreal has been a central meeting space for the Inuit and First Nations communities. This project explores architecture as a medium to promote inclusivity for the Indigenous community within the urban while creating social and cultural engagement. The thesis proposes gathering spaces as a means to facilitate a meeting and exchange of cultures in order to strengthen ways of expression for the urban Indigenous communities in the city, along with other communities.
\end{abstract}

${ }^{1}$ Newhouse, David, Peter, Evelyn. "No Strangers in These Parts" Policy Research Initiative:

Aboriginal Policy Research Conference. Nov. 2002. 


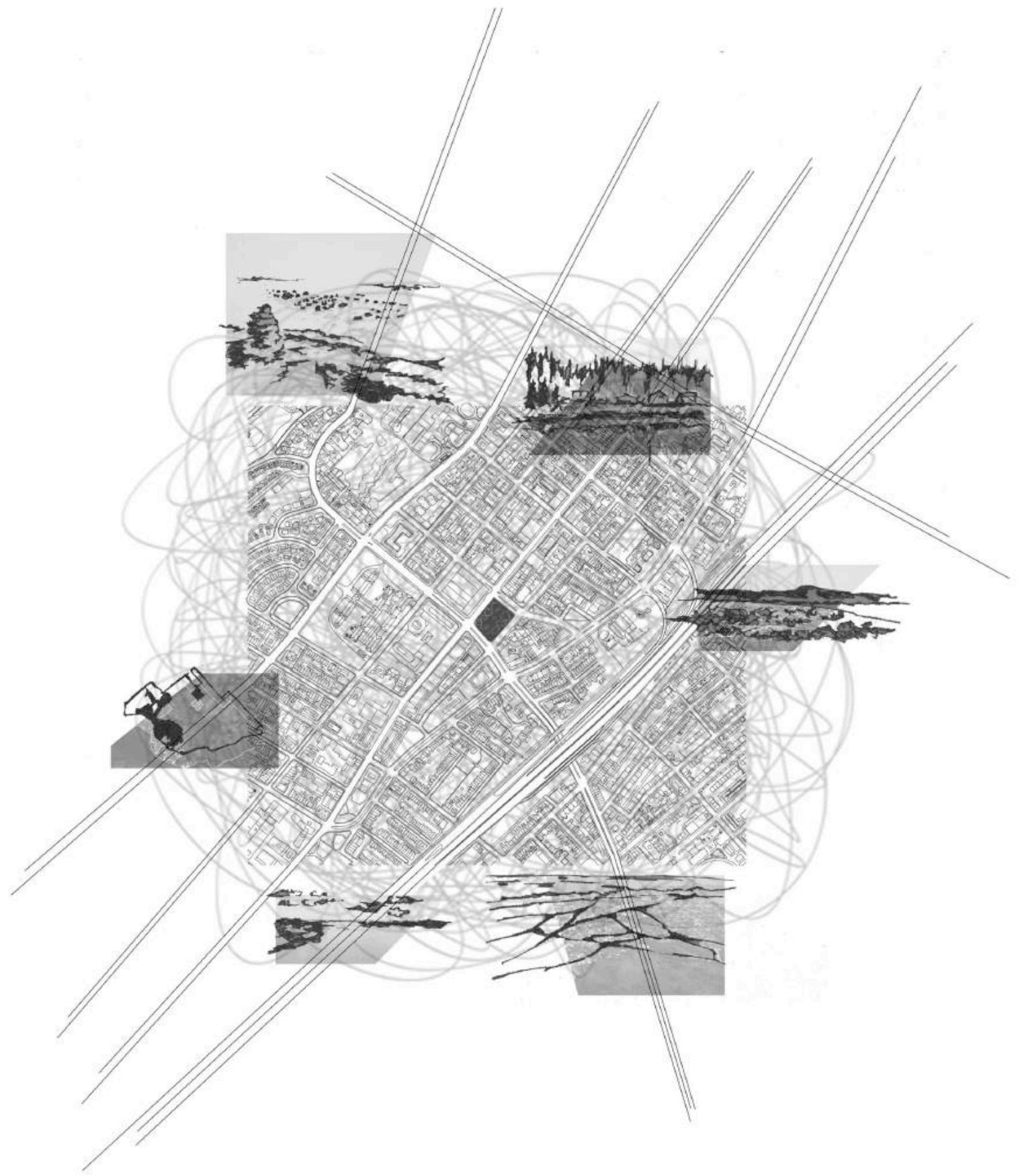

Figure 1: Out of The Square abstract image Source: Michèle Curtis 


\section{ACKNOWLEDGEMENTS}

I am truly grateful, and extend my heartfelt appreciation to the following people who helped make my project a success. Marianna Esponda, thank you so much for your guidance and ideas during the research, writing and design, and sticking with me throughout the long process. Frederica Goffi, thank you wholeheartedly for your genuine support and encouragement. Your professionalism and attitude gave me a huge boost when most needed. Greg Andonian, you have been one of the most important mentors to me while studying architecture. You have made a great contribution to my thesis and undergraduate work.

To all of my friends inside and outside of architecture: Thank you for the stimulating discussions, for the company during long nights in studio meeting deadlines, for the shared ideas, and for the comradeship and laughs over the years. Good luck to you all!

Last but not least, to my family who were always there for me, unconditionally, night and day, giving me praise for the good days, and encouragement and words of wisdom for the off days. Thank you. 



\section{TABLE OF CONTENTS}

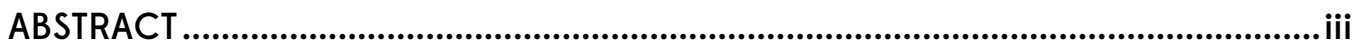

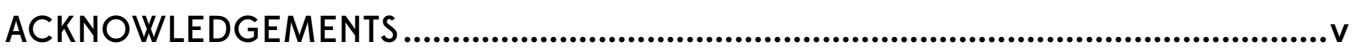

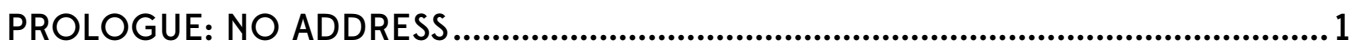

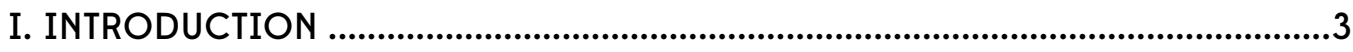

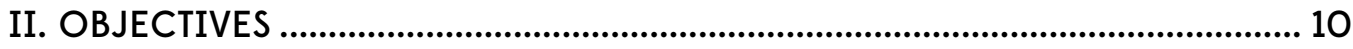

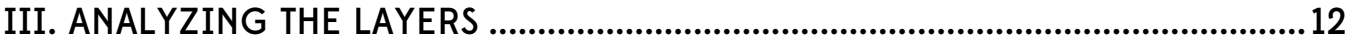

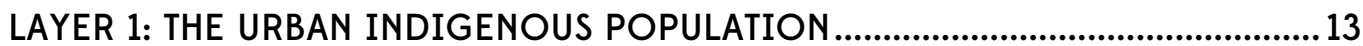

1.1. URBAN INDIGENOUS POPULATION IN CANADA ...................................13

1.2. URBAN INDIGENOUS POPULATION OF MONTREAL.............................15 LAYER 2: EARLY INDIGENOUS PRESENCE IN MONTREAL................................. 22

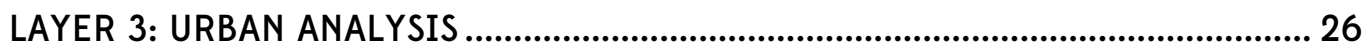

LAYER 4: OTHER URBAN SQUARES OF MONTREAL: PLACE ÉMILIE-

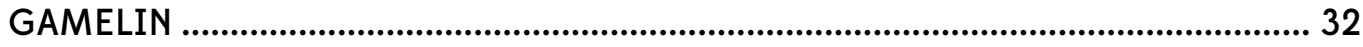

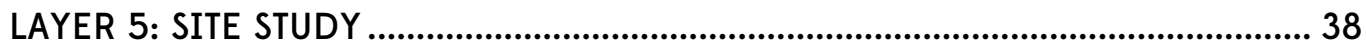

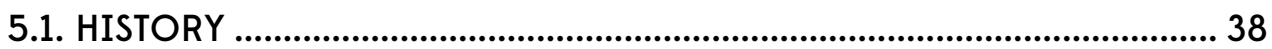

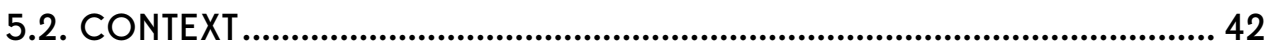

5.3. CURRENT SITUATION: THE CHILDREN'S HOSPITAL................................47

5.4. CURRENT SITUATION: THE CABOT SQUARE PROJECT .......................50

5.5. DEFINING ELEMENTS OF THE SQUARE............................................... 54

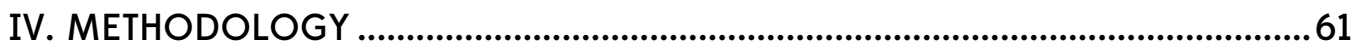

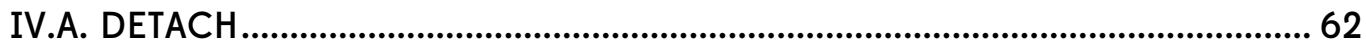

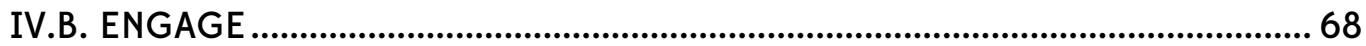

IV.C. CONSERVE

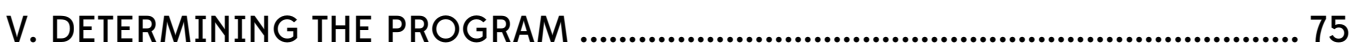

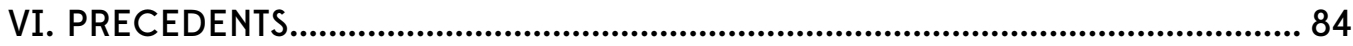

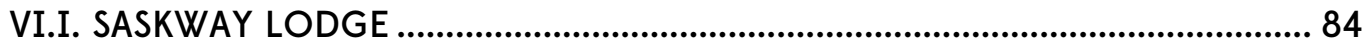

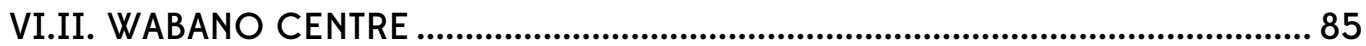

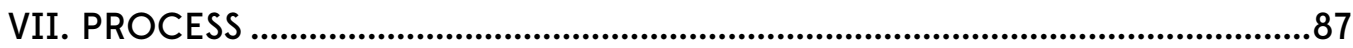

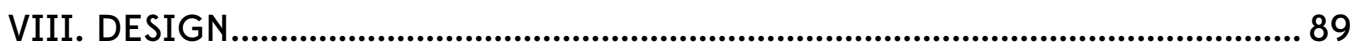

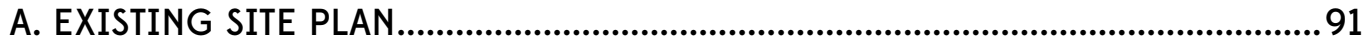

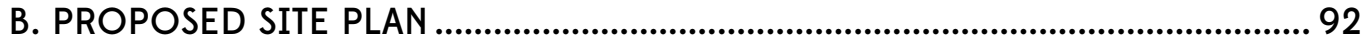

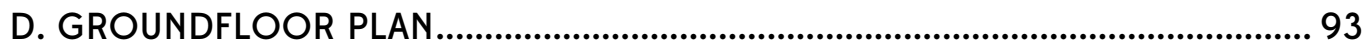

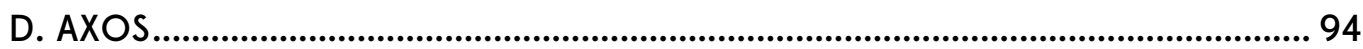

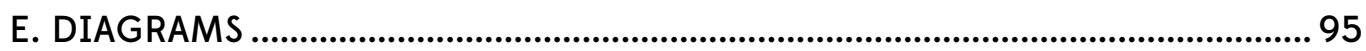

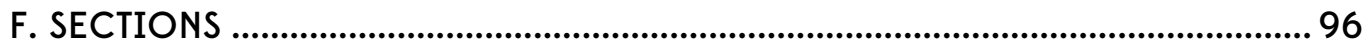

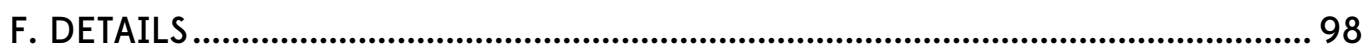




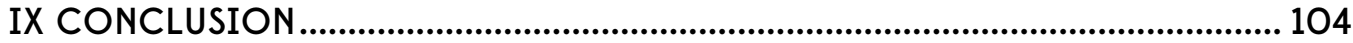

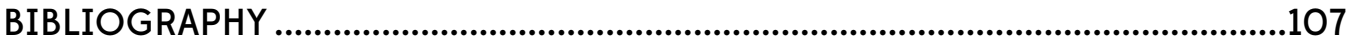

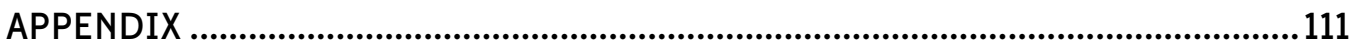





\section{PROLOGUE: NO ADDRESS}

"Many of our young native people come to Montreal with an unclear mind of what a city is all about. They left their communities, sometimes troubled, but at home there was always a place to sleep at night. They come without money; they have no friends and no job. Before long, they end up being part of the homeless community of Montreal."’

"No Address" is a National Film Board of Canada documentary by Alanis Obomsawin, a Canadian filmmaker of Abenaki descent and the writer and director of many NFB documentaries on First Nations issues. The film examines the predicament of Indigenous people who move to Montreal in hopes of finding a job and a healthier life ${ }^{3}$. Frequently arriving in the city without job experience, finances or friends, a large number of them quickly become lost and forgotten in the transient and homeless population. Disconnected from their traditional values and culture and alienated from other communities in the urban centre, they are torn between staying and returning home. ${ }^{4}$

${ }^{2}$ Alanis Obomsawin, No Address, Documentary, directed by Alanis Obomsawin (1988; Montreal: National Film Board of Canada, 1988), accessed 30 Dec. 2016.

${ }^{3}$ Ibid.

${ }^{4}$ Ibid. 


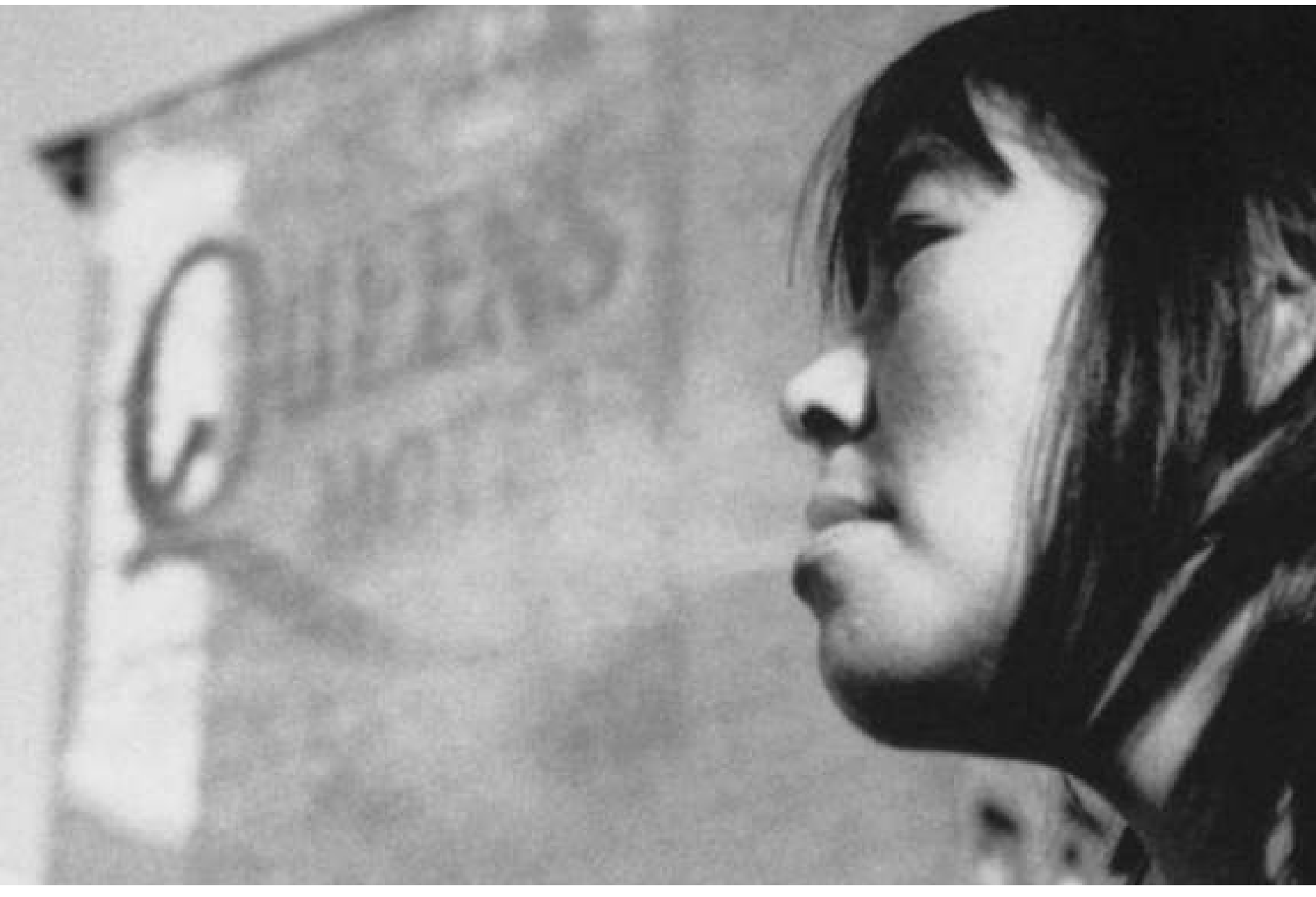

Figure 2: Still from "No Address" Source: $n f b . c a$ 


\section{INTRODUCTION}

Cabot Square has seen many transformations with various uses since its establishment in the late I8oos. It was created as a recreational space for the west-end dwellers of Montreal, and overtime became the site of much debate. The public square has become recognized as a pivotal gathering space for Indigenous Montrealers and other minority communities in the area, and was recently subjected to re-urbanization projects in order to improve its former conditions.

This thesis begins with a personal experience at Cabot Square. Living only blocks away, I would often pass by the park by using the Atwater metro entranceway (at Cabot Square). On more than one occasion, whether alone or with a group of friends, I felt unsafe mostly because of frequenters of the square (that I overlooked at the time) and would flee the area as quickly as possible. After the redevelopment of the park, I was curious to see the new design and prospective improvements. Although Cabot Square did feel much safer, it also felt and looked empty. This thesis looks at ways to improve upon the recent renovations of the square, while focusing on assisting the urban Indigenous community by exploring ways to create engagement and exchange with other communities at the square. 
Cabot Square used to be a place avoided by most passersby, and generally overlooked due to its adverse reputation. But today there is a new outlook, The Cabot Square Project is a strategic plan created by the Montreal Urban Aboriginal Community Strategy NETWORK beginning in $2013,{ }^{5}$ intended to improve the safety, wellbeing and sense of belonging of the Indigenous community of Montreal with a focus on the Ville-Marie borough, where Cabot Square is located. The project is aimed at Cabot Square and scaled to Montreal. ${ }^{6}$ The strategies applied to promote the square's environment have prompted healthier and safer relationships amongst frequenters of the park ${ }^{7}$, and have also encouraged the general public and tourists to visit the area, followed by a new design of the square - a project lead by architects Affleck de la Riva in collaboration with the City of Montreal completed in $2016 .{ }^{8}$ It should be noted that the new design solely focused on creating a safer space for the general public, and was scrutinized for disregarding the urban Indigenous and homeless frequenters of the area.

\footnotetext{
${ }^{5}$ The Montreal Urban Aboriginal Community Strategy (the NETWORK) functions as a collaboration platform where government agencies, including the police, community organizations, Indigenous groups, and citizens come together to undertake research and training, and to co-create effective strategies and projects.

${ }^{6}$ Montreal Urban Aboriginal Community Strategy Network. Final Report, Project: Learning from Cabot Square - Developing the Strategy for Community Safety and Wellbeing. Montreal: Montreal Urban Aboriginal Community Strategy Network, 2013. Accessed 3 Jan 2017.

${ }^{7}$ Montreal Urban Aboriginal Community Strategy Network. Final Report, Project: Learning from Cabot Square - Developing the Strategy for Community Safety and Wellbeing. Montreal: Montreal Urban Aboriginal Community Strategy Network, 2013. Accessed 3 Jan 2017.

${ }^{8}$ Sealy, Peter. "Cabot Square Redux", Canadian Architect. Accessed $24 \mathrm{Apr}$

2017,.https://www.canadianarchitect.com/features/cabot-square-redux/
} 
The re-urbanization of Cabot Square along with the Cabot Square Project frame the issues encountered by the area's occupants, which will further be addressed in this thesis. The proposal encompasses three core approaches influenced by the Cabot Square Project, each including several sub-notions. The first approach will be designated as 'Detach', expressing the issues and difficulties Indigenous peoples experience in relocating to the metropolitan centre. This approach includes the notions of 'Loss of Home', 'Cultural Disconnect' and 'Community Fragmentation', initially introduced by NETWORK for the Cabot Square Project. ${ }^{9}$ These concepts are equivalently considered for other cultural minorities and immigrant communities not only in Montreal and in other cities. The meaning of 'Detach' in the context of this thesis will be analyzed, and the program and design proposal intend to offer a response. The second approach, 'Engage' includes the notions of 'Wellbeing', 'Co-habitation', 'Belonging', and 'Safety' also developed by the Cabot Square Project. ${ }^{\text {10 }}$ This approach is intended to reverse the downward trend and continue improving the situation at Cabot Square along with its surroundings in order to sustain a positive environment, with a focus on engaging different communities and cultures of the area. An additional notion of 'Youth', a significant focus in Indigenous culture, completes the approach and is incorporated in the proposal. The third approach 'Conserve' follows selected principles from the ICOMOS Charter for the Interpretation and Presentation of Cultural Heritage Sites (I. Access and Understanding, 3. 
Attention to Setting and Context, 4. Preservation of Authenticity, 6. Concern for Inclusiveness) with the objective of respecting and building on the heritage values at Cabot Square, other neighboring buildings, and cultural associations developed at park overtime.

All three approaches in the thesis proposal are intended to encourage and create a central place for cultural exchange and everyday interactions within Cabot Square, ultimately aiming to assist urban inclusivity and growth. By valuing the different stakeholders of Cabot Square, particularly the urban Indigenous community, and by respecting the square's heritage value and new design, community engagement and growth will be initiated. Since this thesis focuses on engaging different communities in an urban context, it would only be possible to accomplish a final design, in reality, through the help of the communities, which was not entirely possible due to the duration of this project. This reflects in the core concept that although the program and design have been concluded for this thesis, in reality they are not meant to be finalized without the collaboration of the square's frequenters. The thesis offers a design intervention at the square, but the use of it remains open and adaptable to future change for its occupants. Cabot Square will be introduced with a series of three urban gathering spaces functioning as a central meeting centre in Montreal, aiming to promote Indigenous arts, culture and employment, while welcoming other minority groups, the general public and tourists. 


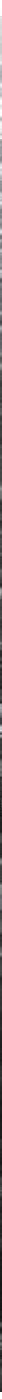

Figure 3: Cabot Square after re-urbaniation,

September 2016

Source: Michèle Curtis 


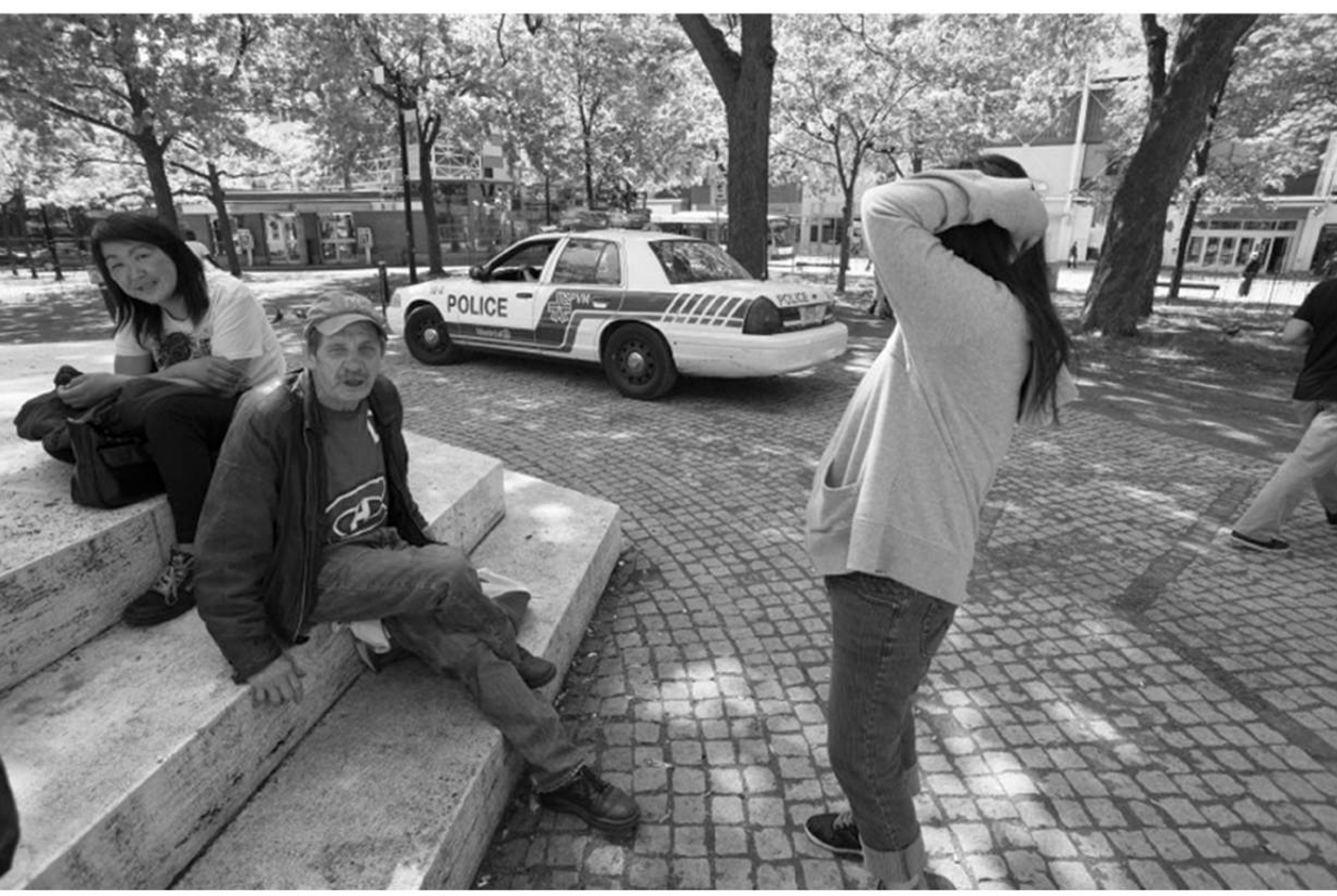

Figure 4: Inuit and homeless people at Cabot Square before re-urbanization Source: robertgalbraith.com 



\section{OBJECTIVES}

- This thesis seeks to understand Indigenous identity in an urban context.

- By doing so, this thesis also seeks to understand Cabot Square's identity (the site, mostly frequented by the urban Indigenous community).

- This thesis explores architecture's potential to contribute to community engagement, focusing on urban Indigenous and minority communities, while generating engagement and inclusiveness within the city environment. 



\section{ANALYZING THE LAYERS}

This thesis explores architecture as a way to help engage different communities in a historical public square, while respecting their identities along with the square's character. In order to thoroughly understand the complexity of the site and its stakeholders, five key layers including (I) The Urban Indigenous Population (Canada and Montreal), (2) History of Early Indigenous Presence in Montreal, (3) Urban Analysis, (4) Urban Squares of Montreal, and (5) Site Study are analyzed. 


\section{LAYER 1: THE URBAN INDIGENOUS POPULATION}

\subsection{URBAN INDIGENOUS POPULATION IN CANADA}

The North American Indigenous population is one of the quickest growing parts of the Canadian population to date, with considerable growth in recent decades. "Following are details provided from the 2006 Census on the urban Indigenous population in Canada.

- More than half $(623,470)$ of the $1,172,79^{\circ}$ people identifying themselves as members of at least one of Canada's Indigenous groups, that is-North American Indian, Métis or Inuit, reside in urban areas. Of this urban Indigenous population, almost $34 \%(213,945)$ live in five major cities: Winnipeg, Edmonton, Vancouver, Calgary and Toronto.

- Over the last 25 years, the urban Indigenous population in Canada has been consistently growing. In some cases, particularly in the larger cities, the Indigenous population has more than doubled. For example, in Winnipeg, the Indigenous population reached nearly 68,000, Io $\%$ of the population - more than four times higher than it was 25 years earlier.

11 "Fact Sheet- Urban Aboriginal Population in Canada", Urban Indigenous Peoples, Indigenous and Northern Affairs Canada, Government of Canada. Accessed 20 Apr 2017, http://www.aadncaandc.gc.ca/eng/1100100014298/1100100014302 
- The rapid growth rate can be attributed to a number of common demographic factors, such as: fertility, mobility and migration. Another important factor is what is referred to as "ethnic mobility", i.e., an increasing tendency for people to identify themselves as Indigenous, who may not have done so in previous censuses.

- The urban Indigenous population in Canada is very young. In 2006, $28 \%$ of the urban Aboriginal population was under i5 years old compared to $17 \%$ of the non-Indigenous population.

- Canada's urban Indigenous population is very mobile. One in four urban Indigenous person was living in a different residence one year prior to the 2006 Census, by moving within the same city or moving from a different community, like a First Nation Reserve or another urban or rural area. This high rate of mobility creates some challenges for accessing and providing services, particularly services like education, employment training and housing.

- Socio-economic indicators such as school attendance, post-secondary completion and employment are improving for Canada's urban Indigenous population. For example, over the last twenty years, a growing number of Indigenous people have completed post-secondary education. This is important because the statistics indicate that the employment gap between Indigenous and Non- 
Indigenous people in urban areas disappears for those who have completed post-secondary education, especially university. However, the pace of improvement has not been high enough, and the gap in university education continued to grow between the Indigenous population and non-Aboriginal population over the 200I-2006 period.

Source: Indigenous and Northern Affairs Canada, http://www.aadncaandc.gc.ca/eng/1100100014298/1100100014302

\subsection{URBAN INDIGENOUS POPULATION OF MONTREAL}

According to the 2006 Census, Montreal is home to more than 17,000 Indigenous peoples, which is among the smallest per capita Indigenous populations of other major cities. ${ }^{.2}$ Below is a list of key Indigenous Montrealer demographic information provided by the Urban Aboriginal Peoples Study ${ }^{13}$.

- $56 \%$ of Indigenous peoples live off reserve and Montreal has the largest urban Indigenous population in the province of Quebec, ranking as the $7^{\text {th }}$ city with the largest Indigenous population in Canada.

- Between 200I and 20II, the Indigenous population in Montreal grew by $135 \%$ due to an increase in offreserve migration to the city.

\footnotetext{
12 Environics Institute. Urban Aboriginal Peoples Study: Montreal Report. Toronto: Environics Institute, 2011. Accessed 24 Apr 2017, http://reseaumtlnetwork.com/network-documents-and-reports/

13 The Urban Aboriginal Peoples Study (UAPS) is conducted by the Environics Institute and guided by an Advisory Circle of recognized exports from academia and from Indigenous communities. The study is an enquiry into the values, experiences, identities and aspirations of First Nations peoples, Métis and Inuit living in Canada's major urban centres..
} 
- 26,28o Indigenous people live in the CMA (Census metropolitan area) of Montreal. The Indigenous population living in Montreal is slightly younger than the non-Indigenous population, with the median age of the Indigenous population of 37 years.

- $62 \%$ of the Indigenous youth aged i5 to 24 have lower school attendance rates than their non-Indigenous counterparts

- The unemployment rate of the Indigenous core working age population ( 25 to 54 years) is $7.5 \%$, which is slightly higher than that of the non-Indigenous population. Unemployment rates were higher for Montreal's Indigenous youth; 14.5\% of First Nations youth aged 15 to 24 years were unemployed, as were I6.4\% of Métis youth and II.9\% of non-Indigenous youth.

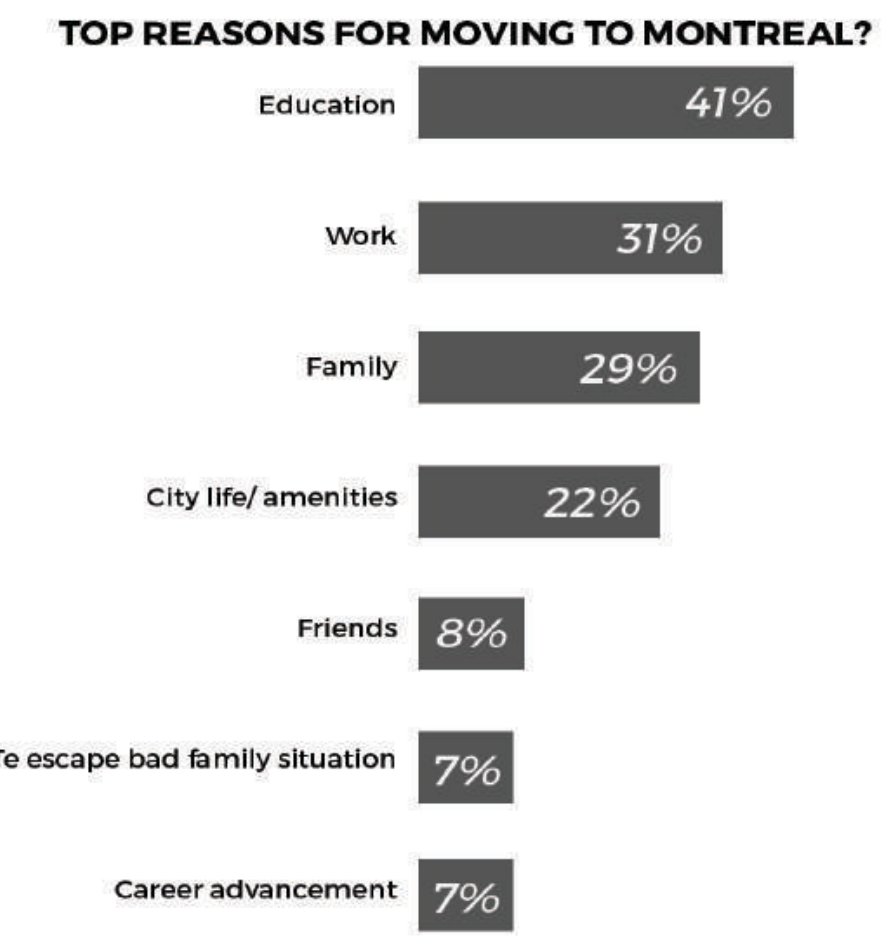


As part of their report, The UAPS consulted with Indigenous and non-Indigenous Montrealers to gain an understanding on both groups' perceptions and experiences within an urban centre, comparing them to other cities surveyed including Vancouver, Edmonton, Calgary, Regina, Saskatoon, Winnipeg, Thunder Bay, Toronto, Halifax and Ottawa these are considered UAPS cities). ${ }^{14}$ Following is a part of the summary of the study highlighting information that is most pertinent to this thesis.

HOW DO NON-ABORIGINAL RESIDENTS OF MONTREAL PERCEIVE INDIGENOUS PEOPLE?

- Among non-Indigenous people in Montreal, the most common top-of-mind impression of Indigenous peoples revolves around their history as the first inhabitants of Canada. The majority says their impressions have not changed over the few years (rather than having improved or worsened).

- Non-Indigenous Montrealers are twice as likely to say that Indigenous people have unique rights and privileges, as the first inhabitants of Canada as to say they are just like other cultural or ethnic groups in Canadian society. Belief in the unique rights of Aboriginal people is more common here than in any other UAPS cities.

${ }^{14}$ Environics Institute. Urban Aboriginal Peoples Study: Montreal Report. Toronto: Environics Institute, 2011. Accessed 24 Apr 2017, http://reseaumtlnetwork.com/network-documents-andreports/ 
- A slim majority of Montreal residents know Indigenous people live in their city, and they are the least aware than those in other cities of an Indigenous community (either physical or social) in their midst. Indeed, very few non-Indigenous Montrealers have regular contact with Aboriginal people, and they are among the least likely to know Indigenous people as close friends, neighbors and coworkers. Although they represent a minority, the proportion of "inattentive skeptics" (individuals who are uninformed and unaware of Indigenous peoples) is more prominent in Montreal than in other UAPS cities.

- Montreal residents clearly recognize that Indigenous people experience discrimination, and at least as much as other groups in Canadian society. Nonetheless, the minorities who do not believe such discrimination exists are somewhat larger in Montreal than in most other cities except Toronto.

- Opinion is divided about whether the current state of relations between Indigenous and non-Indigenous people in Canada is positive or negative, and the majority of non-Indigenous Montrealers are not seeing any change in this relationship over time.

Source: Urban Aboriginal Peoples Study 
IDENTITIES, EXPERIENCES, VALUES AND ASPIRATIONS OF INDIGENOUS RESIDENTS OF MONTREAL

- A majority of Indigenous peoples in Montreal consider the city to be their home, but this sentiment is less widespread here than in any other UAPS city. This appears to be in large part because Montreal has the largest proportion of first generation residents (i.e, Indigenous peoples born and raised in a community other than Montreal).

- This does not preclude a sense of satisfaction with their current city, on par with other UAPS participants. Indigenous peoples like living in Montreal, due to the quality of life and the city life available to them. They also tend to believe they can make a positive difference in the city. Their main concern centres on common urban pressures such as traffic and pollution, and they are much less likely than average to express concerns about crime.

- Indigenous Montrealers also express appreciation for the sense of social acceptance they find in the city, a view that is almost exclusive to Montreal and Toronto, where the size and diversity of the population likely makes it easier to "blend in". As well, while a majority say they have personally been teased or insulted because of their Indigenous background, this proportion is smaller here than in Toronto. 
- Nonetheless, consistent with other UAPS participants, most Indigenous Montrealers feel discrimination of Indigenous peoples is a pervasive problem. The predominant stereotype of Indigenous peoples is believed to be about substance abuse.

- There is strong Indigenous pride among Indigenous peoples in Montreal. Most are very proud of their specific First Nations/Métis/Inuk identity and their collective Indigenous identity. While Indigenous peoples in most other cities are similarly proud of their Canadian identity, strong pride in being Canadian is noticeably lower in Montreal than in any other city except Vancouver.

Source: Urban Aboriginal Peoples Study 



\section{LAYER 2: EARLY INDIGENOUS PRESENCE IN MONTREAL}

An understanding of early Indigenous presence in Montreal provides important context for a study of urban issues facing the contemporary Indigenous community. Historical information is also reflected in elements of the proposed design.

Old Montreal-what is now a public place and central tourist attraction in the city was once a forest enclosing bountiful wildlife, essential features for the survival of early North American peoples. ${ }^{\check{5}}$ The specific physical traits of this region in Montreal at the time played a crucial role in the development of first human occupation. ${ }^{16}$ This area always attracted settlers because it was accessible by a central waterway: the Little River. It was also a main connection point between the St. Lawrence River and a route that made it possible to avoid the Lachine Rapids. ${ }^{17}$ The Little River waterway additionally formed a natural harbour where the first inhabitants docked their canoes and later where the first French colonists arrived..$^{18}$

In the historic district of Old Montreal, near present-day Rue Saint-Paul, two archaeological sites believed to be from this time have provided invaluable information on the peoples of the vanished civilization, known as the Lamoka, a distinct culture that occupied the area north of the Little River around

\footnotetext{
${ }^{15}$ Forget, Madeleine, Lauzon, Gilles, et al. Old Montreal: History through Heritage. Québec: Les Publications du Québec, 2004, 9.

16 Ibid.

17 Ibid.

18 Ibid.
} 
2500 BC. ${ }^{19}$ The discovery of Lamoka type tools confirms the presence of the hunter-gatherers, who were mobile in the region and recognizable for their dependence on hornfels, ${ }^{20}$ a local stone from the Monteregian Hills, to which Mount Royal belongs. ${ }^{21}$

In 1535 , When Jacque Cartier, the first European known to have set foot in Montreal, sailed up the St. Lawrence River, the early Indigenous nomadic group named the St. Lawrence Iroquoians occupied the entire Laurentian Valley. ${ }^{22}$ However, when Samuel de Champlain sailed the river decades later, they seemed to have vanished. It is speculated that some Iroquoians may have been captured, while others may have joined different groups as a means of protection. ${ }^{23}$

Adjacent to the mouth of the Little River lies another area that was frequented by many Indigenous peoples who left behind material evidence; Place Royale is the main archaeological site in Old Montreal for understanding periods of early life of the region. ${ }^{24}$ In I6II, Champlain determined an appropriate site for settlement and decided that it would be Place Royale, "one

\footnotetext{
${ }^{19}$ Forget, Madeleine, Lauzon, Gilles, et al. Old Montreal: History through Heritage. Québec: Les Publications du Québec, 2004, 13.

${ }^{20}$ Hornfels was formed over one hundred million years ago, when magma rose to the surface through limestone on the Montreal Plain. For three millennia, the Amerindians extracted this material from outcrops at the foot of Mount Royal, where a vast extraction site of the materials has been found. p. 14

${ }^{21}$ Forget, Madeleine, Lauzon, Gilles, et al. Old Montreal: History through Heritage. Québec: Les Publications du Québec, 2004, 17.

${ }^{22}$ Ibid.

${ }^{23}$ Ibid., 20.

${ }^{24}$ Ibid., 17.
} 
league from Mount Royal”̌, which is where Pointe-à-Callière is located today.

In February ı642, an important mass was held at the Notre-Dame de Paris Cathedral in Paris. The members of the Société de Notre-Dame of Montreal had designated the city of present-day Old Montreal to the Virgin Mary and named it Ville-Marie. ${ }^{26}$

"The members of the Société intended, through the French colonists, to build houses to lodge the Amerindians, clear the land to feed them, build seminaries to teach them and build a hospital to care for their sick. It should be noted that France and all of Western Europe were then under the influence of the Counter-Reformation, a movement that revived interest in missions and advocated a return to the worship of the Holy Family." ${ }^{27}$

One of the most intriguing remains from this period is still in evidence today - the first Catholic cemetery in Montreal at Pointe-à-Callière. In the late 1980 , archeological excavations were executed, uncovering an important part of the cemetery adjacent to the initial European settlement of $1642 .{ }^{28}$ Thirty-eight burials were recorded during the excavation, and seven of which were thoroughly examined. The most complete grave included

\footnotetext{
${ }^{25}$ Forget, Madeleine, Lauzon, Gilles, et al. Old Montreal: History through Heritage. Québec: Les Publications du Québec, 2004, 23.

${ }^{26}$ Ibid., 28.

${ }^{27}$ Ibid., 29.

${ }^{28}$ Ibid., 30.
} 
remains of a coffin built of white pine, in which a Frenchman in his early thirties was buried. ${ }^{29}$ Twelve of the thirty-eight bodies discovered were Indigenous, and only baptized adults and children are believed to have been buried in this cemetery. Remarkably, an inner partition signifies that the graves of the Indigenous peoples and colonists were separated. ${ }^{30}$

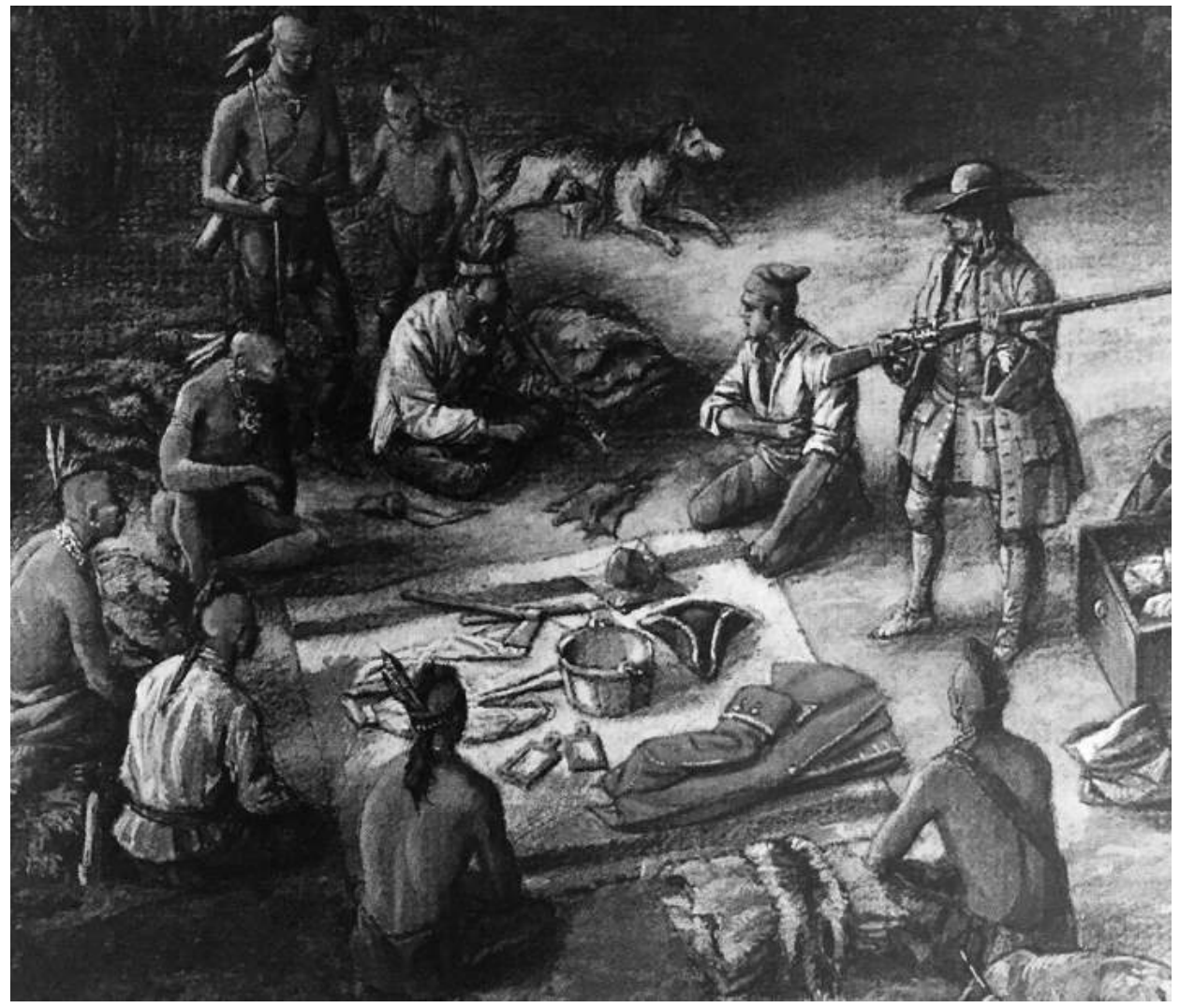

Figure 6: Exchange of goods between Indigenous peoples and the French Source: Francis Back, Old Montreal: History through heritage, 2004.

${ }^{29}$ Forget, Madeleine, Lauzon, Gilles, et al. Old Montreal: History through Heritage. Québec: Les Publications du Québec, 2004, 30.

${ }^{30} \mathrm{Ibid}$ 


\section{LAYER 3: URBAN ANALYSIS}

This thesis aims to reflect the urban fabric, above and below ground of Cabot Square and its surroundings, in order to generate engagement not only with different communities of the area but with the city itself. The square finds itself between two distinguished boroughs; Ville-Marie, which is downtown's largest and main borough and Westmount, one of the city's most expensive municipalities. Following are a series of maps distinguishing the site's surrounding boroughs, the underground metro transit system which has a direct connection to Cabot Square (Atwater Metro) and major roads and buildings around the park to understand the density of the site. 


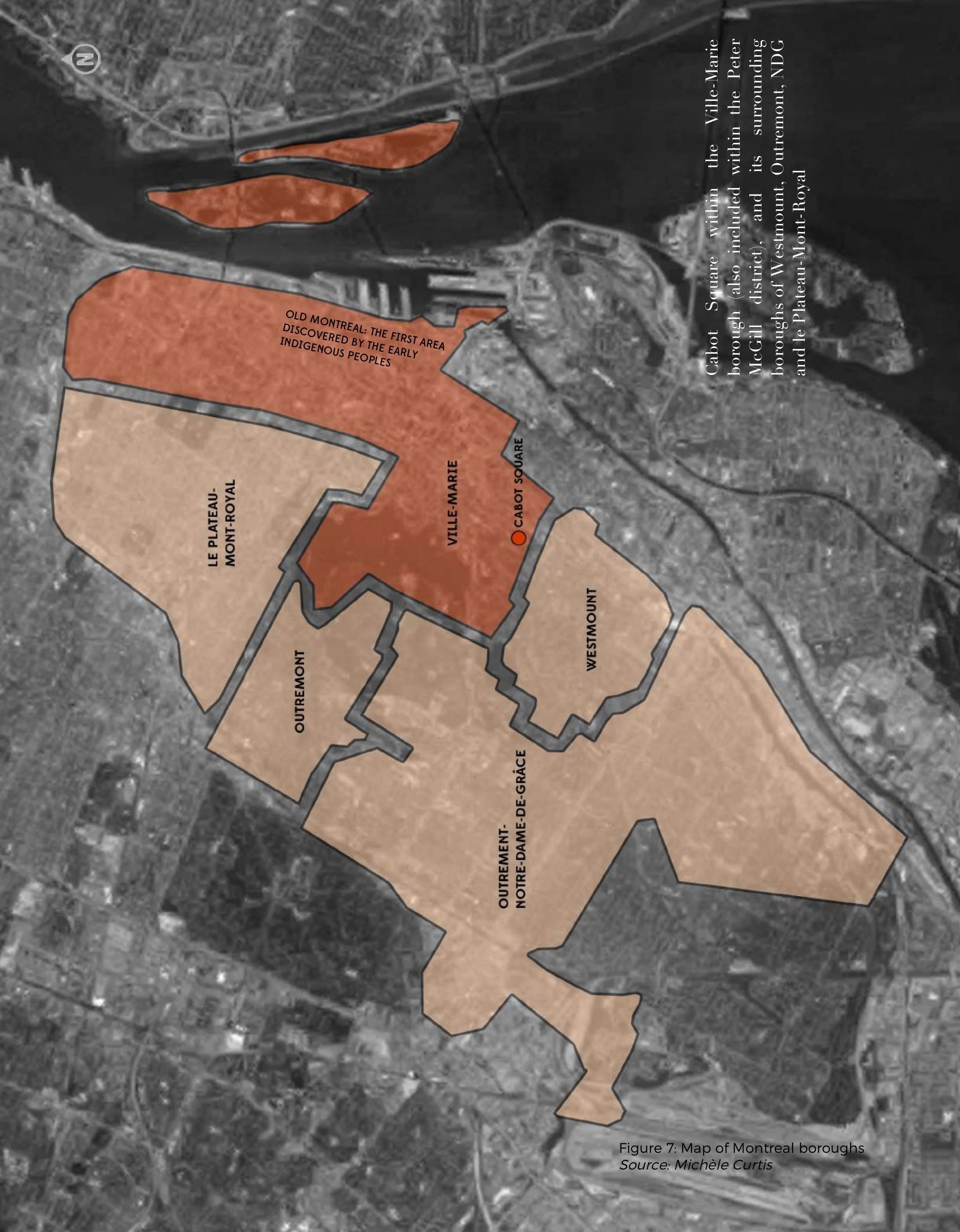


(2)

党

Ad<smiles></smiles>

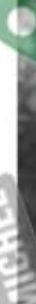

喜
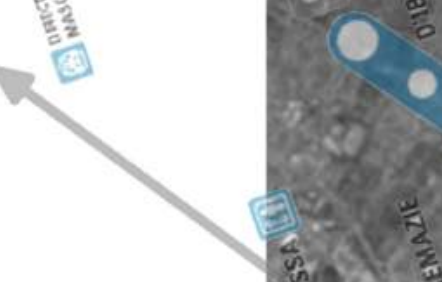
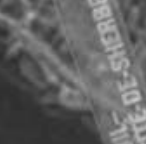

As

군 g.

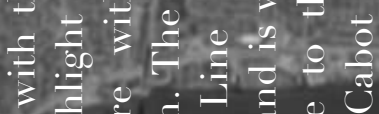

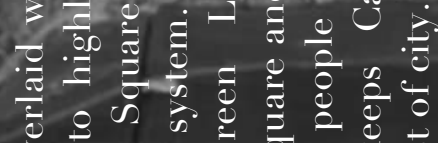
5.

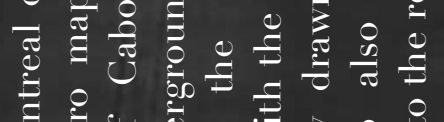

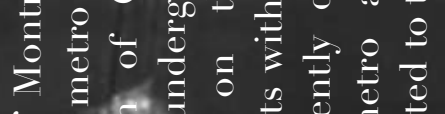
6.

H人

默

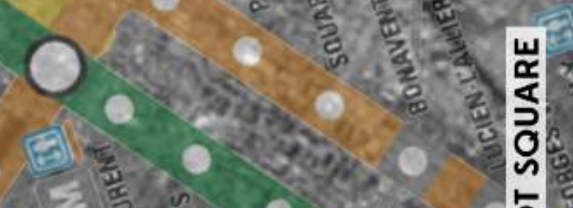

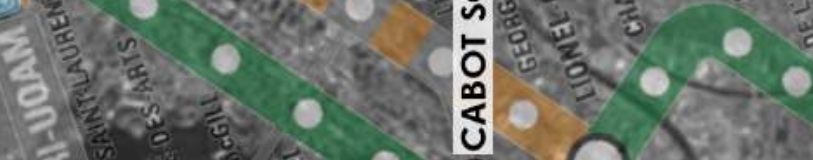
( $\% \cdot 0.0$

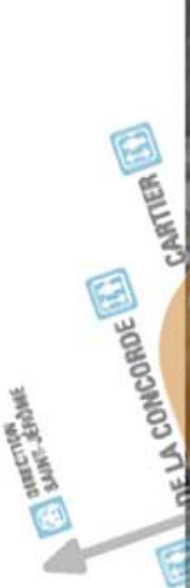

察
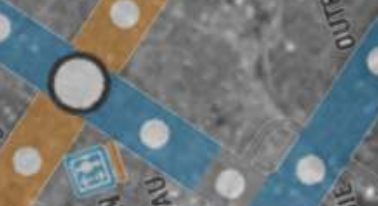

$20-\frac{1}{6}$

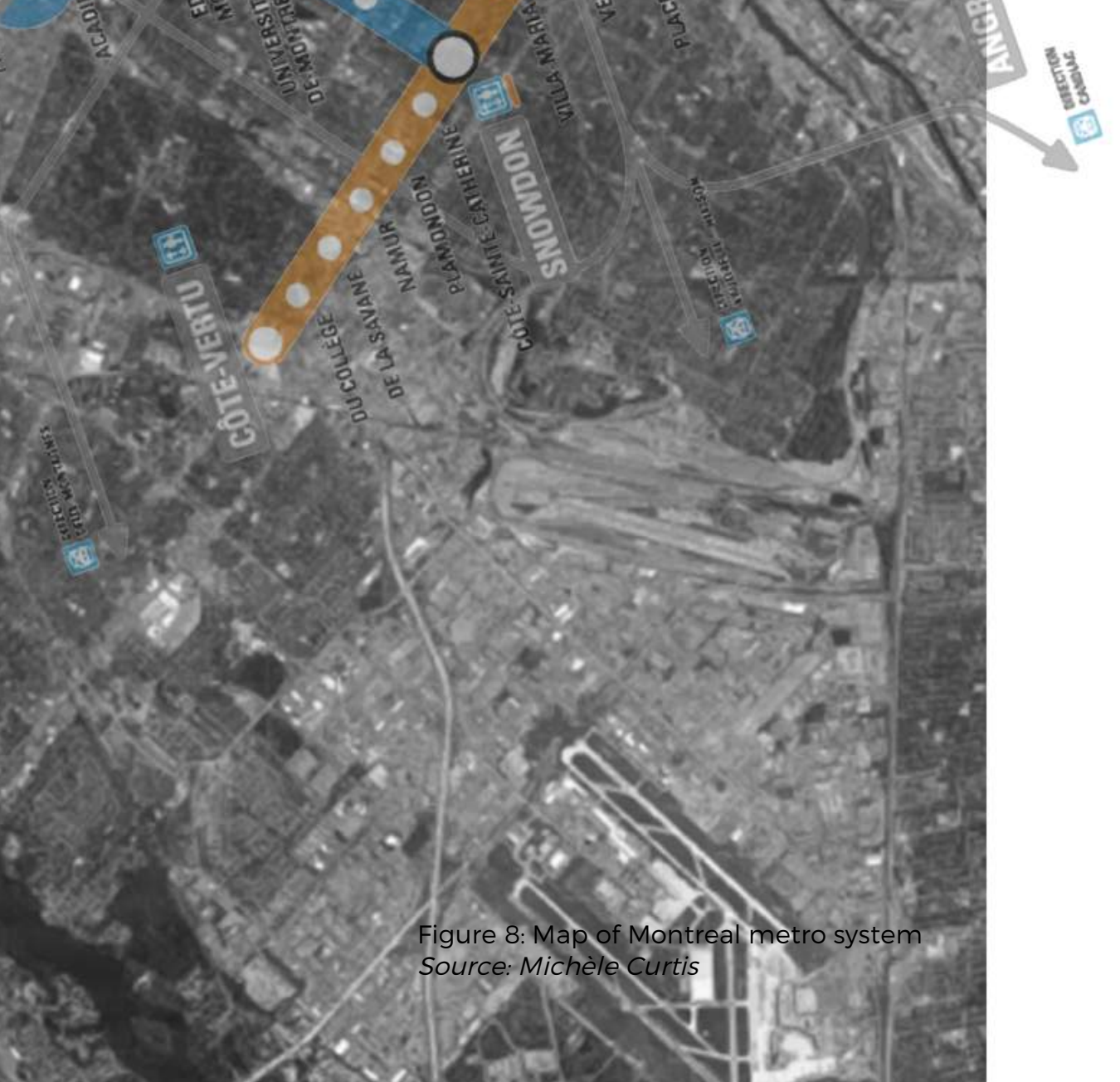


Moving closer to Cabot Square - a map of the Peter McGill district (within the Ville-Marie borough) with Cabot Square in the centre. The following images highlight the different building and road types in order to gain a sense of the density of the commercial area that the park is located within.

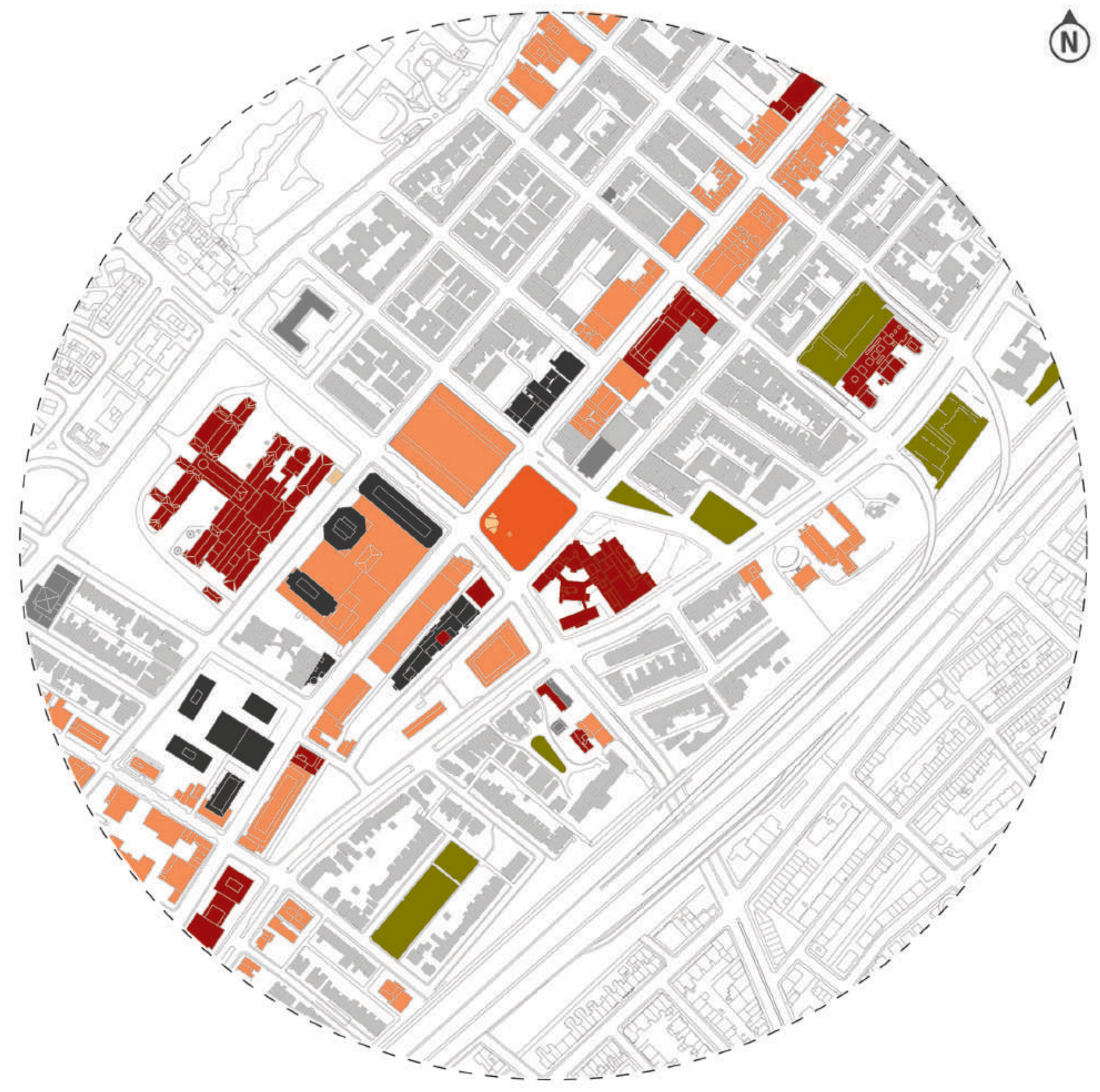

- MIXED USE

Figure 9: Urban analysis map

- COMMERCIAL Source: Michèle Curtis

- RELIGIOUS

- RESIDENTIAL

- INSTITUTIONAL

- PARK

- METRO

- SITE 


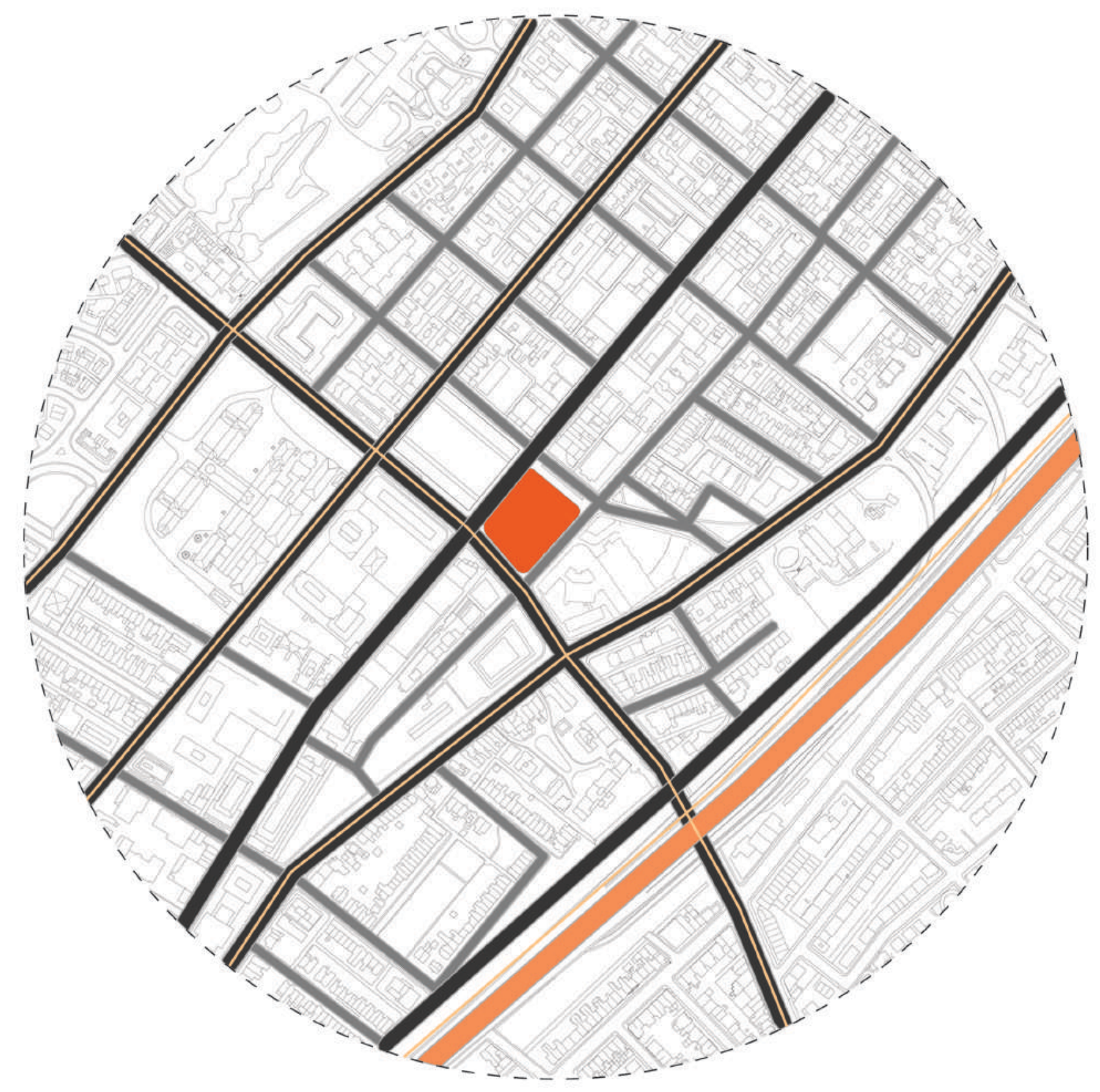

- PRIMARY ROAD

- local ROAD

- HIGHWAY

- MAIN TRANSIT ROUTE

- SITE
Figure 10: Urban analysis map Source: Michèle Curtis 
Lastly, the information below offers a closer look at the immigrant and itinerant communities of the Ville-Marie borough in order to better understand the diversity of the population that Cabot Square and its surroundings see.

- $\quad 77 \%$ of the population are Canadian citizens.

- One third of the population are immigrants.

- One out of three immigrants is a new immigrant.

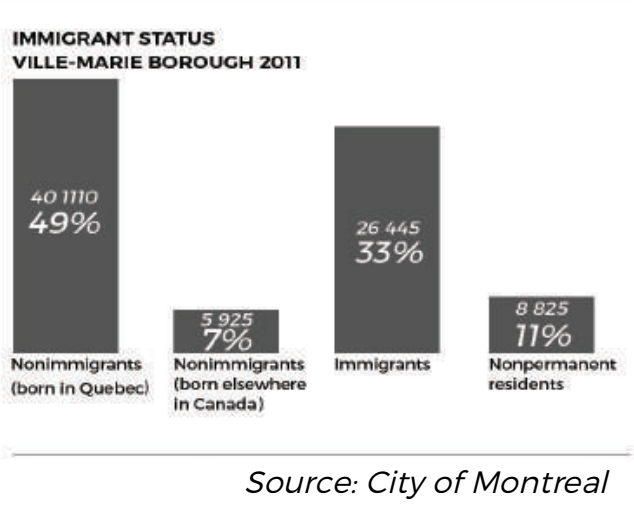

- There is an estimated 3000 homeless people in Montreal.

Immigrants make up $10 \%$ of the itinerant

- population, and among immigrants, 39 per cent are women.

Of the women who are itinerant, 10\% have

- children, a figure that jumps to $22 \%$ for immigrant women.

Aboriginal people are over-represented in homeless figures, the census shows. While

- making up only $0.6 \%$ of the city's population, they account for 10\% of the homeless population. And within that group, Inuit make up $40 \%$ of those who are homeless.

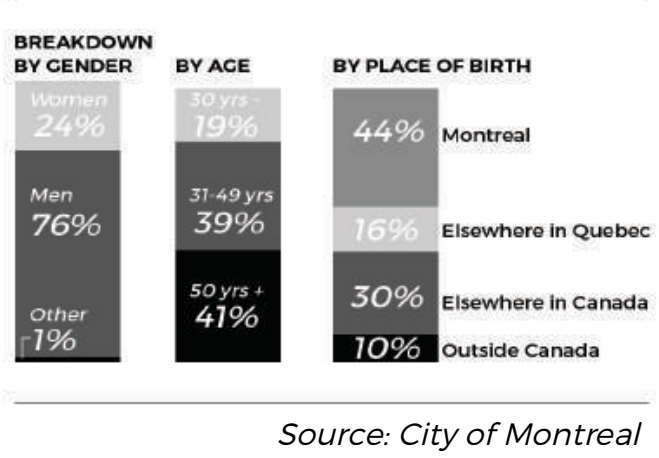

- Ville-Marie sees $56 \%$ of itinerants in the city 


\section{LAYER 4: OTHER URBAN SQUARES OF MONTREAL: PLACE ÉMILIE-GAMELIN}

Place Émilie Gamelin is a public square in Montreal that has long been disputed, similar to Cabot Square, having also recently been intervened with a new design in 20I5. An analysis of Place Émilie-Gamelin in comparison to Cabot Square follows, with the objective to understand the differences of their re-urbanization and how it may affect their frequenters and future development within the city, since both parks are known as gathering areas for the homeless community and the urban Indigenous community.

The following image highlights Cabot Square and Place ÉmilieGamelin, along with the other public squares of the Ville-Marie and Westmount boroughs. 
Public squares are part of a city's major components; they form focal points in crowded areas and create space for community gatherings and expression. ${ }^{31}$ Place Émilie-Gamelin in the east end of Ville-Marie and Cabot Square are public parks that have seen different uses overtime and are both known to being socially and culturally diverse places.

Similar to Cabot Square, Place Émilie-Gamelin has also been redeveloped in order to create a safer and more welcoming area due to a higher demographic of itinerant frequenters. But the redevelopment projects of both squares, following similar mandates, have resulted in different uses, drawing different groups of people. The squares have been subjected to different design changes - while Place Émilie-Gamelin is introduced with adaptable and temporary installations for different events, Cabot Square was presented with permanent renovations. ${ }^{32}$

The use of public spaces, traditionally known for political rallies, has evolved overtime. Cabot Square and Place Émilie-Gamelin both demonstrate the changes and versatility of public space today, but prove to have different results with their recent reurbanization projects. A look at the differences of both squares' renovations and their separate outcomes and uses today helps to sustain this thesis' proposed program and design.

\footnotetext{
${ }^{31}$ Zhai, Binqing. "Definition and Concept of Urban Squares in View of Urban Spaces and Buildings" Bulletin of the Georgian National Academy of Sciences, 2014: vol. 8 no.1. Accessed 9 Dec. 2016, http://bnas.org/.

${ }^{32}$ Curtis, Michèle. "Thinking Outside of the Square: Cabot Square \& Place Émilie-Gamelin:

Cultural Diversity in Changing Places", Carleton University, December 122016
} 
Place Émilie-Gamelin was founded in 1992 and has since been a central venue in the city for major social and cultural demonstrations and events. ${ }^{33}$ The name was given after the founder of the congregation of the Sisters of Providence, Émilie Gamelin. ${ }^{34}$ In the 1960 , the City of Montreal acquired the park and wanted to turn the site into a festivities centre for Montreal's $350^{\text {th }}$ anniversary celebrations. ${ }^{35}$ Place Émilie-Gamelin was introduced with a design approach involving elements that were meant to reflect Montreal's main symbolic elements the mountain, the water and the surrounding neighborhoods) ${ }^{36}$

Overtime, the site became a main gathering and starting point for protests and demonstrations due to it's neighboring districts. Around the same time as the Cabot Square interventions (201520I6), the Entertainment District collaborated with the VilleMarie borough for the square's redevelopment plans in the hopes of also creating a safer area for the general public. ${ }^{37}$ Similar to Cabot Square, mandates for Place Émilie-Gamelin's project included hiring street intervention workers for the homeless people who continuously frequent the park. The main difference with Place Émilie-Gamelin is the flexibility of the new programming and events at the park, rather than a permanent design like Cabot Square's. ${ }^{38}$

\footnotetext{
${ }^{33}$ Valois, Paradis, "Place Émilie-Gamelin in Montréal: Landscape Narrative, Meaning and the Uses of Public Space". Journal of Landscape Architecture, 2010: 5:2, 72-83. Accessed 11 Dec. 2016

${ }^{34}$ Ibid.

${ }^{35}$ Ibid.

${ }^{36}$ Ibid.

${ }^{37}$ Kelly, Jeanette. "Gritty Parc Émilie-Gamelin gets glamorous makeover" CBC News, CBC News, 8 May 2015. Accessed 11 Dec, 2016. http://cbcnews.ca/news/canada/montreal.

${ }^{38}$ Ibid.
} 


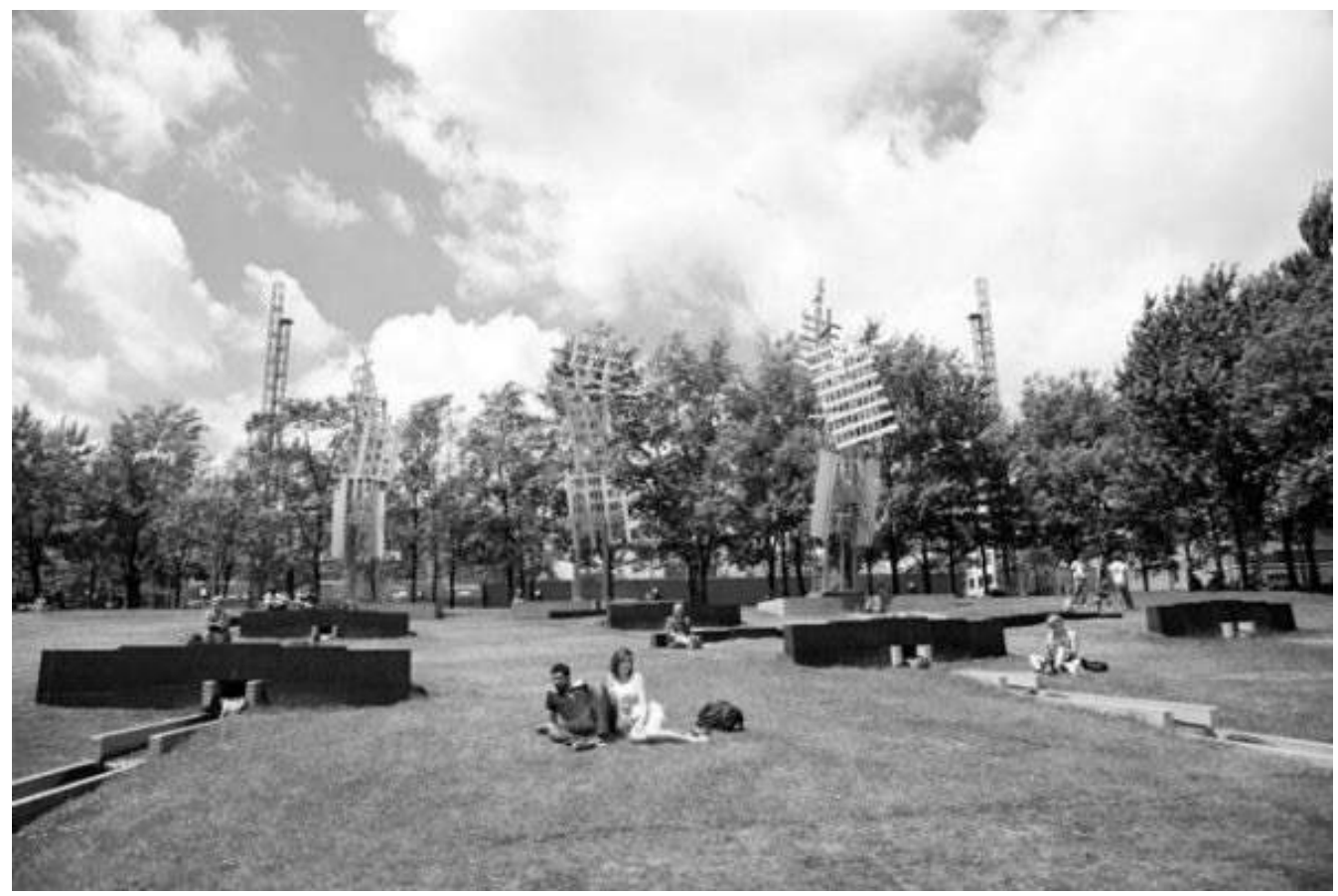

Figure 12: Place Émilie-Gamelin before re-urbanization

Source: quartierdesspectacles.com

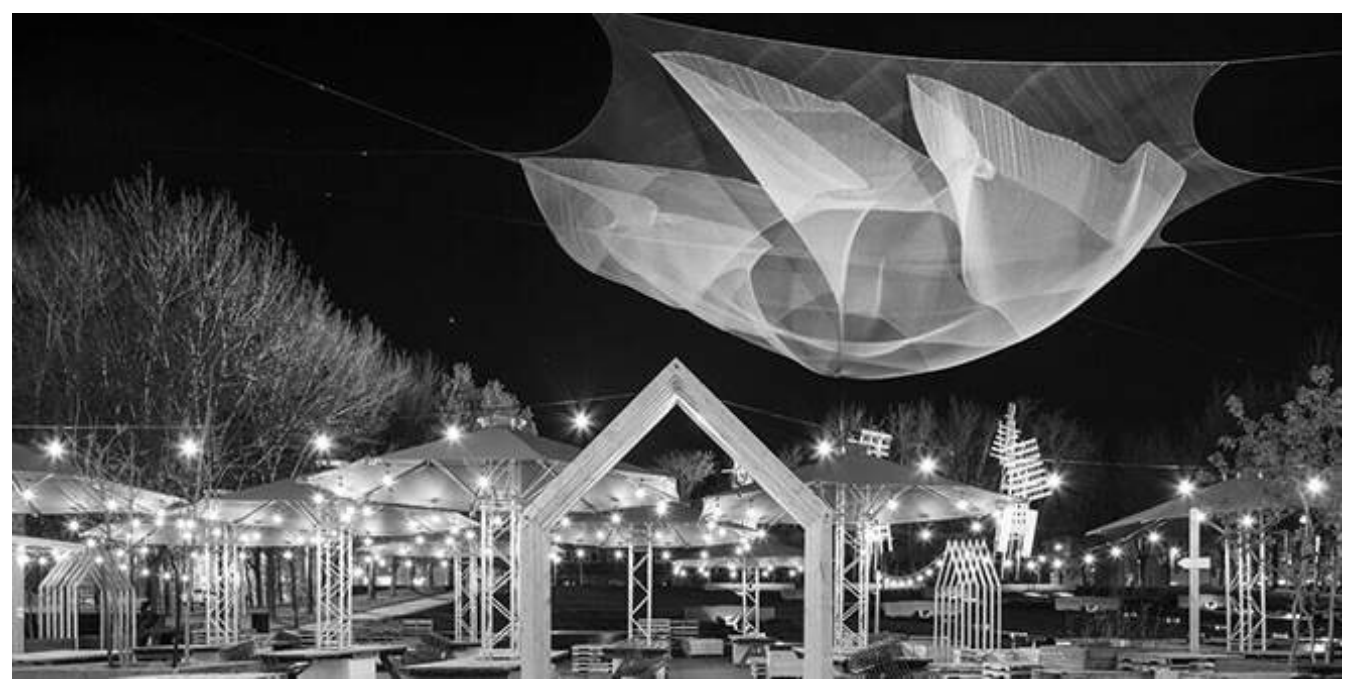

Figure 13: Place Émilie-Gamelin after re-urbanization in 2015 Source: quartierdesspectacles.com 
For Place Émilie-Gamelin, what was then a questionably unsafe area, is now attracting more people. Unlike Cabot Square, instead of the new design that could potentially cause the urban Indigenous community (and homeless groups) to leave the park, Place Émilie-Gamelin's new design elements emphasize openness and adaptability of the space, while making it safer for the homeless people already there and more attractive for the general public.

Place Émilie-Gamelin is introduced as a strong precedent here to question the current design of Cabot Square, which simply included more paved ground to create a more open, safe space and more seating and lighting for the general public. The design is permanent and standard, and its potential of being a great social and cultural space is overlooked.

For this thesis, although a program is determined, a main concept of the project is to create an adaptable and flexible space at Cabot Square (building on its current design), since not only is it being used by various groups of people but the different seasons, including the city's various events and pattern usage, is considered and applied here too. 


\section{LAYER 5: SITE STUDY}

\subsection{HISTORY}

Cabot Square, previously called Western Square, was built in I870 for recreational purposes by the prevailing municipal administration. ${ }^{39}$ The name "Cabot Square" was introduced when the monument of John Cabot, commemorating the English explorer's affiliation to the Italian community of Montreal, replaced the square's central fountain. ${ }^{40}$ The park's boundaries include Avenue Atwater, Rue Clossé (present-day Rue St-Lambert Clossé), Rue St-Catherine and Rue Quiblier (present-day Rue Tupper), in the Peter-McGill district in the west end of downtown Montreal's Ville-Marie borough. In the early twentieth century, two major developments attracted people to the square, the Montreal Forum (prior home of the Montreal Canadians hockey franchise) and the former Children's Memorial Hospital, which was recently moved to the McGill University Health Center (Super Hospital).

Eventually, buses replaced the tramway system and the Atwater Terminus was established in 1956 , circulating around Cabot Square and creating a constant flow of activity. ${ }^{\text {it }}$ Ten years later, the underground metro system was introduced to Montreal and a major station was added to the square. While the metro and buses created easy access to the area in close proximity to a hospital and commercial outlets, it also started appealing to the

\footnotetext{
39 Wilkins. "Cabot Square, Formerly Western Square." Wordpress, Montreal Gazette, 30 Nov. 2013, accessed 11 Dec 2016, http://rnwilkins.wordress.com/

${ }^{40}$ Ibid.

${ }^{41}$ Ibid.
} 
homeless population. Cabot Square offered a safe and convenient place to gather, and itinerants began to use the terminus and metro structures as shelter.

By the 1970 s, healthcare programs offered to Indigenous peoples, particularly Inuit from Nunavut, initiated by the YMCA on Rue Tupper and at the Montreal Children's Hospital adjacent to the square attracted the early urban Indigenous community to Cabot Square. The Square became one of the main gathering places for Indigenous people in the city. ${ }^{12}$ More facilities and shelters grew over the years in proximity to Cabot Square and the Peter-McGill district, assisting the homeless and Indigenous communities of the area. An Inuit Montreal from Nunavut who frequents Cabot Square on a regular basis described the space; "[...] This is where our friends and family meet. It's our home and community. Sometimes when our family visits from the North, they bring us Arctic char and we eat it right here without family and friends. The facilities we need are within a couple of blocks of here.”33

The following map shows shelters and help-centres (Native Friendship Centers) within proximity to Cabot Square and identifies main areas in Montreal where the urban Indigenous community gathers.

\footnotetext{
42 Galbraith, Robert. "Montreal Cabot Square Inuit Homeless Survive on the Street", 3 July 2014, (Blog) accessed 11 Dec. 2016, http://robertgalbraith.com/

${ }^{43}$ Ibid.
} 

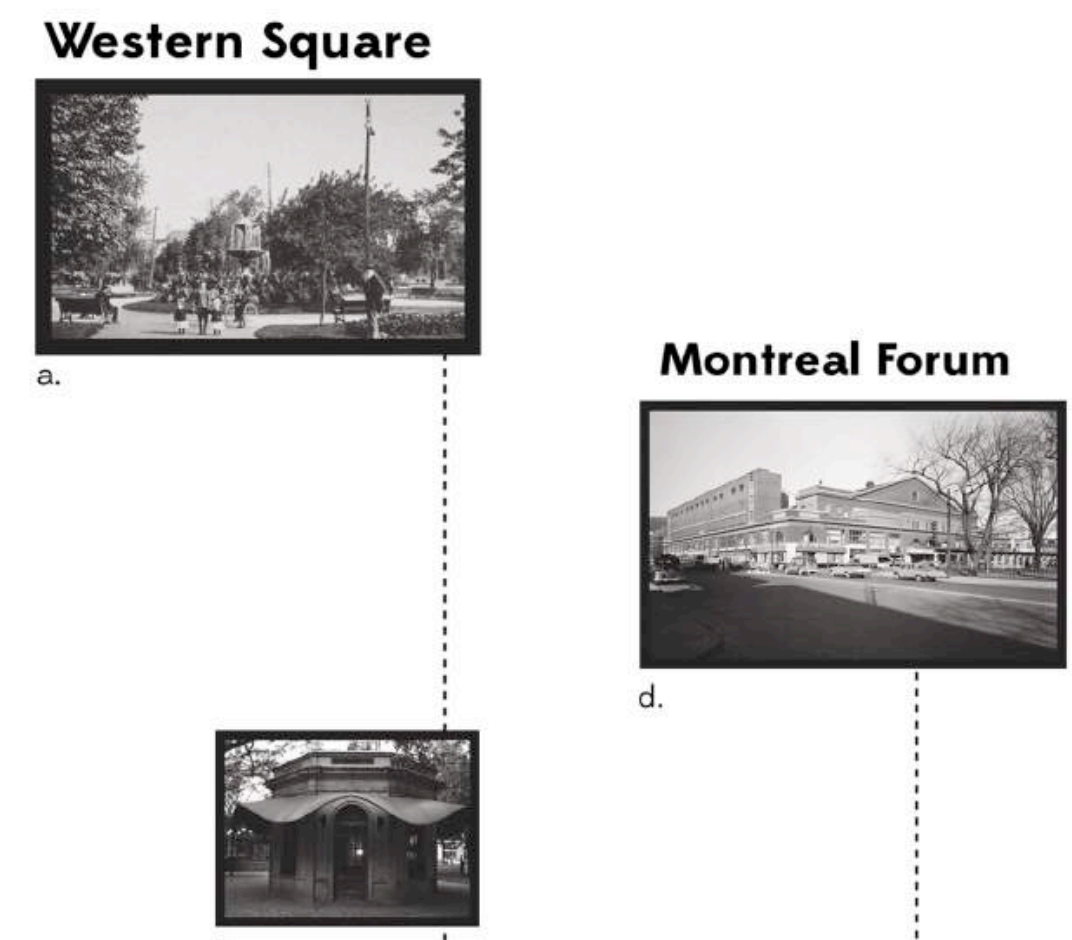

\section{Atwater Terminus}

d.

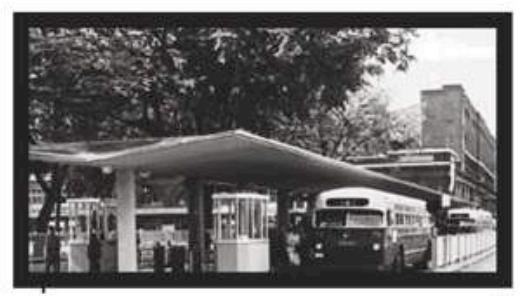

b.

Figure 14: Site and context timeline

Source: Michèle Curtis

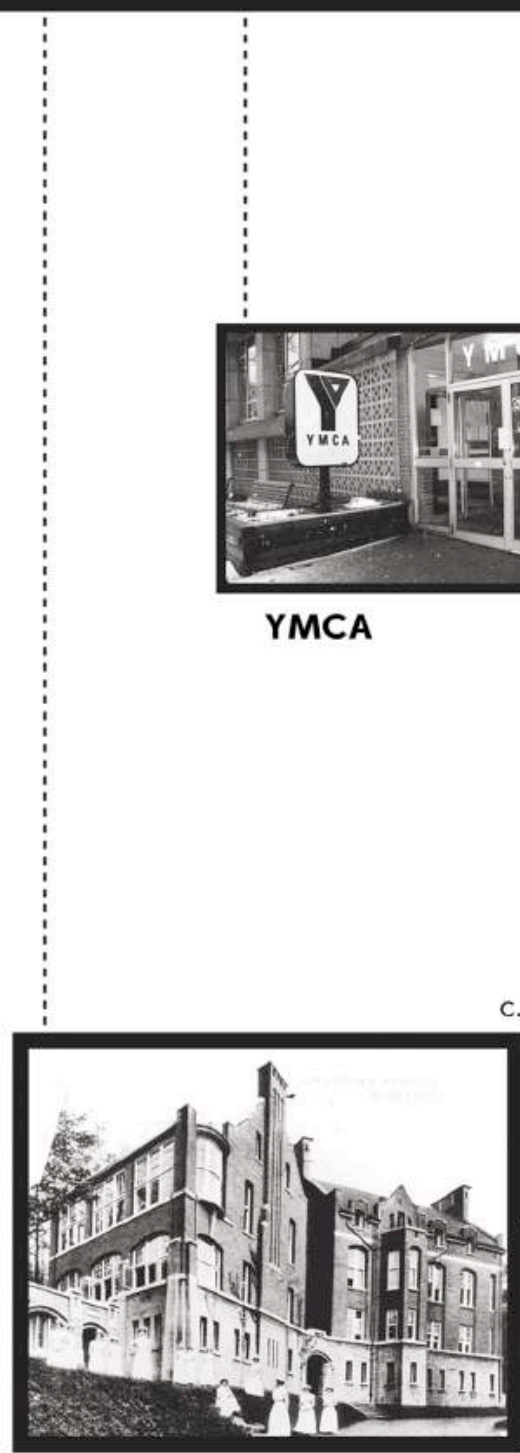

Children's Memorial Hospital (CMH)

\section{0}

1956

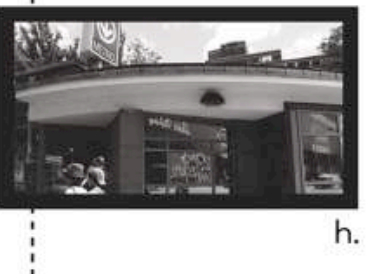




\section{Cabot Square}
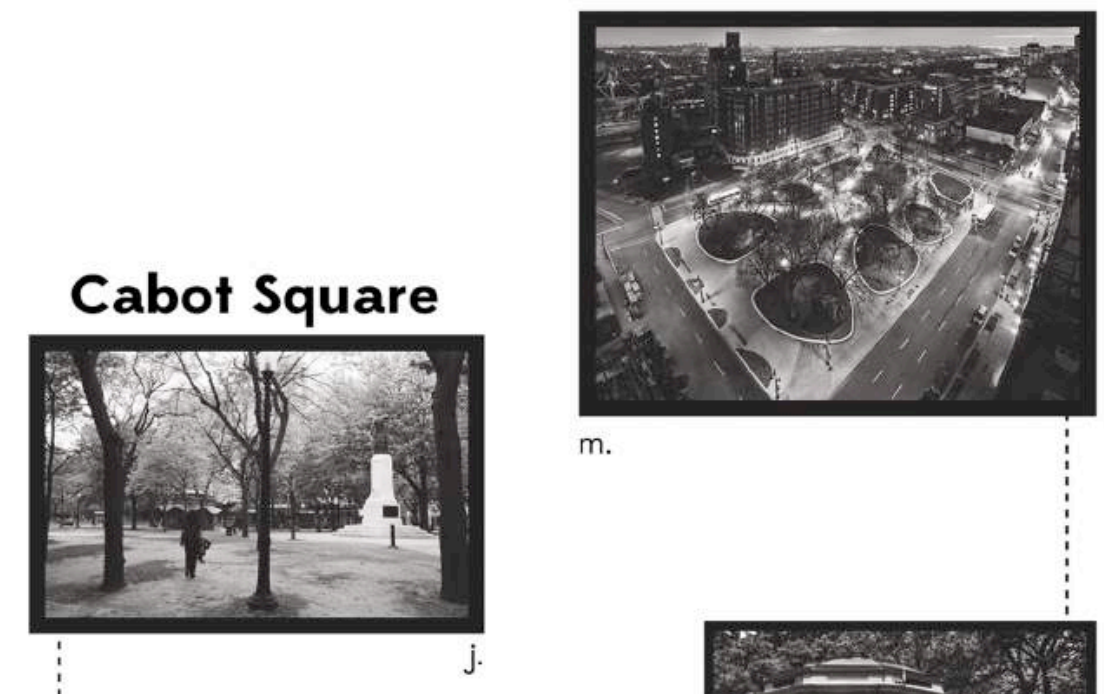

$\mathrm{m}$.

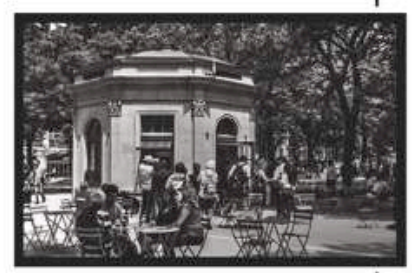

\section{6}

n.

k.

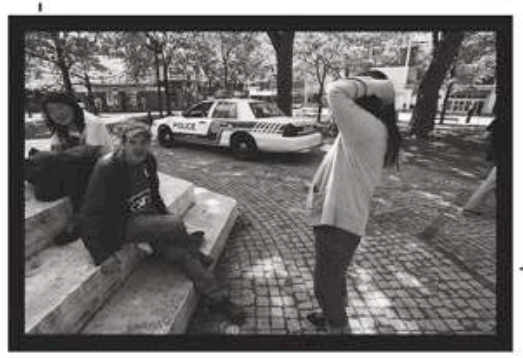

Urban Aboriginal Strategy Network
Cabot Square was previously known as Western Square, created by municipal administration in 1870. It initially served the recreational needs of Montreal and surrounding

a. boroughs. In 1930 the John Cabot monument was addedCabot is an English explorer recognized for his role in discovering what is now Newfoundland and for his affiliation with Montreal's Italian and Newfoundlander community.

b. Vespienne at Western Square- men's only bathroom

The Children's Memorial Hospital first opened its doors on

c. January 30,1904, on Guy Street in Montreal. It was a bilingual institution and the first hospital in Montreal with the sole mandate of caring for sick children.

Main historical events at Cabot Square have been related

d. to the Montreal Forum built in 1924 adjacent to the square (such as riots from hockey games).

Created in 1931, the YMCA Residence provides short-term

e. housing for refugees, asylum seekers, homeless citizens of Montreal and Inuit from Northern Quebec who have been referred by its partners.

The square used to be a central stop for the tramway but

f. once they were pulled from Montreal streets and replaced with buses, a modern terminus was opened in 1956, named the Atwater Terminus, fully encircling Cabot Square.

Growth of services required another expansion and move g. in 1956, when The Children's Memorial moved to 2300 Tupper and became The Montreal Children's Hospital.

h. Atwater metro- a central stop to the metro system constructed in 1966.

In the 1970 s, Indigenous organizations began opening i. shelters and day health care centers to help the urban Indigenous peoples and homeless Montrealers.

Eventually the bus shelters attracted a higher homeless people demographic in the area. Overtime the central bus terminal at Cabot Square slowed down with more bus

j. routes leading to main stops more central to the city. Since the 1970s, the urban Indigenous community has been drawn to the square since it is in proximity to various heath services and shelters.

NETWORK was established in 2006 with the mandate to be the decisional body and provide opportunities for orga-

k. nizations serving the Indigenous peoples in the greater Montreal area and manages the Cabot Square project, an initiative building and working on a strategy addressing Indigenous homelessness in Montreal beginning with Cabot Square.

I. The Children's Hospital was relocated to the MUHC in May 2015.

Working with City of Montreal, architect Wade Eide and $\mathrm{m}$. landscape architects Fahey et associés re-urbanized Cabot Square in 2016.

The Round House Café at Cabot Square is a collaboration between Ville-Marie, the Cabot Square Project and

n. L'Itinéraire. It occupies the structure previously used as the vespienne and offers job opportunities to Indigenous Montrealers. 


\subsection{CONTEXT}

The following maps show shelters and help-centres (Native Friendship Centres) within proximity to Cabot Square and identifies main areas in Montreal where the urban Indigenous community congregates, this mainly in part because of the proximity of the help centres. The second map highlights main facilities around the park to understand the density of the neighborhood. 


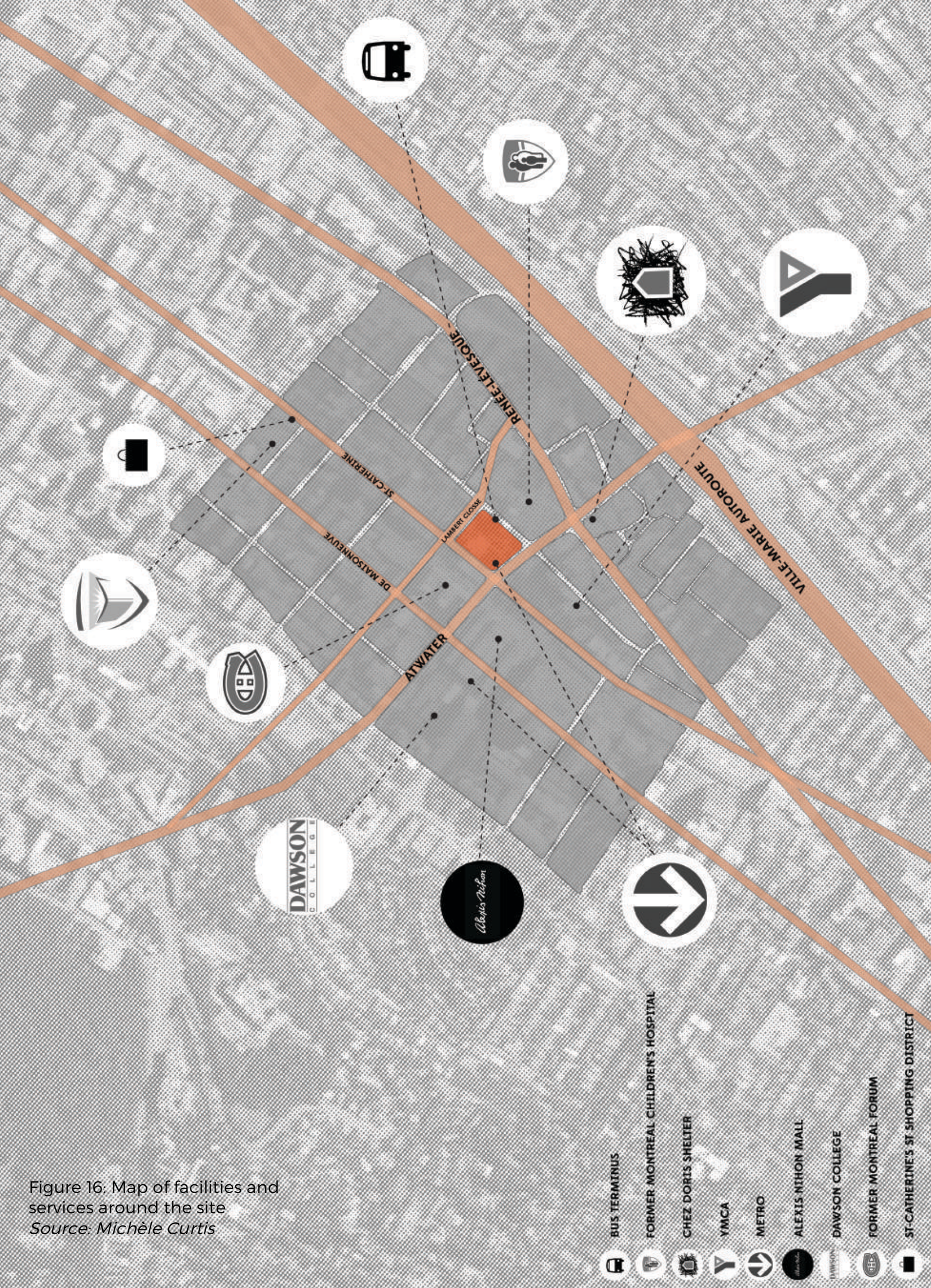


Following are images of Cabot Square's immediate urban fabric and context.

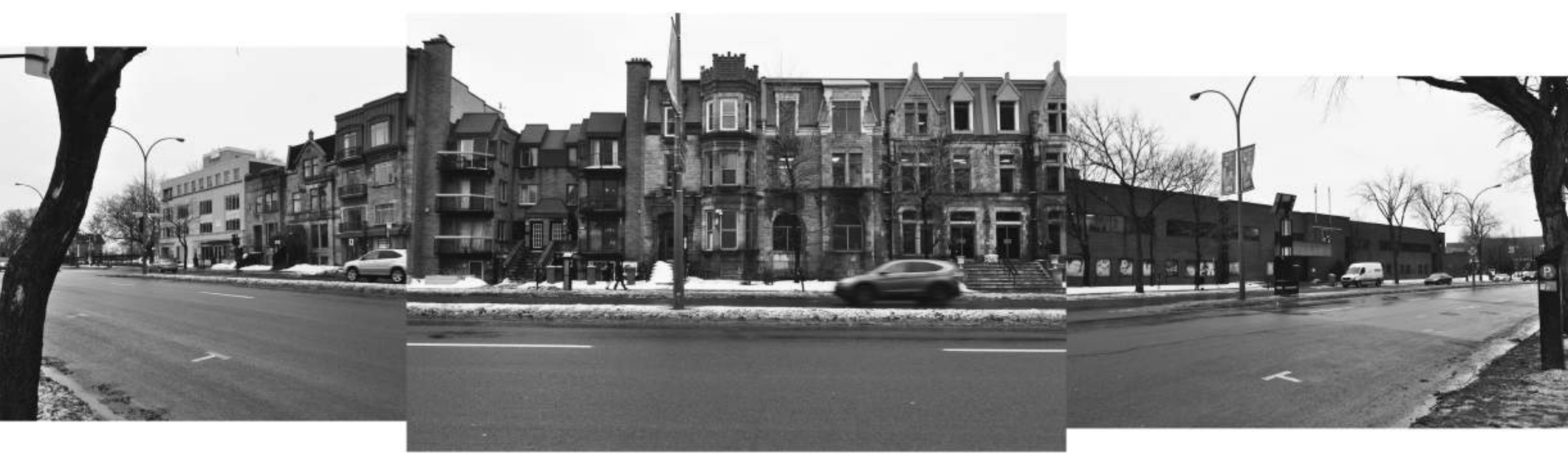

Figure 17: Boulevard Renée-

Lévesque, South of Cabot Square

Source: Michèle Curtis

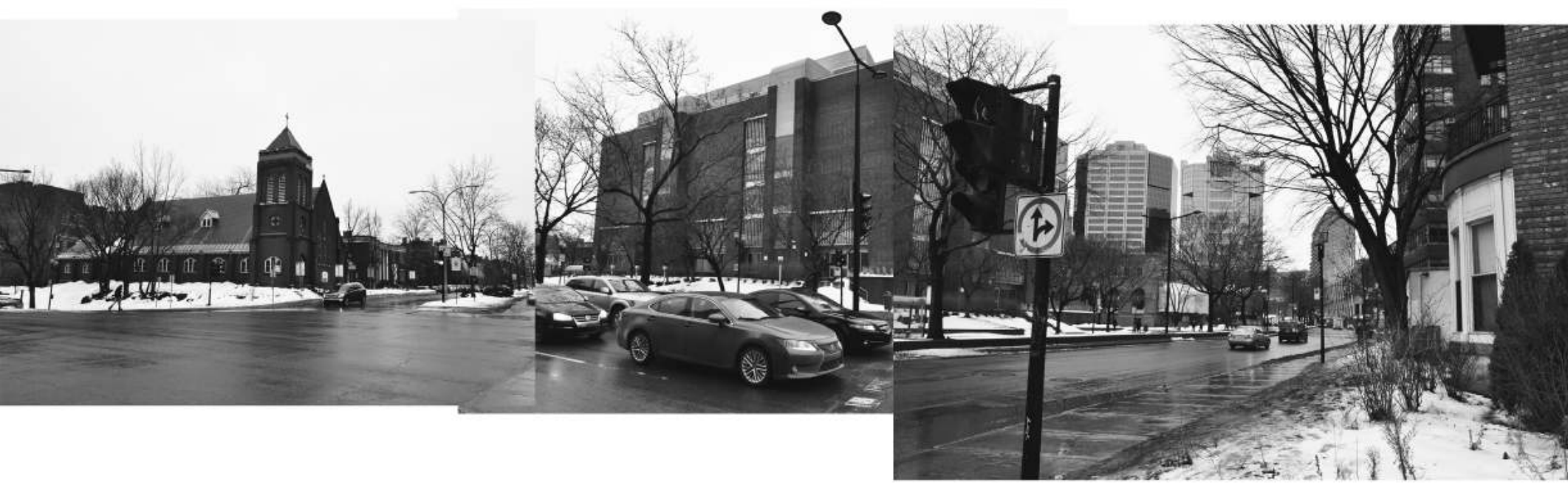

Figure 18: Atwater Avenue, West of Cabot Square

Source: Michèle Curtis 


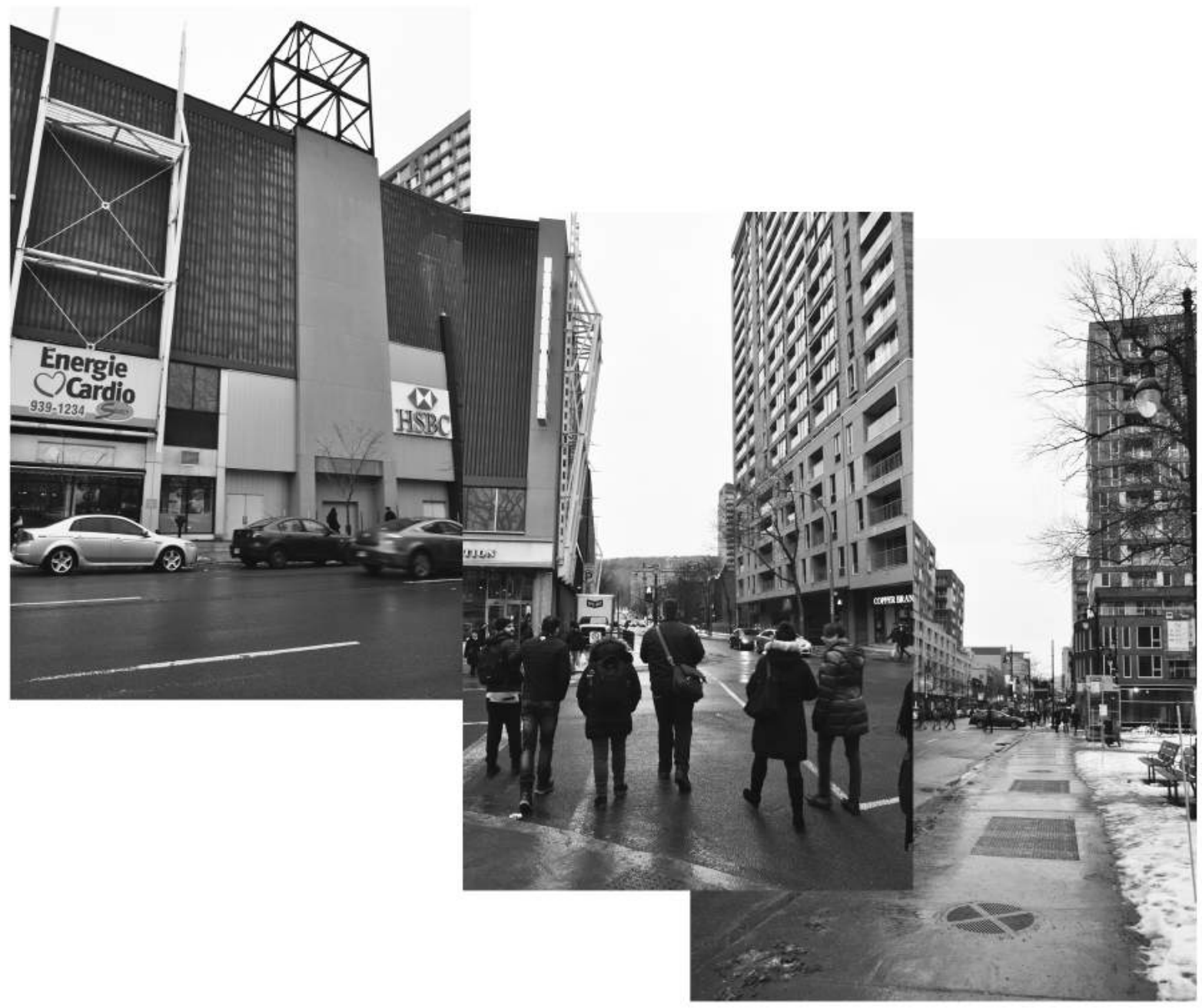

Figure 19: Rue St-Catherine, North of Cabot Square

Source: Michèle Curtis

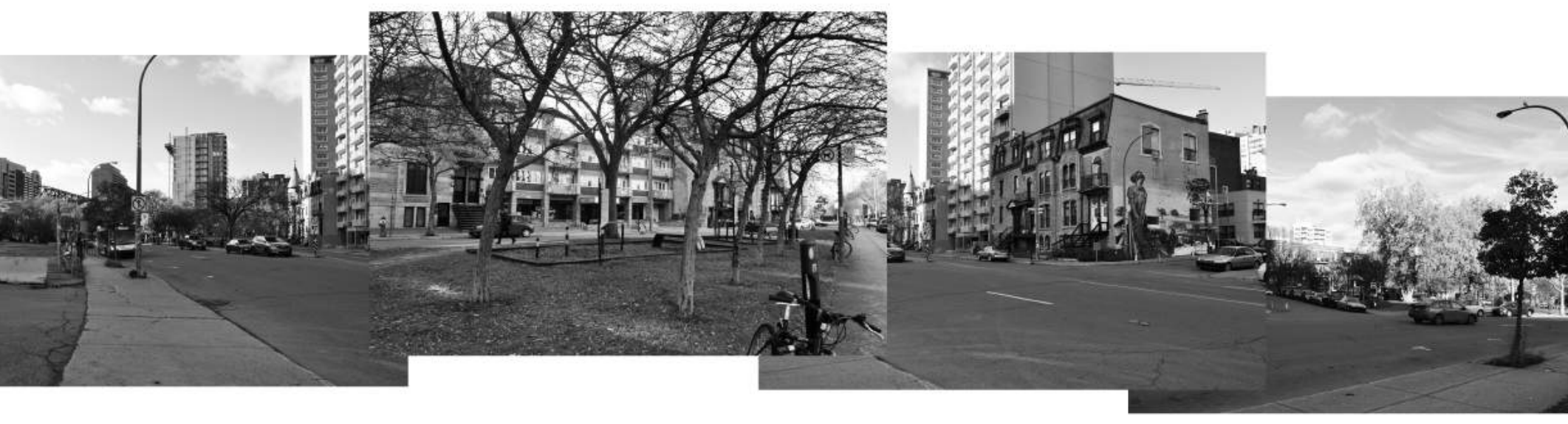

Figure 20: Rue Sussex, East of Cabot Square

Source: Michèle Curtis 


\subsection{CURRENT SITUATION: THE CHILDREN'S HOSPITAL}

Cabot Square has a long-rooted connection to the adjacent site of the former Children's Hospital. When the metro system was introduced and a central entranceway was built on the square, many people would pass through the square to reach the hospital, and eventually a main gathering space was established for patients and visitors, particularly the Inuit community.

Last November, the former site of the Montreal Children's Hospital was purchased and transferred to its winning bidder, a private real estate developer. ${ }^{41}$ The future of the site is currently undetermined, since various organizations and parties have different opinions and ideas of what should be converted, and what should be preserved as heritage. Condominium units, corporate space and a community centre are expected to be part of the new project. ${ }^{45}$ The future of the former hospital's site could have an impact on the growth of Cabot Square.

Stéphane Febbrari, coordinator for the Peter-McGill Community Council, is negotiating for the site in hopes that a new library, and elementary school may be considered as part of the development..$^{6}$ The area is also lacking in social housing; there are only forty-two housing units for approximately thirty-five

\footnotetext{
44 "Former Montreal Children's Hospital Officially Sold to Developer for \$25M", CBC News, 2 Dec 2016, accessed 3 Jan 2017, http://www.cbc.ca/news/canada/montreal/former-montrealchildren-s-hospital-officially-sold-to-developer-for-25m-1.3878571

45 Ibid.

${ }^{46}$ Pucci, Michelle, "Election Candidates Weigh in on Future of Former Montreal Children's Hospital Site", CBC News, Aug 27 2015, accessed 3 Jan 2017,

http://montrealgazette.com/news/local-news/election-candidates-weigh-in-on-future-offormer-montreal-childrens-hospital-site
} 
thousand residents of the Peter-McGill district in the western extremity of the Ville-Marie borough. ${ }^{17}$

Daniel Green, an environmentalist running for the Green Party, believes that the city should keep the hospital public and be funded by the federal government for the maintenance of the buildings, with a focus on developing social housing and services for neighborhood residents. Green believes that incorporating more green space would also be beneficial since the site currently lacks any..$^{48}$

Annmarie Adams, specialist in hospital architecture history and Chair of the department of Social Studies in Medicine at McGill University argues that the site should maintain its commitment to caring for children-the original purpose of the hospital. 49 Adams explains, "The noble thing to do would be to reuse the building for the benefit of the children of Montreal". 5o As youth is a highly important period in the life of Indigenous peoples, the proposed program and design interpret and reflect this.

\footnotetext{
${ }^{47}$ Pucci, Michelle, "Election Candidates Weigh in on Future of Former Montreal Children's Hospital Site”, CBC News, Aug 27 2015, accessed 3 Jan 2017,

http://montrealgazette.com/news/local-news/election-candidates-weigh-in-on-future-offormer-montreal-childrens-hospital-site

${ }^{48}$ Ibid.

49 "Former Montreal Children's Hospital Officially Sold to Developer for \$25M", CBC News, 2 Dec 2016, accessed 3 Jan 2017, http://www.cbc.ca/news/canada/montreal/former-montrealchildren-s-hospital-officially-sold-to-developer-for-25m-1.3878571

${ }^{50}$ Ibid.
} 


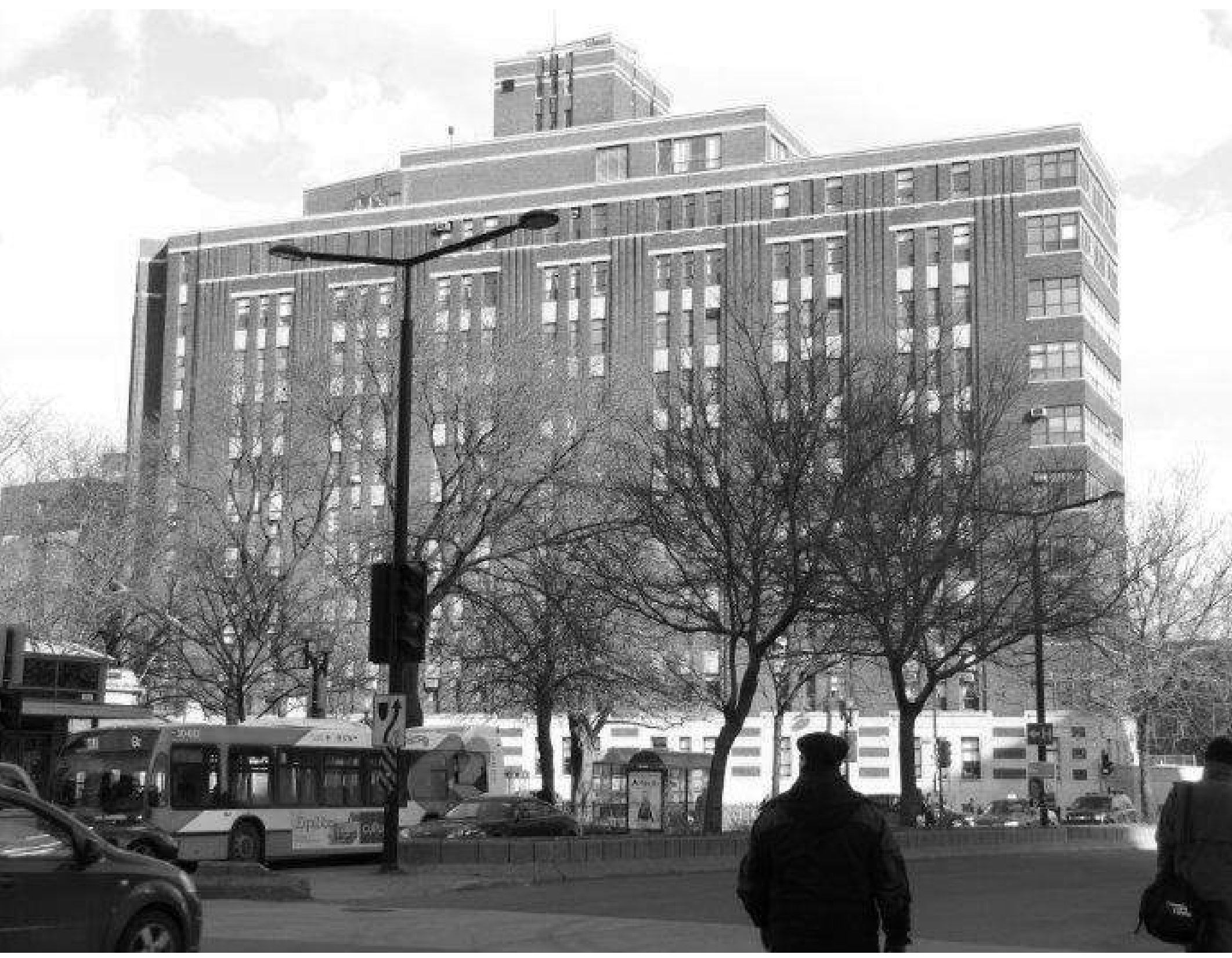

Figure 21: The former Children's Hospital. View walking from Cabot Square (to the left) Source: wikimapia.org 


\subsection{CURRENT SITUATION: THE CABOT SQUARE PROJECT}

Recent renovations to the park were finalized in August 2016 and were principally funded by the Ville-Marie borough and the City of Montreal. ${ }^{51}$ Although these renovations did help improve the safety of the area for the general public, the square's renewal failed to address the primary frequenters of the space. The renovations include additional lighting, seated areas, installations, paved pathways and more open accessibility throughout the park. This thesis proposal aims to respect the new changes made to Cabot Square. The new design of the park defines this design proposal.

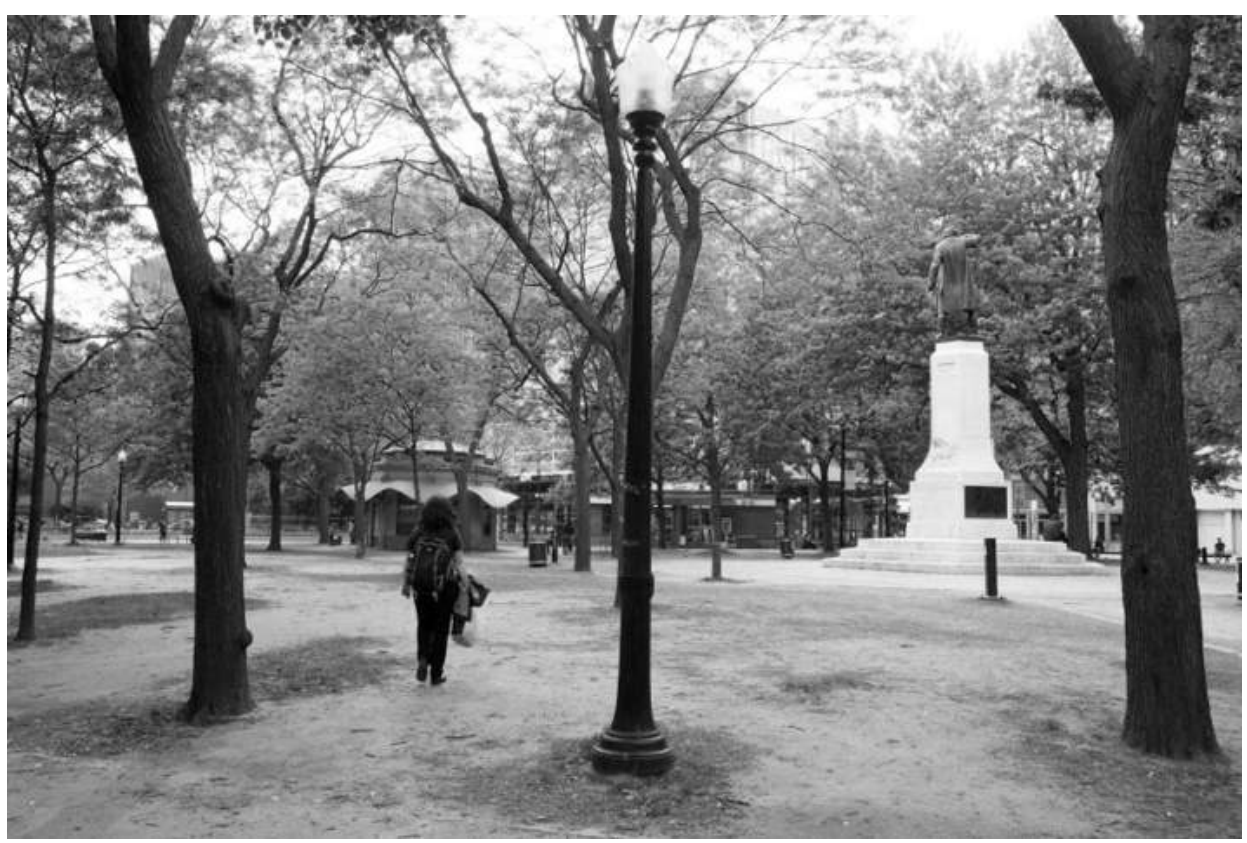

Figure 22: Cabot Square before re-urbanization Source: robertgalbraith.com

\footnotetext{
${ }^{51}$ Montreal Urban Aboriginal Community Strategy Network. Final Report, Project: Learning from Cabot Square - Developing the Strategy for Community Safety and Wellbeing. Montreal: Montreal Urban Aboriginal Community Strategy Network, 2013. Accessed 3 Jan 2017.
} 
In 2017, Cabot Square is seeing positive improvements with the Cabot Square Project, initiated by the Indigenous organization Montreal Urban Aboriginal Community Strategy NETWORK and funded by the Ville-Marie borough, the J.W. McConnel Family Foundation, the YMCA, and various other collaborators. ${ }^{52}$ The project began in 2013 when NETWORK consulted and worked directly with the Indigenous, cultural minority and homeless communities frequenting Cabot Square, with the objective of creating a safer and welcoming environment. ${ }^{53}$

Following is a list of key actions and initiatives that resulted from the efforts of the Cabot Square Project. The project hopes to continue its work in the area and to scale up to other communities..$^{54}$

\footnotetext{
52 Montreal Urban Aboriginal Community Strategy Network. Final Report, Project: Learning from Cabot Square - Developing the Strategy for Community Safety and Wellbeing. Montreal: Montreal Urban Aboriginal Community Strategy Network, 2013. Accessed 3 Jan 2017.

53 Ibid.

54 Ibid.
} 
I. Introduction of two outreach workers in the park

2. Cultural Practices Sensitization for the Montreal police $(\mathrm{SPVM})$

3. Joint SPVM and community protocols for missing and murdered Indigenous women

4. The Indigenous Commité de Vigil for the SPVM

5. A new position of an Indigenous Liaison Officer for the SPVM

6. The newly renovated Café Roundhouse run by l'Itinéraire

7. Cultural events in Cabot Square funded by the Borough of Ville-Marie and the Ville de Montreal

8. Indigenous housing needs research run through the Homelessness Sub-Committee of the NETWORK

9. Creation of an Inuit radio program (Nipivut) in collaboration with the Nunalijjuaq Project at Concordia University

Source: Montreal Urban Aboriginal Community Strategy NETWORK

The program and design proposal are highly influenced by the initiatives of the Cabot Square Project by NETWORK, specifically parts I, 6 and 7. The program section of this thesis will further expand on the influence of the Cabot Square Project's initiatives to the determined program. 


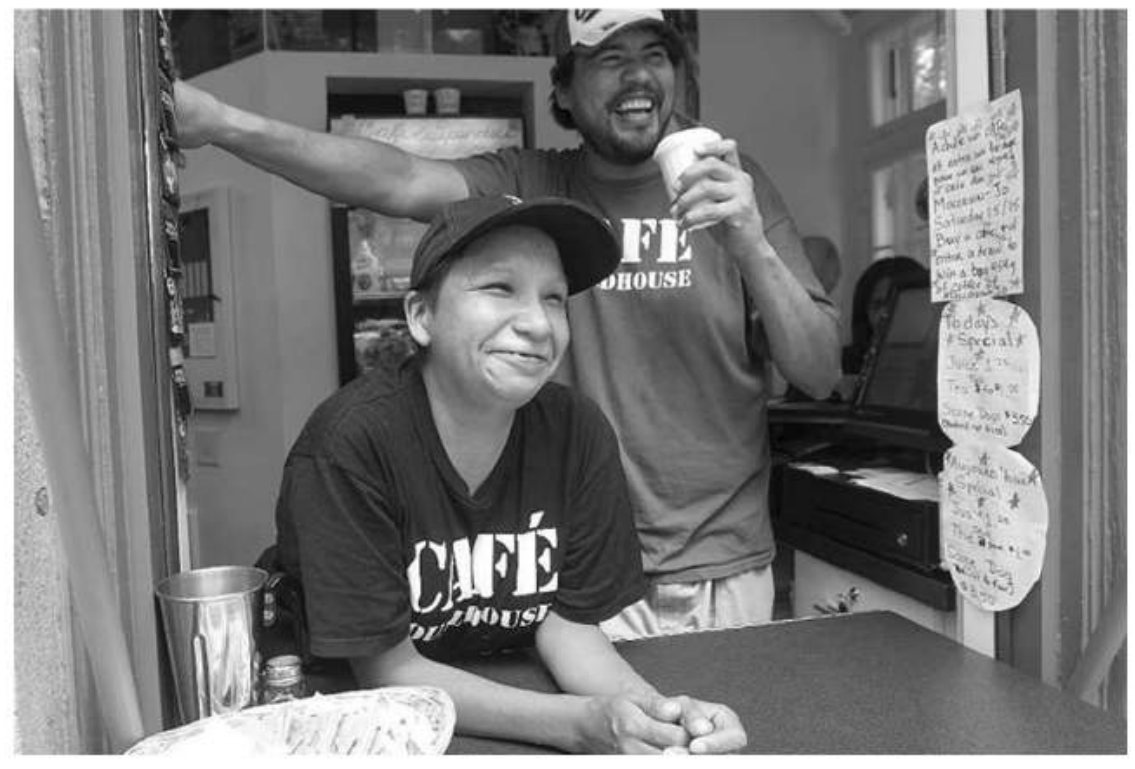

Figure 23: Shirley Dewing working at Roundhouse Café in Cabot Square Source: cbc.ca

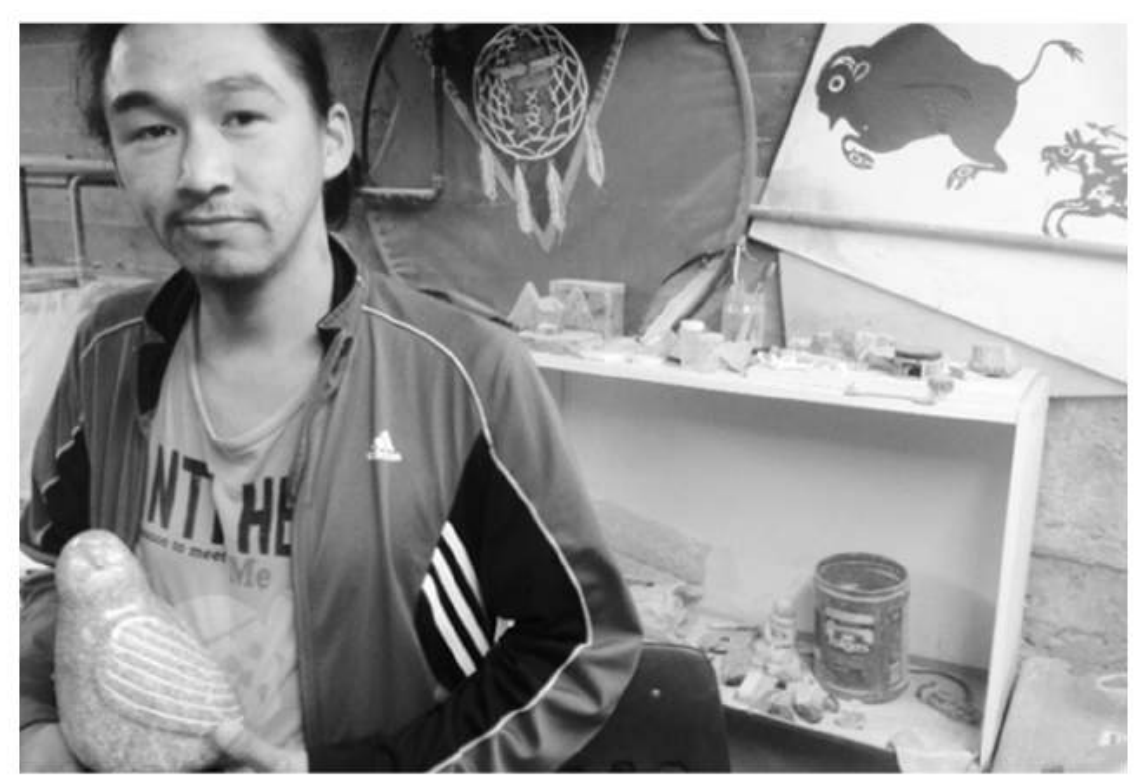

Figure 24: Artist Simiuni Nauya giving soapstonecarving workshops in Cabot Square Source: cbc.ca 


\subsection{DEFINING ELEMENTS OF THE SQUARE}

Cabot Square acts as a terrain with many layers of history, and with that comes associations within the site, whether tangible or intangible, developed over time by the communities and even by visitors. Below are four key characteristics of defining elements at Cabot Square that help to understand the structure of the public square and are instrumental to the proposal. 
The heritage building of the former vespasienne ${ }^{55}$ is the presentday Roundhouse Café, which is one of the initiatives of the Cabot Square Project. The café promotes Indigenous employment and offers traditional Indigenous dishes and coffee. This progressive program creates an exemplary space for cultural exchange. This is a core element and idea emphasized in the proposal and design, reinforcing the concepts of engagement and inclusiveness of this thesis.

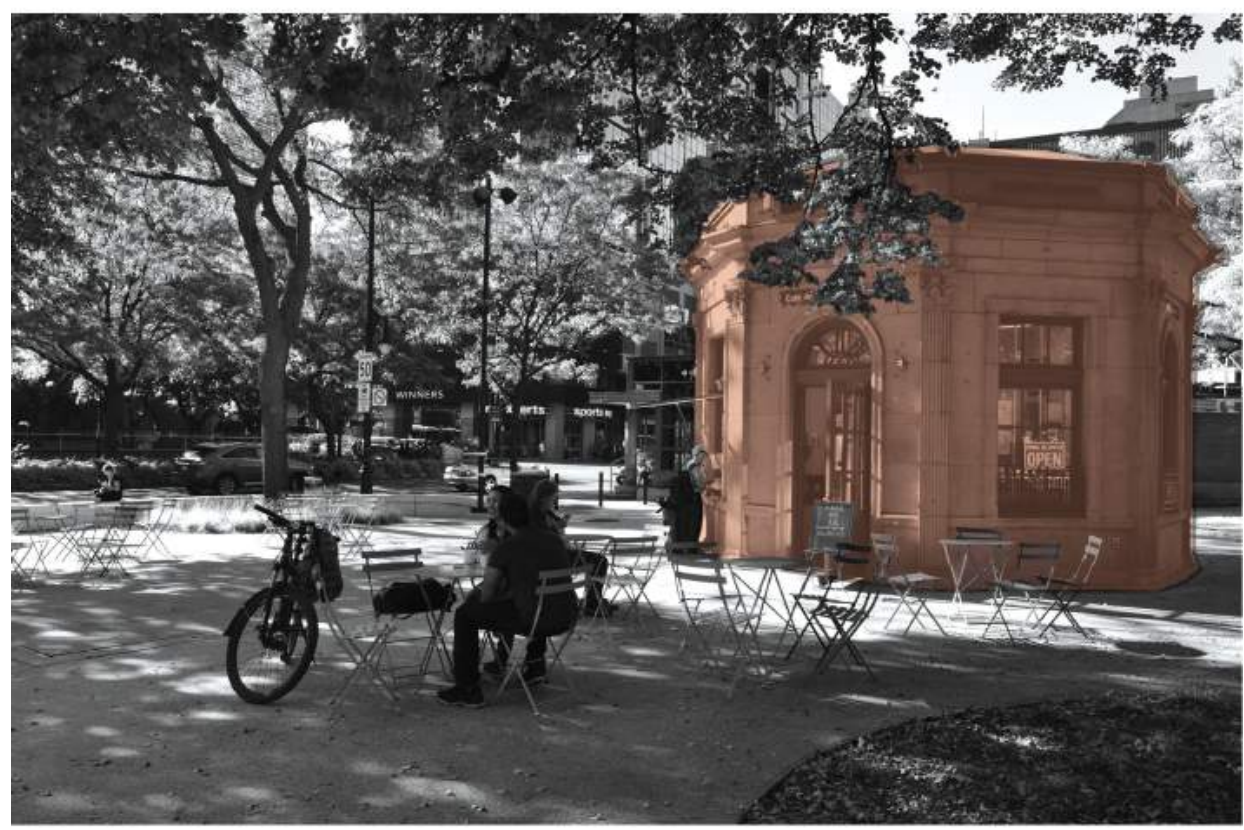

Figure 25: The former vespasienne now known as the Roundhouse Café in Cabot Square Source: Michèle Curtis

\footnotetext{
${ }^{55}$ A vespasienne is a structure that provides support and screening of urinals in public space, common in European parks.
} 
Central to the square is the John Cabot monument that replaced a fountain in the former Western Square in $1956 .{ }^{56}$ The monument was not a part of the original design of the Square. John Cabot was an English explorer known for discovering Newfoundland and, as a historical figure, has an affiliation with the Italian community of Montreal, ${ }^{57}$ but the Italian quarter is not near Cabot Square. The monument is important to understand the "Detach" principle of the methodology (which is explained in the methodology section.)

To better understand this decision, a brief study of the history of John Cabot and his contact (supposed) with early Indigenous peoples follows.

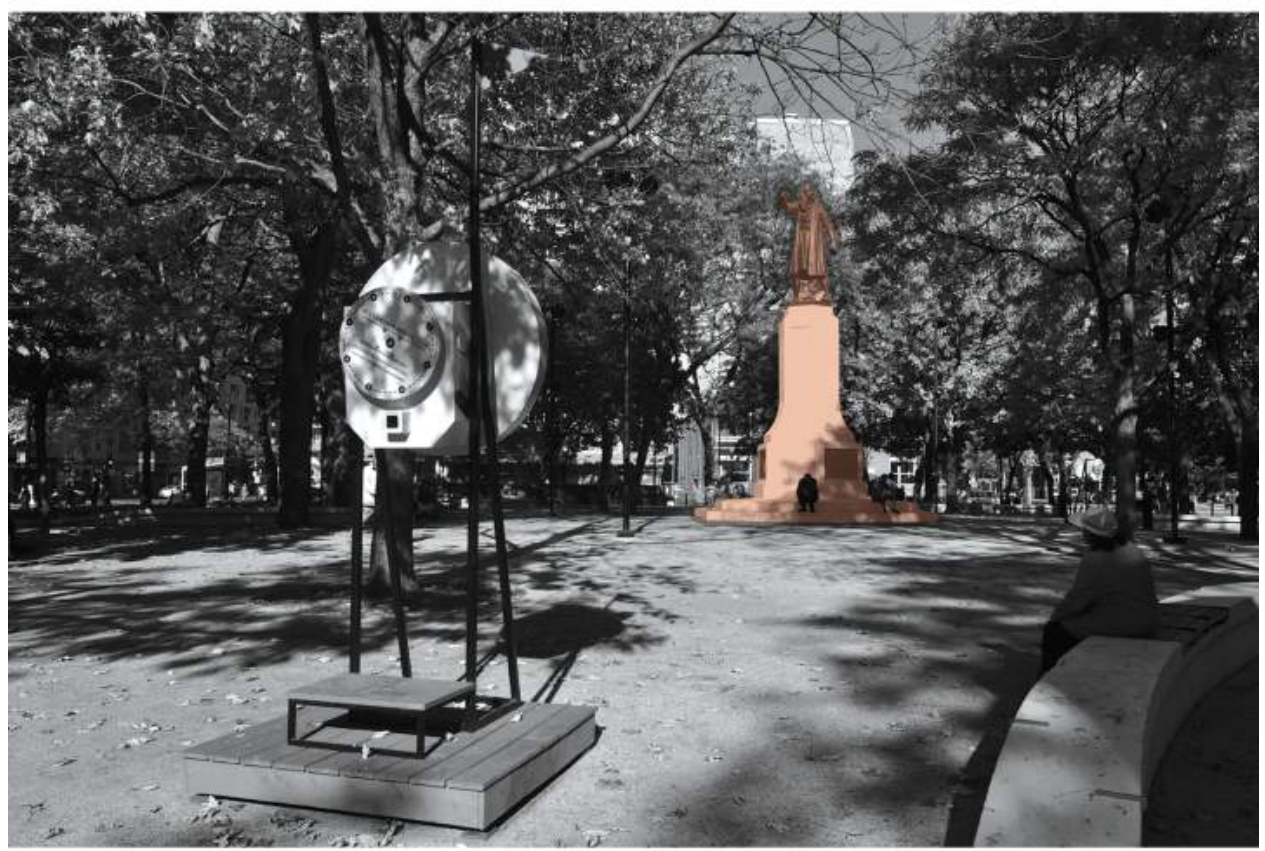

Figure 26: John Cabot Monument Source: Michèle Curtis

\footnotetext{
${ }^{56}$ Wilkins. "Cabot Square, Formerly Western Square." Wordpress, Montreal Gazette, 30 Nov. 2013, accessed 11 Dec 2016, http://rnwilkins.wordress.com/

${ }^{57}$ Ibid.
} 
Very little historical information exists about John Cabot (born Giovanni Caboto, in either Castiglione Chiavarese, Genoa or Gaeta, Naples, Italy I/50) and his two voyages to North America in I/497 and again in $1498 .{ }^{58}$ Written reports are scant, and maps and logs have either disappeared or been destroyed..$^{59}$

John Cabot was searching for a new route to Asia by sailing westward over the Atlantic and on June 2/4 I 497 first made landfall, it is believed, off the coast of Newfoundland or Cape Breton Island, thereby claiming the land for England.$^{60}$ By all accounts he saw surrounding signs of human activity (campfires and trails), but it is unclear whether he had made contact with indigenous people, although it's a possibility that he may have narrowly missed meeting the Micmacs, an may have later on met the Beothuks. ${ }^{6 r}$ In February I 498 , John Cabot set sail for his second voyage westbound. His expedition was never heard of again, and presumed lost at sea. ${ }^{62}$

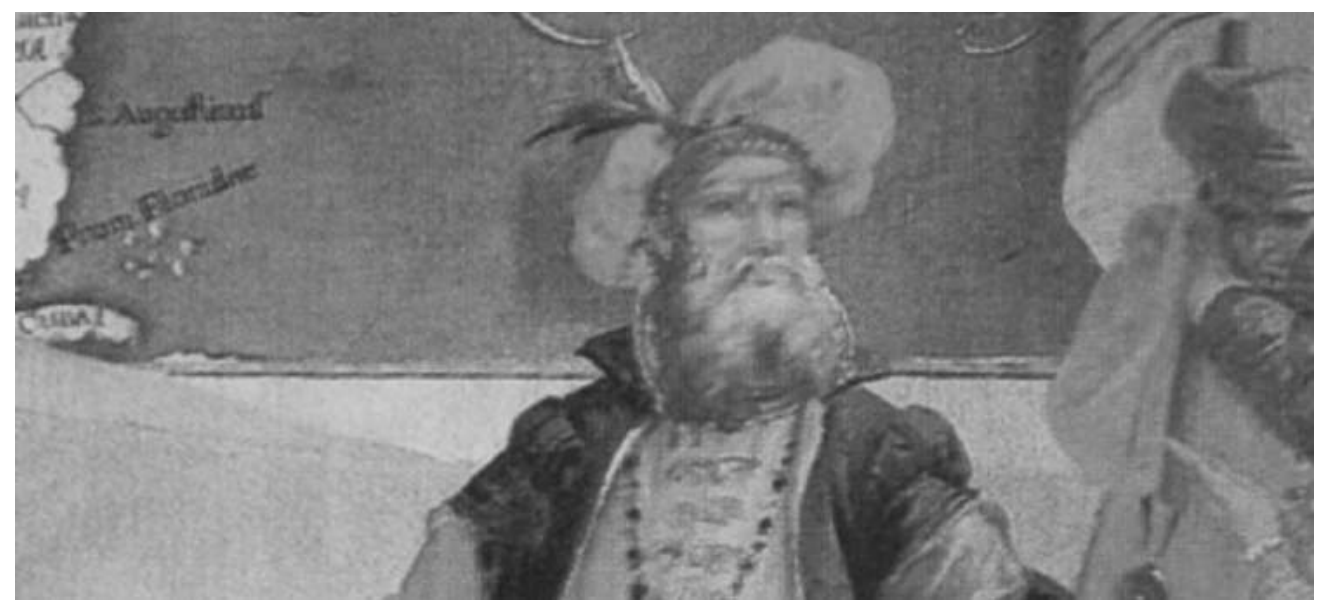

Figure 27: John Cabot

58 A\&E Television Networks. "John Cabot", Biography. April 28 201\%. Accessedraphy.com http://www.biography.com/people/john-cabot-9234057

59 Ibid.

${ }^{60}$ Ibid.

${ }^{61}$ Sudhakar, Kuruvada. "What was John Cabot's relationship with the Indians?" blog post from Yahoo.com, 2014. Accessed Apr. 302017.

https://answers.yahoo.com/question/index?qid=20130110192629AARaPof

62 Ibid. 
The Atwater metro entrance, introduced in the 1960 s is often occupied as a shelter for itinerants. To address this issue, the City of Montreal has resorted to partially demolishing the structure.

Overtime, the Atwater metro has consistently attracted people to the park whether for sporting events, for shopping or to visit the hospital. The proposal intends to respect the metro entranceway as is (for this thesis, the city's demolishment is not considered, it is considered fully functioning). This reflects on the importance and value of this element to Cabot Square but also of the concept of transit and circulation on different level planes (above and below ground, the urban fabric) in Montreal that connect directly to the site.

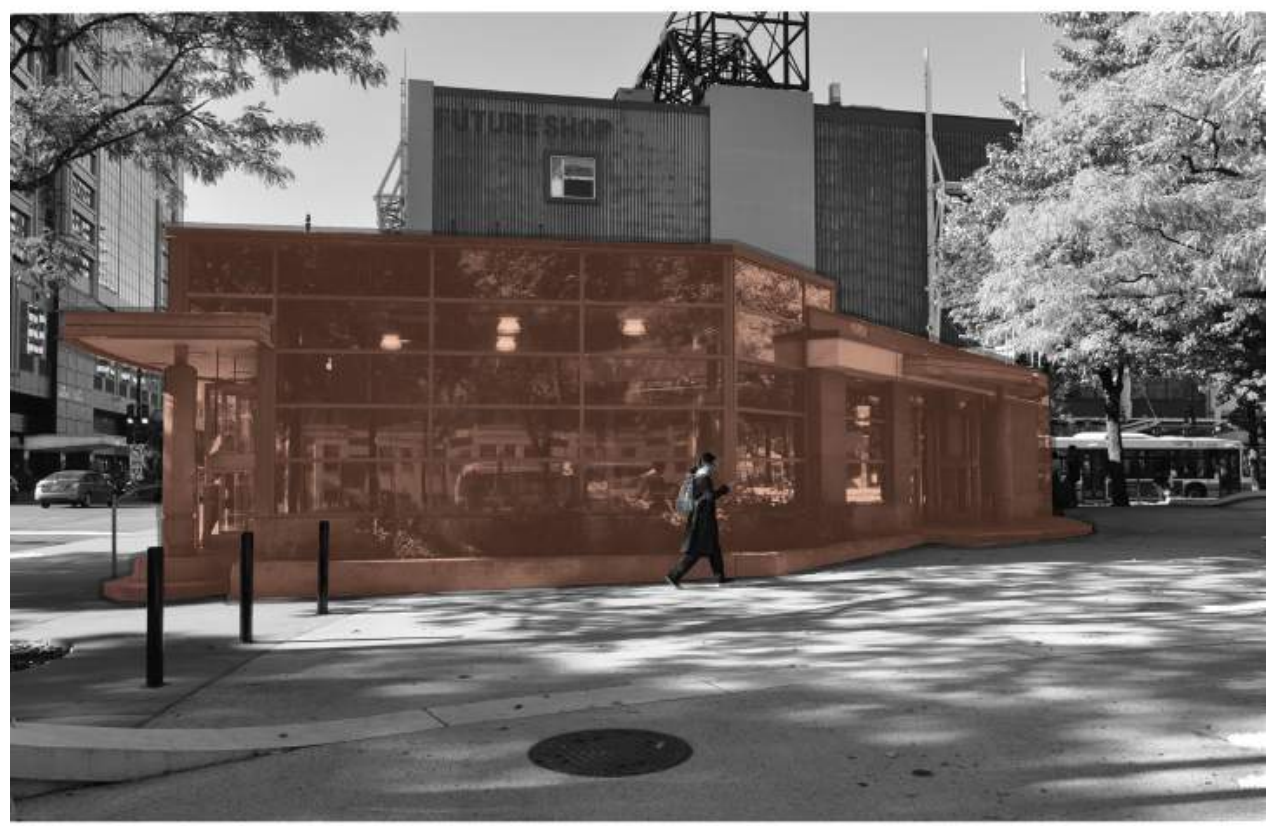

Figure 28: Atwater metro entrance Source: Michèle Curtis 
The most prominent feature of Cabot Square is the trees. Most of the greenery and trees have remained since the original Square was established decades ago. Following Cabot Square's recent renovations last summer, the trees have been well conserved in the park. The design proposition continues to respect the trees, which helps develop the form of the design and strengthen the concepts of engagement and inclusiveness.

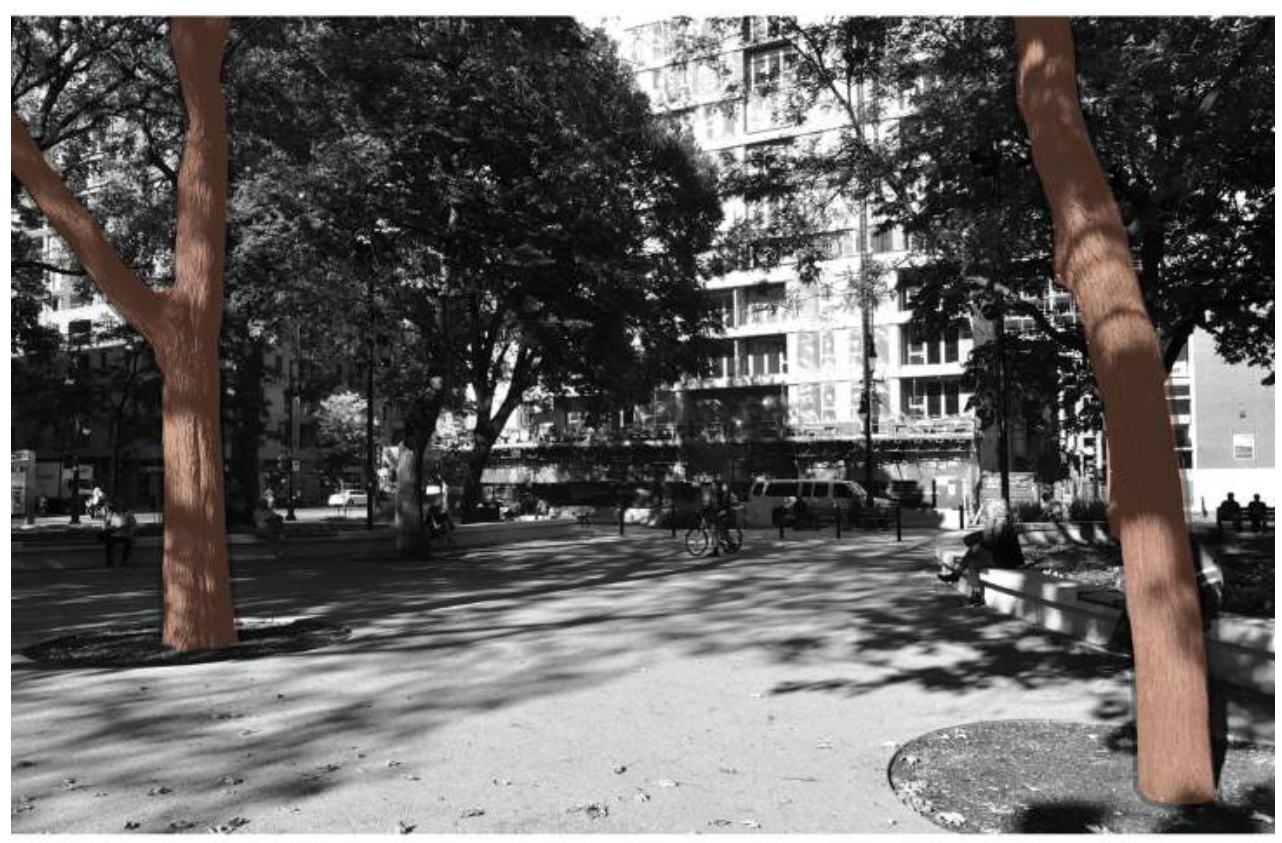

Figure 29: Trees in Cabot Square Source: Michèle Curtis 


\section{METHODOLOGY}

Three core approaches to meet the objective of creating urban gathering spaces are explained in the following section. The approaches 'Detach,' 'Engage' and 'Conserve' are groupings of notions that are interpreted and applied equally to the design and program. 


\section{IV.A. DETACH}

To detach is "to disconnect, disengage, or remove something from something else that it is connected to." ${ }^{63}$ Triggering this sense of detachment in the urban Indigenous community is a lack of awareness on the part of the general public and a lack of acknowledgement of the story of Indigenous and foreign peoples new to the city, specifically in terms of the issues they encounter as a result of urbanization. ${ }^{64}$ The Urban Aboriginal Peoples Study (UAPS) surveyed urban Indigenous peoples in the city of Montreal and found that "a slim majority of Montreal residents know Indigenous people live in their city [...]. Indeed, very few non-Aboriginal Montrealers have regular contact with Aboriginal people (which is understandably more common in cities with larger relative Indigenous populations), and they are among the least likely to know Indigenous people as close friends, neighbors and co-workers. ${ }^{" 5}$

Indigenous urbanization is still a very contemporary term. While there is very little history that examines urban Indigenous peoples in cities, there are numerous examples that suggest the absence of Indigenous peoples in urban centres up until the mid to late Igoos, as the result of policies that displaced them from urban areas. ${ }^{66}$ "These policies included the selection of reserve lands far from the city and practices that confined First Nations

\footnotetext{
63 Dictionary.com, accessed 3 Jan 2017, http://www.dictionary.com/browse/detach?s=t

${ }^{64}$ Environics Institute. Urban Aboriginal Peoples Study: Montreal Report. Toronto: Environics Institute, 2011. Accessed 12 Oct 2016.

${ }^{65}$ Newhouse, David, Peter, Evelyn. "No Strangers in These Parts" Policy Research Initiative: Aboriginal Policy Research Conference. Nov. 2002.

${ }^{66}$ Ibid.
} 
peoples to these areas, the dispossession of Métis people from their lands and their settlement on urban fringes, and the expropriation of reserves and communities overtaken by expanding urban boundaries." ${ }^{{ }_{7}}$ The idea of an urban Indigenous person conflicts with the images of Indigenous peoples in community reserves that have developed over the past century. Consequently, Indigenous people who chose to live in cities were seen as abnormalities or as people who had turned their backs on their own culture. ${ }^{68}$

Indigenous peoples (and other immigrant groups) experience a break from their culture, home and community when they move to the city. NETWORK describes the results of this experience as a 'Loss of Home,' 'Community Fragmentation' and 'Cultural Disconnection. ${ }^{69}$ These outcomes of displacement in the urban centre form three core notions reflected in the proposal. The design intention is a progressive response to these negative notions. The 'Detach' approach, which may be questioned and debated amongst occupiers, tourists and stakeholders from the community, helps to draw more awareness to the problems that many cultural newcomers experience when relocating to the city, and to make the general population more sensitive and responsive to the challenges of integration.

\footnotetext{
${ }^{67}$ Newhouse, David, Peter, Evelyn. "No Strangers in These Parts" Policy Research Initiative: Aboriginal Policy Research Conference. Nov. 2002.

${ }^{68}$ Ibid.

${ }^{69}$ Montreal Urban Aboriginal Community Strategy Network. Final Report, Project: Learning from Cabot Square - Developing the Strategy for Community Safety and Wellbeing. Montreal: Montreal Urban Aboriginal Community Strategy Network, 2013. Accessed 3 Jan 2017.
} 
A detailed breakdown of the three themes developed by NETWORK:

\section{"Loss of Home"}

Home is the familiar, taken-for-granted world where most of us are nurtured, comforted and loved. For the majority, home is a safe and welcoming place. Home transcends the domestic physical structure, encompassing cultural, symbolic and psychological dimensions. It extends to the neighbourhood, city, region and nation. Home provides a sense of belonging in the world and is a refuge from the dangers and uncertainty of the environment at large. It is the centre of important human relationships and their accompanying domestic roles, rituals and routines. Home is a symbol of personal identity and worth, where the individual can exercise a degree of power and autonomy denied elsewhere. ${ }^{70}$

${ }^{70}$ Thompson, Susan, "Home and Loss", Media Culture Journal, Aug 2007, accessed 3 Jan 2017,

http://journal.media-culture.org.au/0708/07-thompson.php 


\section{"Community Fragmentation"}

In urban sociology, fragmentation refers to the absence or the underdevelopment of connections between the society and the groupings of some members of that society along the lines of a common culture, nationality, race, language, occupation, religion, income level or other common interests. This gap between the concerned group and the rest might be social, indicating poor interrelationships, structural, based on economic inequality; institutional, in terms of political, occupational, educational or associative organizations; or geographic, implying regional or residential concentration. $^{\text {I }}$

71 "Fragmentation (sociology)", Wikipedia, accessed 3 Jan 2017,

https://en.wikipedia.org/wiki/Fragmentation_(sociology) 


\section{"Cultural Disconnection"}

A cultural divide or disconnection is a boundary in society that separates communities whose social and economic structures, opportunities for success and conventions are so different that they result in substantially different psychologies. A cultural divide is the virtual barrier caused by cultural differences that hinder interactions and harmonious exchange between people of different cultures. For example, avoiding eye contact with a superior shows deference and respect in East Asian cultures, but can be interpreted as suspicious behavior in Western cultures. Studies on cultural divide usually focus on identifying and bridging it at different levels of society..$^{2}$

72 "Cultural Divide”, Wikipedia, accessed 3 Jan 2017,

https://en.wikipedia.org/wiki/Cultural_divide 
As for the concept of the 'Detached' principle being translated and applied to the John Cabot monument; Cabot Square is traditionally centered around the John Cabot Monument. The monument is here considered as the "solid" centre of the square, while the Roundhouse Café is now considered the new, "open" centre of square (since the concept of the café has highly influenced the concepts of gathering and exchange).

The new "open" centre of the square differentiates itself from the former "solid" centre/ the monument and this reflects a detachment from certain associations with the meaning of the monument. 


\section{IV.B. ENGAGE}

To engage is to "attract, involve or take part in," "to interest someone in something and keep them thinking about it." ${ }^{3}$ Used here, it is the act of acknowledgement and inclusion of Indigenous issues, and one of the fundamentals of this thesis. To represent this second core approach, Montreal Urban Aboriginal Strategy NETWORK created a theory using four principles that, once interconnected, can begin assisting spaces like Cabot Square as well as larger-scale areas in the urban centre. ${ }^{74}$ The principles are "Well-being," "Co-habitation," "Belonging," and "Safety." They exemplify the effort, engagement and initiatives that people and organizations are beginning to establish for the urban Indigenous, minority and the homeless populations in the city. These principles constitute a significant influence for the proposal, with an additional theme of "Youth" - a valued attribute in Indigenous culture-helping to provide a renewed sense of hope and vitality. Youth is also an important topic here, as it reflects an association with the former Montreal Children's Hospital and may help reconnect the community to the site.

\footnotetext{
${ }^{73}$ Dictionary.com, accessed 3 Jan 2017, http://www.dictionary.com/browse/engage?s=t

${ }^{74}$ Montreal Urban Aboriginal Community Strategy Network. Final Report, Project: Learning from Cabot Square - Developing the Strategy for Community Safety and Wellbeing. Montreal: Montreal Urban Aboriginal Community Strategy Network, 2013. Accessed 3 Jan 2017.
} 
Below are the four principles established by NETWORK that are incorporated in the program:

\section{"Wellbeing"}

Improved and increased services aimed at mental, physical, spiritual, and emotional well-being

\section{"Co-habitation"}

Indigenous and non-Indigenous people participate in projects, communication and physical spaces in healthy, safe and mutually respectful ways. There is a sense of greater community for homeless and nonhomeless people, Inuit and First Nations, and Indigenous and non-Indigenous people in the Cabot Square area

\section{"Belonging"}

The city and services embrace and show understanding of Indigenous culture and people. Indigenous people use and see themselves reflected and welcome in public spaces

\section{"Safety"}

Improved perceptions and experiences of safety for park users

Source: Montreal Urban Aboriginal Community Strategy NETWORK 


\section{IV.C. CONSERVE}

The third approach focuses on conserving and reflecting key heritage elements at Cabot Square and the former Montreal Children's Hospital. It also equally applies to the intangible value of the square, which is the park frequenters. In order to meet this objective, four out of seven principles from the 2008 ICOMOS Charter for the Interpretation and Presentation of Cultural Heritage Sites ${ }^{75}$ are analyzed, interpreted through the context of this thesis and applied to the program and design. It should be noted that the ICOMOS Charter principles primarily concerns heritage buildings and sites, but are re-interpreted for this thesis. Following are the selected four principles with their objectives (I,3, 4 and 6 ) and how they are applied to the design and program proposal.

${ }^{75}$ Interpretation and Presentation of Cultural Heritage Sites. ICOMOS, 16 ${ }^{\text {th }} \mathrm{GA}$, Québec, 2008. 
ICOMOS Charter for the Interpretation and Presentation of Cultural Heritage sites (2008) selected principles:

\section{Principle 1: Access and Understanding}

Objective: Facilitate understanding and appreciation of cultural heritage sites and foster public awareness and engagement in the need for their protection and conservation.

How it's applied to this thesis: Hypothetically, if Cabot Square were to undergo further construction, the construction phasing for this thesis is an important concept, since it would allow for frequenters to continuously visiting the park throughout the redevelopment.

Involving the community and occupants with the construction process of the project is an important way to facilitate understanding and appreciation of the site, by understanding the changes that are being made and by incorporating their input.

\section{Principle 3: Attention to Setting and Context}

Objective: Safeguard the tangible and intangible values of cultural heritage sites in their natural and cultural settings and social contexts.

How it's applied to this thesis: Allowing the communities access the square during construction 
phases safeguards the main intangible value of the site; its frequenters, which involves constant activity and interactions (with other people and Cabot Square itself).

\section{Principle 4: Preservation of Authenticity}

Objective: Respect the authenticity of cultural heritage sites, by communicating the significance of their historic fabric and cultural values and protecting them from the adverse impact of intrusive interpretive infrastructure, visitor pressure, inaccurate or inappropriate interpretation.

How it's applied to this thesis: All character defining elements of the square, which also have significant heritage value, are left untouched, except for a new build extension of the Roundhouse Café. The new build extension of the RoundHouse Café structure respects three rules from the Standards and Guidelines of Canada: the new addition will be reversible, distinguishable from, subordinate to and physically compatible with the heritage structure..$^{-6}$ This concept aims to respect and function with the original design and use of the square, including its ouddefining heritage elements and the traditional activity of a public square (circulation, travelling from

${ }^{76}$ Standards and Guidelines for the Conservation of Historic Places in Canada (2010). Canada's

Historic Places. Accessed 30 Apr. 2017, http://www.historicplaces.ca/en/pages/more-

plus/contact.aspx 
one end to the next), and also respecting the recent re-design of it, while emphasizing the new use and frequenters focused on in this thesis. The proposal focuses on creating a connection with the old and new park.

\section{Principle 6: Concern for Inclusiveness}

Objective: Encourage inclusiveness in the interpretation of cultural heritage sites, by facilitating the involvement of stakeholders and associated communities in the development and implementation of interpretive programmes.

How it's applied to this thesis: Inclusiveness is a core concept of this thesis. The proposed program fully aims to facilitate social and cultural exchange, therefore aiming to create inclusivity amongst stakeholders and hopefully to transcend further into other places and communities in Montreal. Each proposed gathering space introduced to the square are designed to facilitate interaction amongst frequenters (whether interior or exterior).

Source: ICOMOS Charter for the Interpretation and Presentation of Cultural Heritage Sites 


\section{DETERMINING THE PROGRAM}

This proposal follows the concept of engagement and inclusivity, with a focus on the urban Indigenous community who are the main frequenters of Cabot Square today. In order to determine the suitable programming, consultations with the urban Indigenous communities at Cabot Square conducted by the Montreal Urban Aboriginal Community Strategy NETWORK were analyzed to understand the main concerns and needs of the stakeholders at the square. The final report "Learning from Cabot Square - Developing the Strategy for Community Safety and Wellbeing" also helped with the initial steps of the Cabot Square Project and for determining the program for this thesis. Another instrumental step in determining the program was various conversations with personnel at the Montreal Native Friendship Centre, the Vanier Wabano Centre for Indigenous Health, the Montreal Urban Aboriginal Community Strategy, and other people having worked with Indigenous communities.

Below is a list of solutions that NETWORK, in collaboration with the City of Montreal, determined to be valuable for the well being, safety, sense of belonging, and future of the urban Indigenous people of Cabot Square, that were selected to support this thesis. ${ }^{7}$ Highlighted information is incorporated in the proposed program of this thesis.

${ }^{77}$ Montreal Urban Aboriginal Community Strategy Network. Final Report, Project: Learning from Cabot Square - Developing the Strategy for Community Safety and Wellbeing. Montreal:

Montreal Urban Aboriginal Community Strategy Network, 2013. Accessed 3 Jan 2017. 
Solution 1: Front line coordination and support

Mission: Support front-line workers who already work with the target population and offer a private space for consultations between workers and the population that will act as a meeting place for the sharing of information between front-line workers from different organizations

How it translates to the proposed program: Public and private consultation spaces in the main meeting and help centre.

Solution 2: Offer a gathering space for the target population

Mission: Provide a gathering space for the target population during evenings and weekends

How it translates to the proposed program: The program exclusively aims to draw and gather people together.

Solution 3: Avoid the displacement of the target population

Mission: Ensure access to Cabot Square during the reredevelopment phase to avoid displacing the target population. 
How it translates to the proposed program: Allowing access to the square during the (thesis) construction phases.

Solution 6: Improve cohabitation between all users of the space

Mission: (A) Improve communication between all stakeholders. (B) Increase the general public's awareness and get the target population involved

How it translates to the proposed program: The program exclusively focuses on engagement, interaction and inclusivity.

Other recommendations: Promote Indigenous culture. The Art and Culture Working Committee of the NETWORK aims to establish an Indigenous Community Cultural Centre in Montreal, which would house exhibitions, performances, workshops, roundtables, readings and other types of projects and events. Open to all generations and nations, this centre would contain a cultural archive of the Indigenous people in the greater Montreal area, and inform and educate the general public about Indigenous art and culture. 
How it translates to the proposed program: The program promotes Indigenous arts, culture and employment.

Source: Montreal Urban Aboriginal Community Strategy NETWORK 
Following a study of the NETWORK consultations with the urban Indigenous people frequenting the square, the surrounding facilities of Cabot Square were analyzed to further highlight the notions of community engagement and inclusivity. In order to meet this, familiarization with the area and the city context is imperative. The existing program of each establishment adjacent to Cabot Square is reflected in the newly proposed program at the square, a method that aims to promote a sense of familiarization with the neighboring area and with the city, and could hopefully be repeated in other urban parks.

The program greatly focuses on offering employment to the urban Indigenous communities with the hopes of furthering engagement with other Montrealers, and creating an informal space for cultural and social exchange and learning. This concept is an extension of the Roundhouse Café program already existing at Cabot Square initiated by the Cabot Square Project, as previously mentioned.

The following images highlight the adjacent buildings to Cabot Square, helping to define the proposed program which is influenced by the existing program of its surrounding and the Cabot Square Project report findings. 
Figure 30: Cabot Square

surrounding buildings

Source: Michèle Curtis

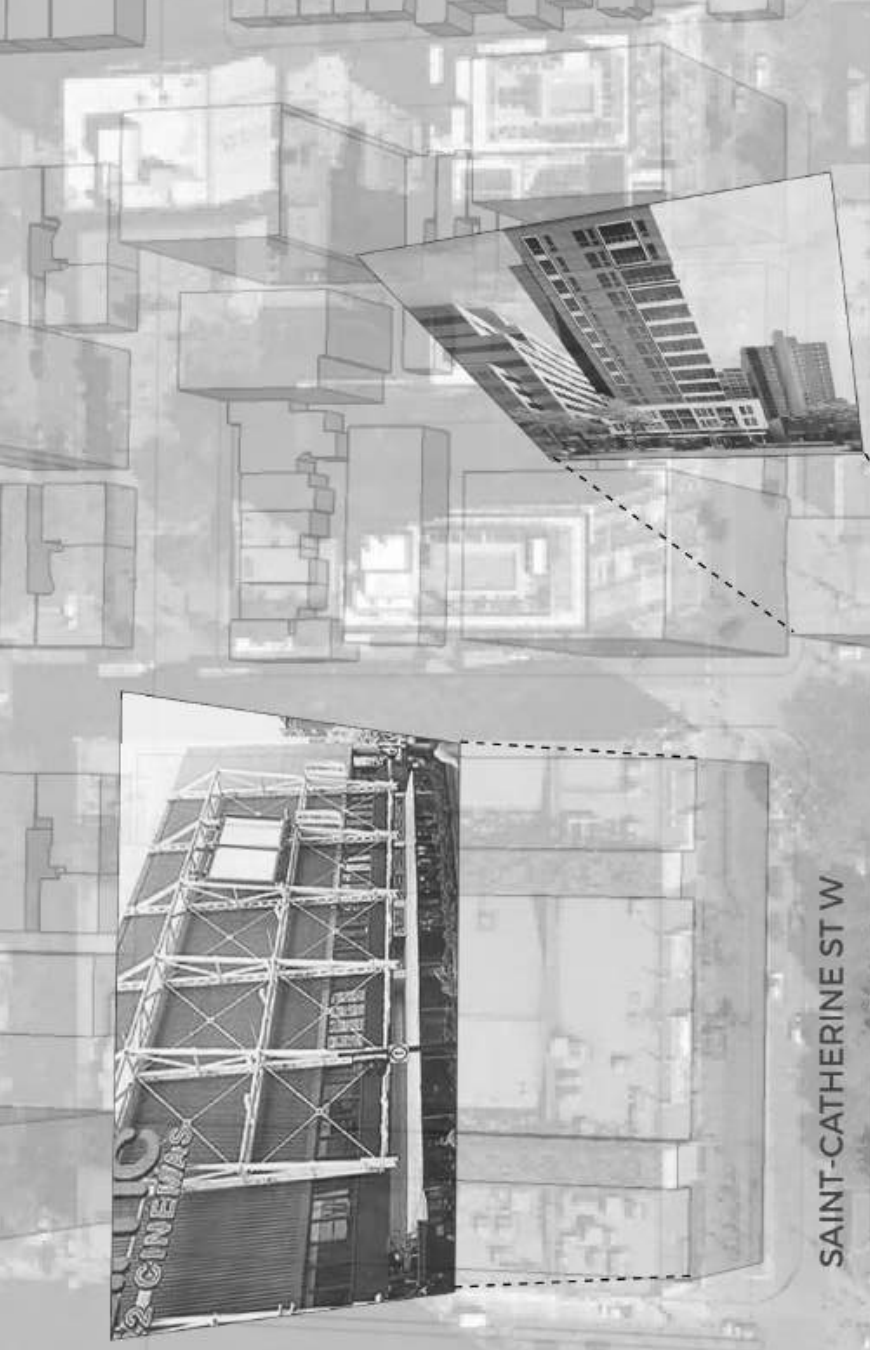

WII
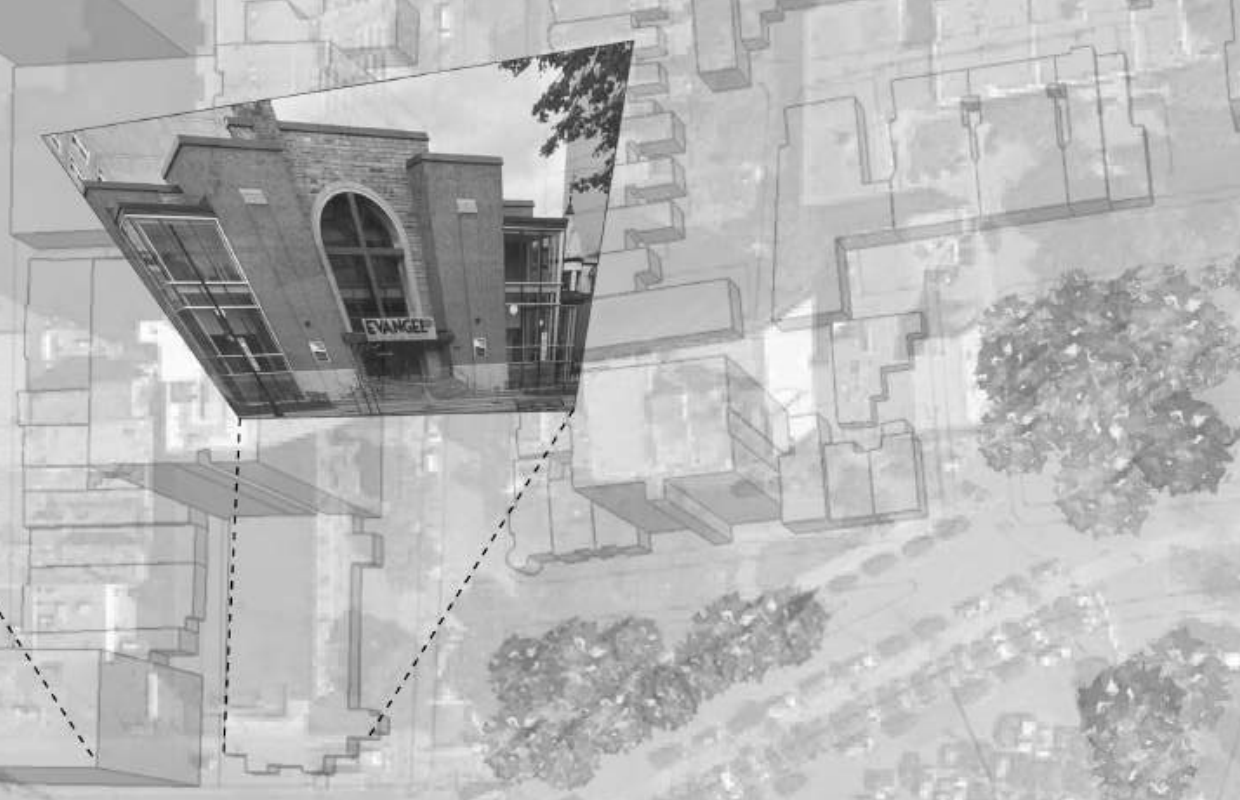

\section{LAMBER-CLOSSE ST}

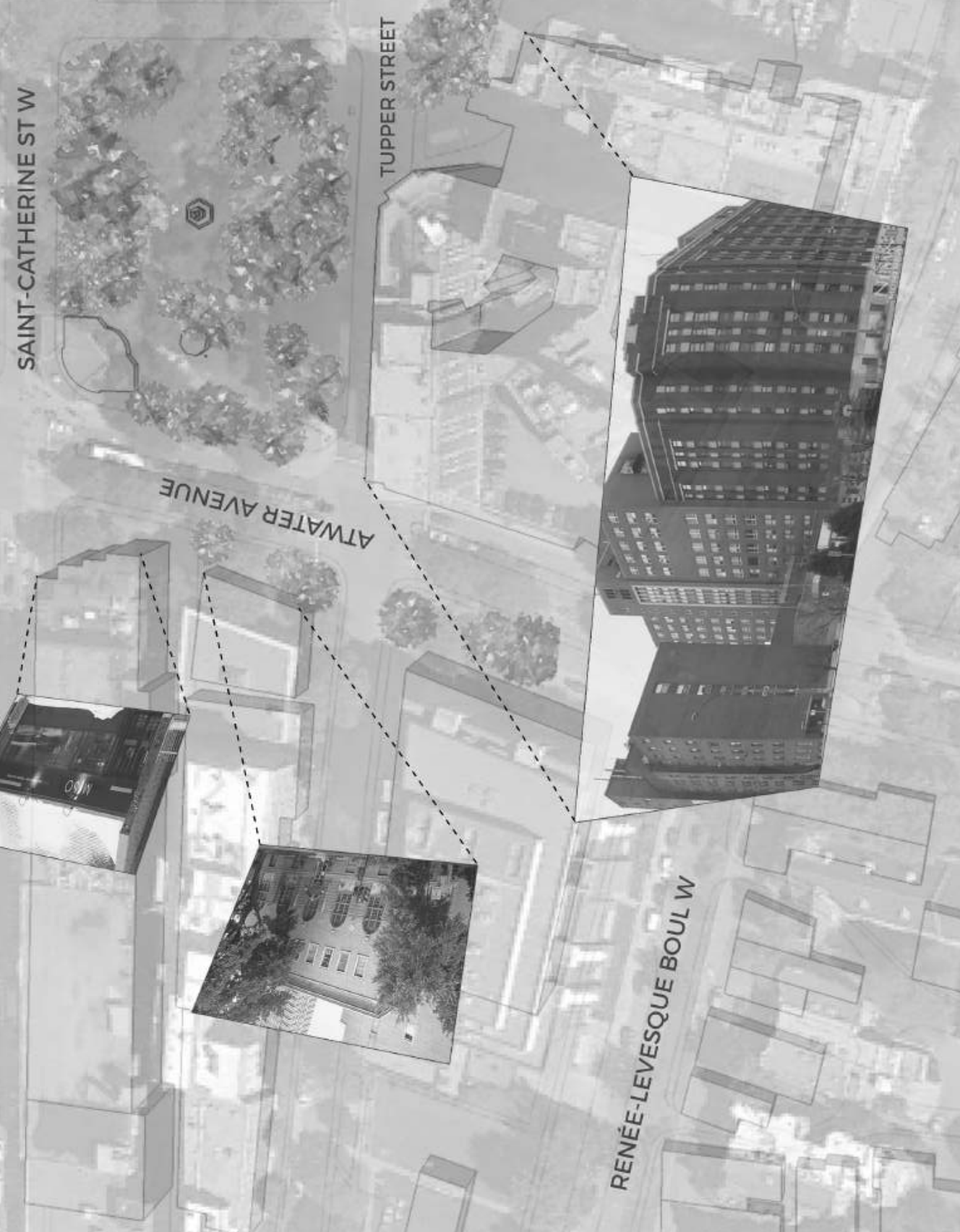



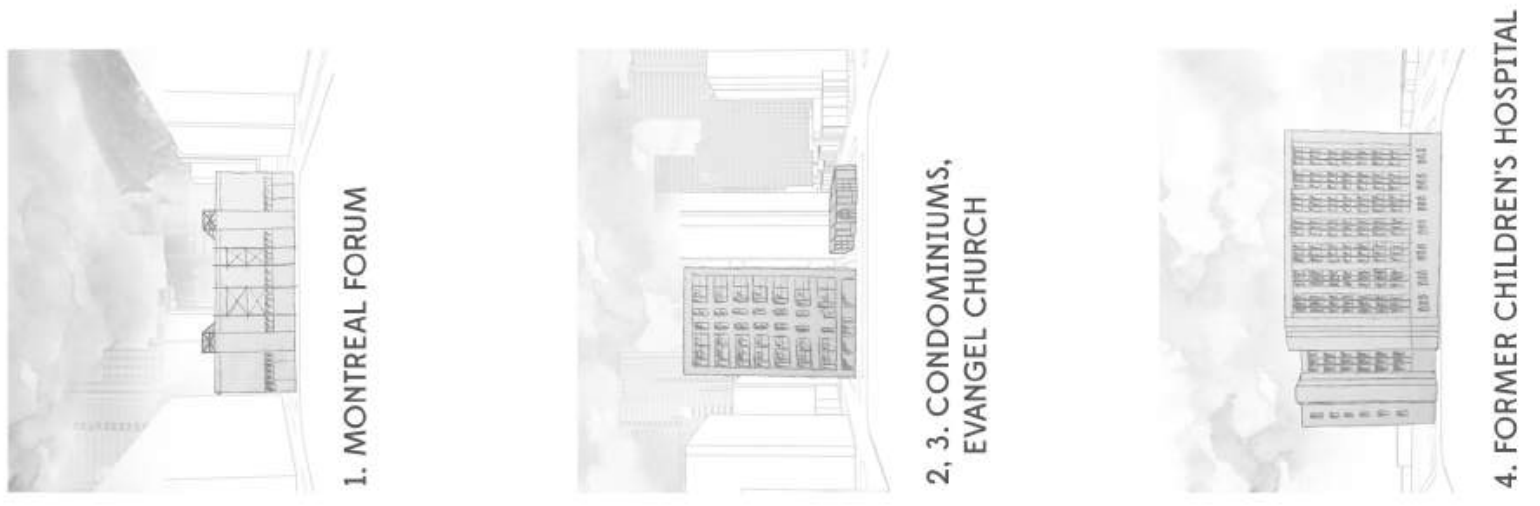

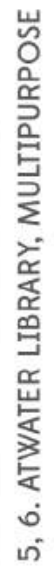
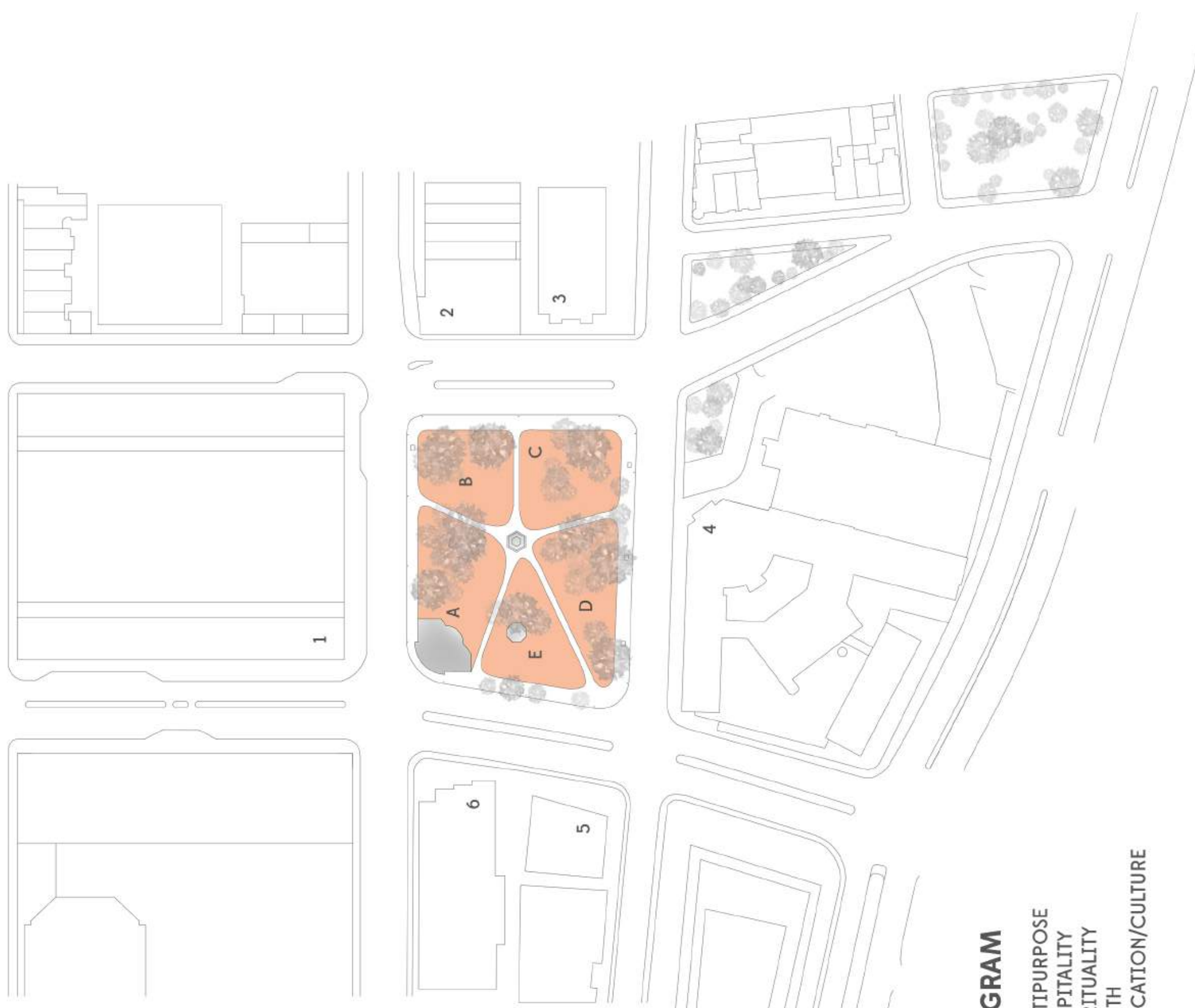
Following the solutions and initiatives established by the Cabot Square Project by NETWORK and influenced by the existing program of the adjacent establishments, below is a more detailed list of the thesis' program.

A. MULTIPURPOSE: Event and performance space, gallery, exhibition

B. HOSPITALITY: Consultation and meeting centre

C. SPIRITUALITY: Reflection space

D. YOUTH: Playground, workshop space

E. EDUCATION/ CULTURE: Workshops and main gathering/exchange space

The program is further expressed in plan and section in the design chapter. It should be highlighted that the program of this project is focused on promoting Indigenous culture, arts and employment, a concept that emphasizes the current Roundhouse Café by the Cabot Square Project. By doing so, a comfortable space for cultural and social exchange may evolve, much like the Roundhouse Café that is already starting to create a positive impact in Montreal and is a great precedent to this thesis.

Since a core objective of this thesis is to facilitate community engagement and inclusiveness, it is important that the proposed program, much like the design, remain a proposal and is open to 
other suggestions and changes (hypothetically). This is in part since it was not possible to involve all communities in the decision making of the thesis process, but also to reflect adaptability and openness, key concepts that may help draw more people together in a public space, as Place Émilie-Gamelin proved to do so. 


\section{PRECEDENTS}

\section{VI.I. SKWACHÀYS LODGE}

Architect: Joe Wai

Location: Vancouver, British Columbia

Year: 2014

Program: Boutique Hotel, Indigenous artist residency and subsidized short-term housing for First Nations at risk of homelessness ${ }^{78}$

The Skwachàys Lodge supports Indigenous culture by incorporating the gallery boutique as a significant program in the hotel. A temporary housing unit is offered to the resident artist whose work is featured in the gallery. ${ }^{79}$

Promoting employment of Indigenous Montrealers and incorporating Indigenous art and culture in a way that can be easily shared with the public is the main focus of this thesis' proposal. The Skwachàys Lodge Hotel is an exemplary project that has proven successful results for the Indigenous community in Vancouver. ${ }^{80}$

78 "Skwachàys Story", Skwachays, accessed 3 Jan 2017,
http://skwachays.com/the-lodge/
79 Ibid.
${ }^{80}$ Ibid.

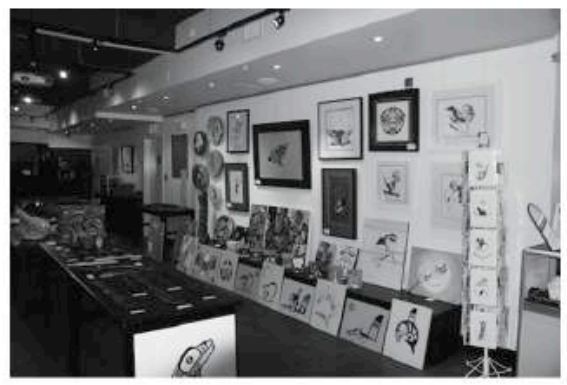

Figure 32: Skwachàys Lodge Boutique Hotel Source: skwachays.com 


\section{VI.II. WABANO CENTRE}

Architect: Douglas Cardinal and Bret

Cardinal

Location: Ottawa, Ontario

Year: 2000

Program: Community Centre for Indigenous

health $^{81}$

Although the Wabano Centre's health program is

exemplarity and the architects work in collaboration with the stakeholders of their projects, the design is in question for this thesis due to the way it stands out in its context. Located in Vanier near the heart of downtown Ottawa and surrounded by a city fabric, the centre fails to fit in with its surroundings, a core concept of this thesis.

While the Wabano Centre is significantly important for helping the Indigenous community of Ottawa, in my opinion, the design doesn't respond to its environment. This project studies the Indigenous communities engagement with other communities in the urban centre, therefore offering a building that stands out from the rest of the environment may not be beneficial.

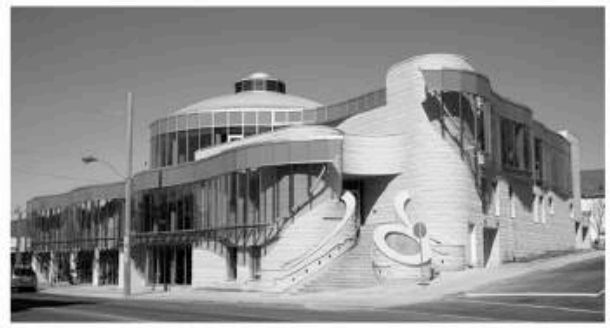

Figure 33: Wabano Centre Source: wabano.com

${ }^{81}$ Wabano, accessed 3 Jan 2017, http://www.wabano.com/about/ 


\section{PROCESS}

This thesis involved a lengthy process of understanding who the

site frequenters are the urban Indigenous community but also all other communities) and what would be appropriate and fundamental as an intervention respecting their values and associations with Cabot Square while also respecting the heritage value of the square. A previous design was proposed that did not sympathize well enough with some heritage elements of the square, and therefore did not express the concepts of engagement and inclusivity well enough, although the core concept of introducing a central gathering space has always been met. The following list highlights what I've learned from the former design that was reassessed and is redefined in the new design proposal.

- More than $50 \%$ of the square was intervened with permanent structures. In order to respect the traditional use of the public square, it is important that a majority of open space remains.

- The monument was overlooked, while it should be incorporated in the design since it has significant heritage value.

- Overall, although the design attempted to create a connection with the park frequenters, it didn't connect well enough to Cabot Square.

- Although the form of the previous design aimed to respect the square's circulation, a more organic, 
rounded form (respecting the existing footprint), encourages easier flow and circulation.

- The building design appeared fragmented, the new proposal shows three major spaces, offering a more fluid and connective understanding.

The first design is found in the appendix. 


\section{DESIGN}

This thesis proposes a series of urban gathering spaces in Cabot Square aiming to draw the public together in new, informal ways, creating a central place in Montreal that focuses on Indigenous culture and arts, and providing an information and meeting centre for those seeking guidance in the city. Following is a diagram of the summarized methodology along with core design concepts that were developed after determining the methodology. 


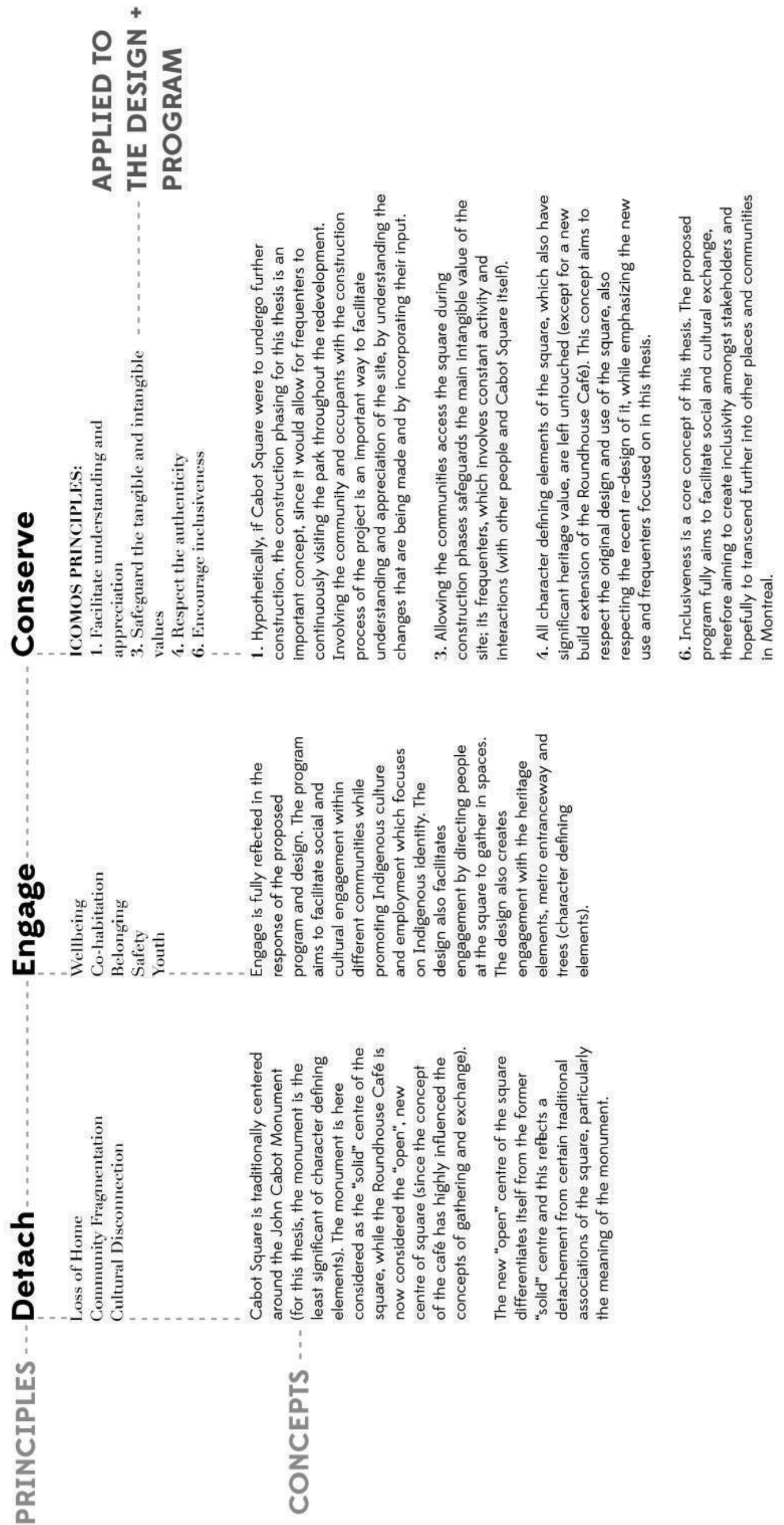



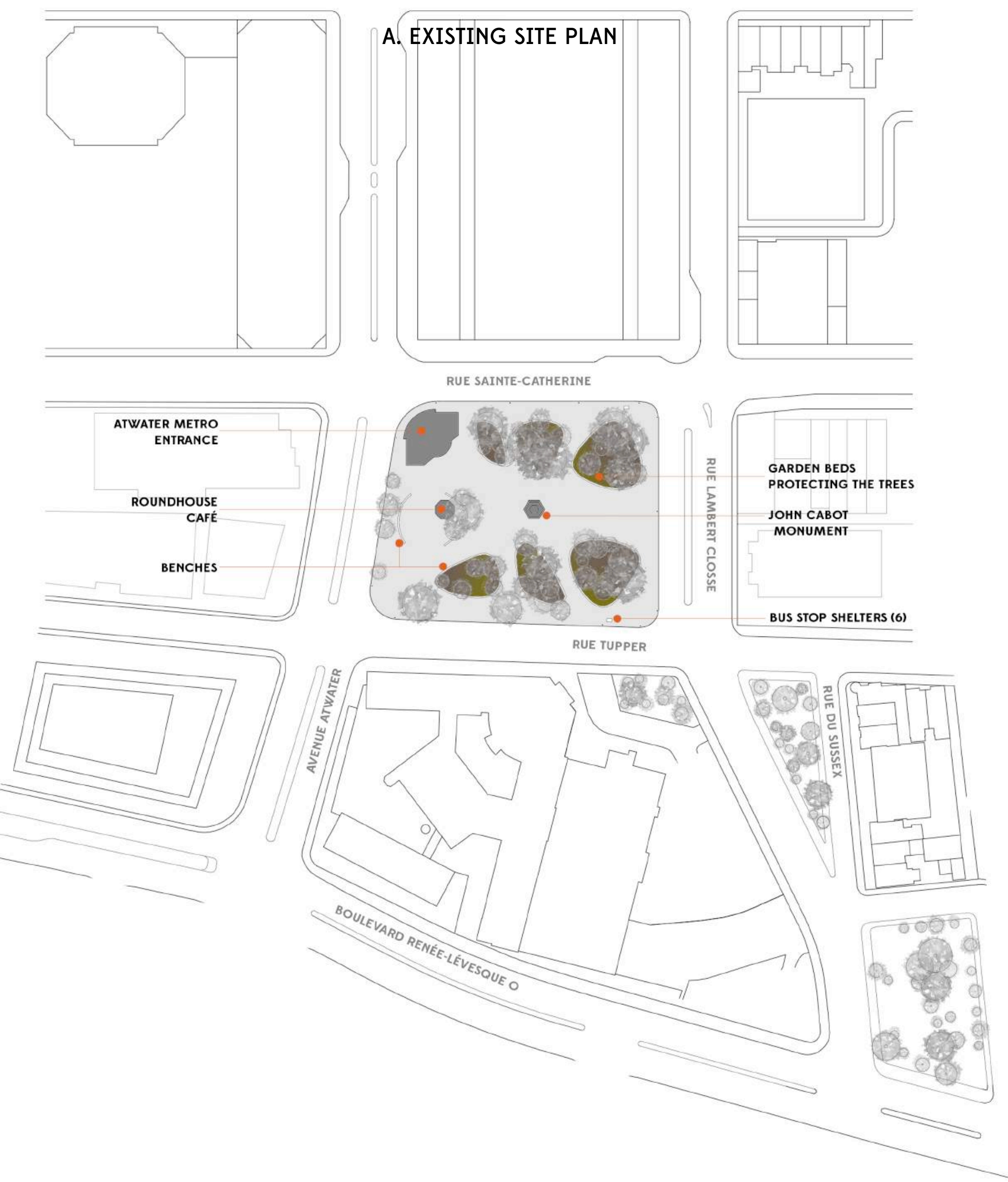

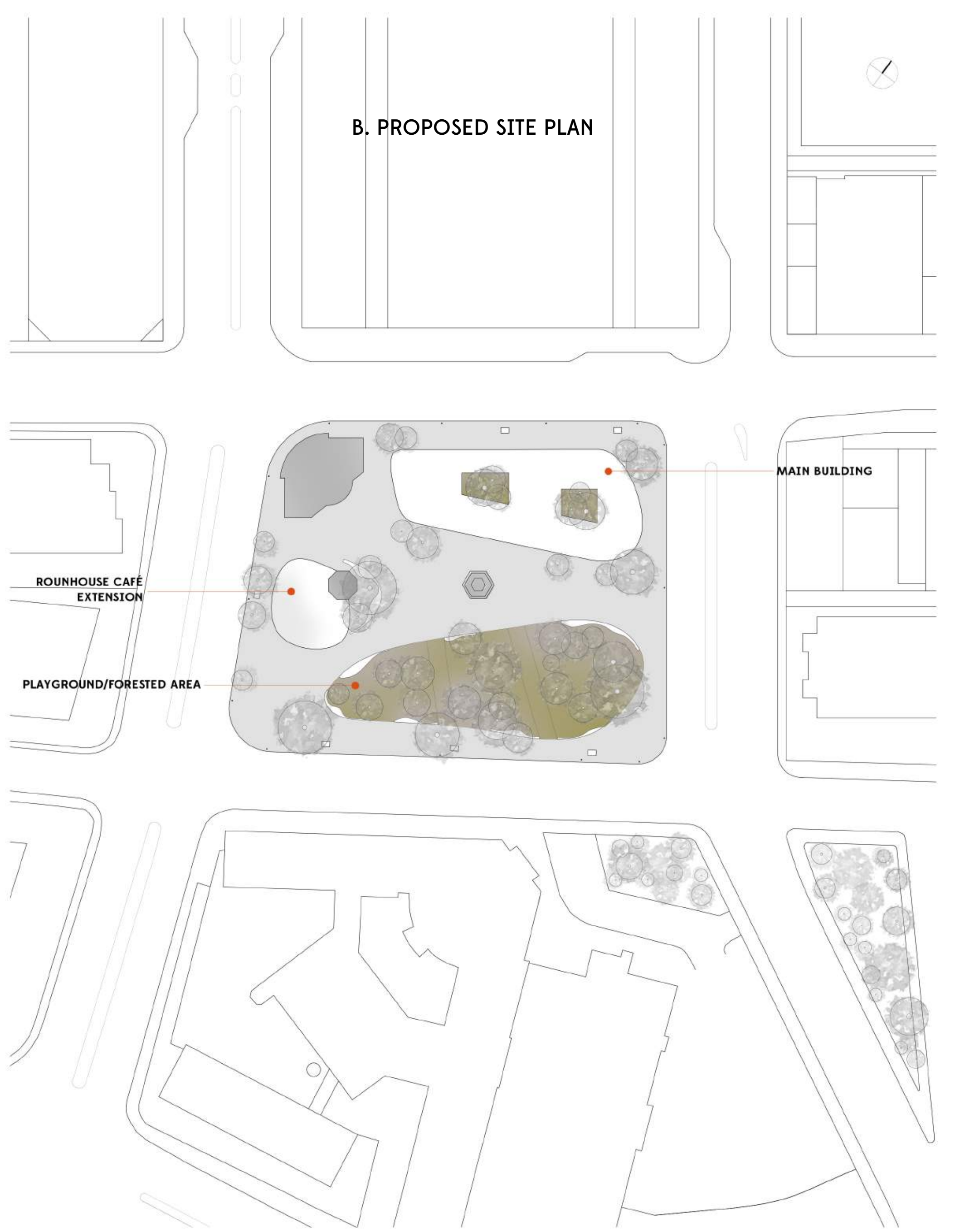


\section{GROUNDFLOOR PLAN}

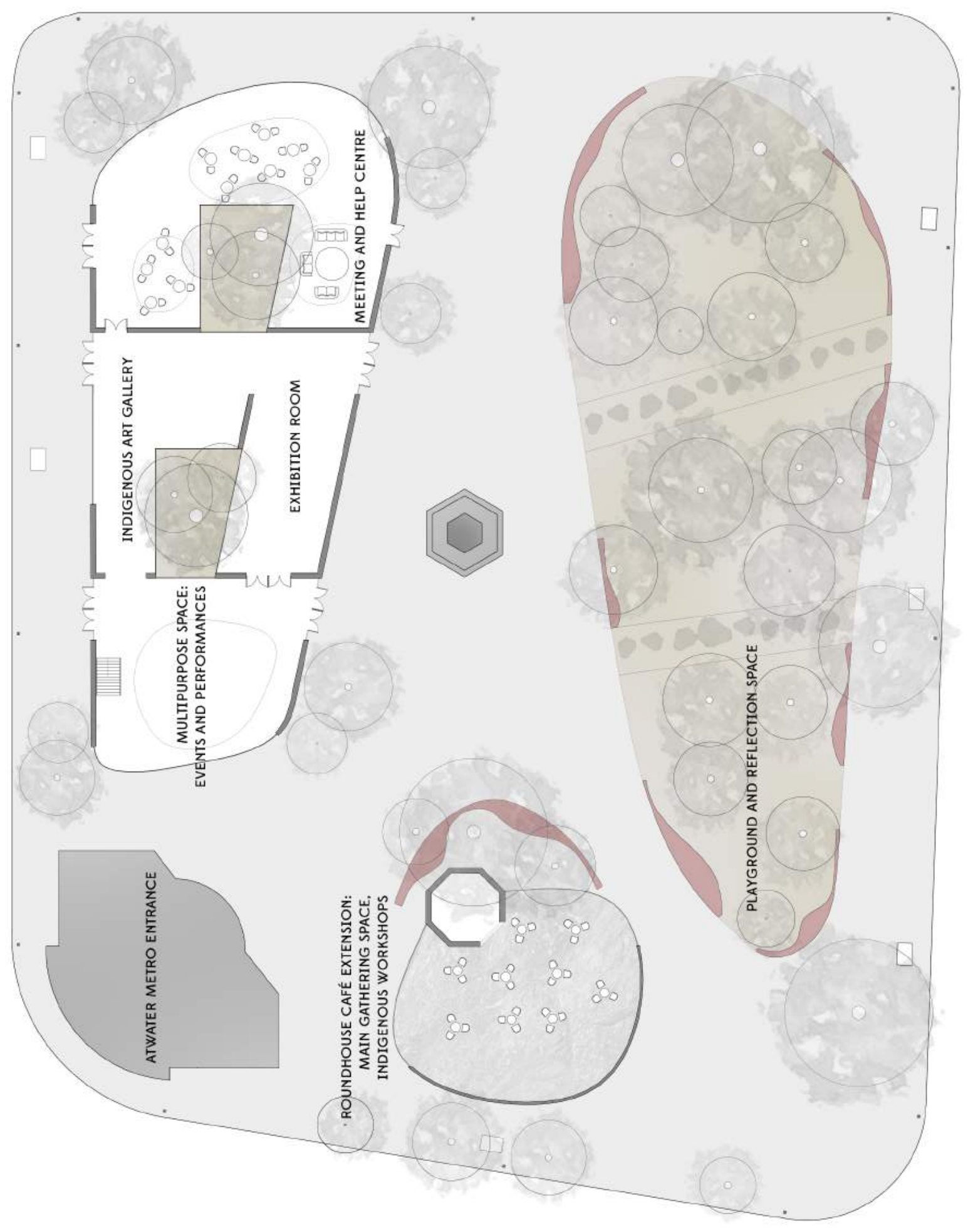




\section{AXOS}

DETACH

The detach principle from the methodology is applied to the new centre focal point of the square which is the Roundhouse Café (and new extension), it is the foundation concept of this thesis and distinguishes itself from the former focal point of the square which is the monument. The monument is here considered as the "solid" centre, while the new centre is considered the "open" centre, which could also be reflected as the new Indigenous centre of Cabot Square. This axo highlights the monument focal point moving towards the Roundhouse Café focal point, which is considered as the "detachement" principle.

\section{ENGAGE}

Engage expresses the core concept of this thesis, which is to create interaction and inclusivity within different communities at the square. This image highlights the proposed gathering spaces that allow for engagement whether it be with the occupants, with the space (exhibitions) or with Cabot Square itself. The pathways moving through the forested area are designed to create engagement with the nature and landscape elements of the park, while allowing for personal engagement and reflection as one passes through.

\section{CONSERVE}

This image highlights the defining elements of the square (metro entrance, Roundhouse Café, John Cabot monument and the trees). The intervention focuses on being compatible with the existing elements of the site, therefore conserving and respecting them. The "conserve" principle is also applied to the park frequenters since the basis of this project is to engage communities in the park, they are being "conserved" in their initial gathering place.
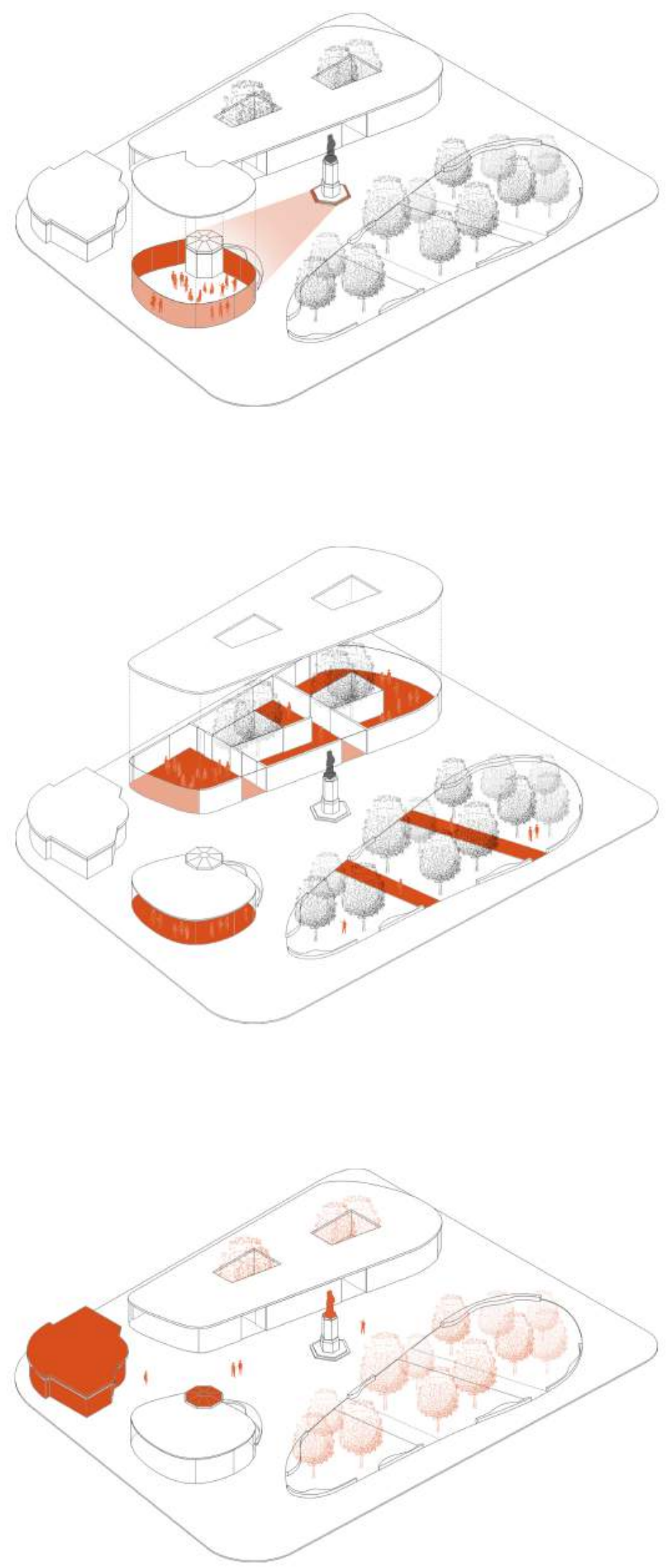


\section{E. DIAGRAMS}

A. The new design of Cabot Square introduced curvilinear benches around the trees, to preserve the trees, to differentiate space for the Roundhouse Café and to create pathways. The proposal aims to respect these shapes and preserve as many trees possible.

B. The bench footprint of the new design is entirely respected and shaped the main building, the café extension and the playground/forested area. As a landscape detail, the proposed benches are different and offer a more interactive approach. Further explained in detail drawing $\mathrm{I}$

C. Whether interior or exterior, a clear demarcation of the circulation is designed to guide people through the spaces and through the square, to not lose the original design intent of a public square. Further explained in detail drawing 2)
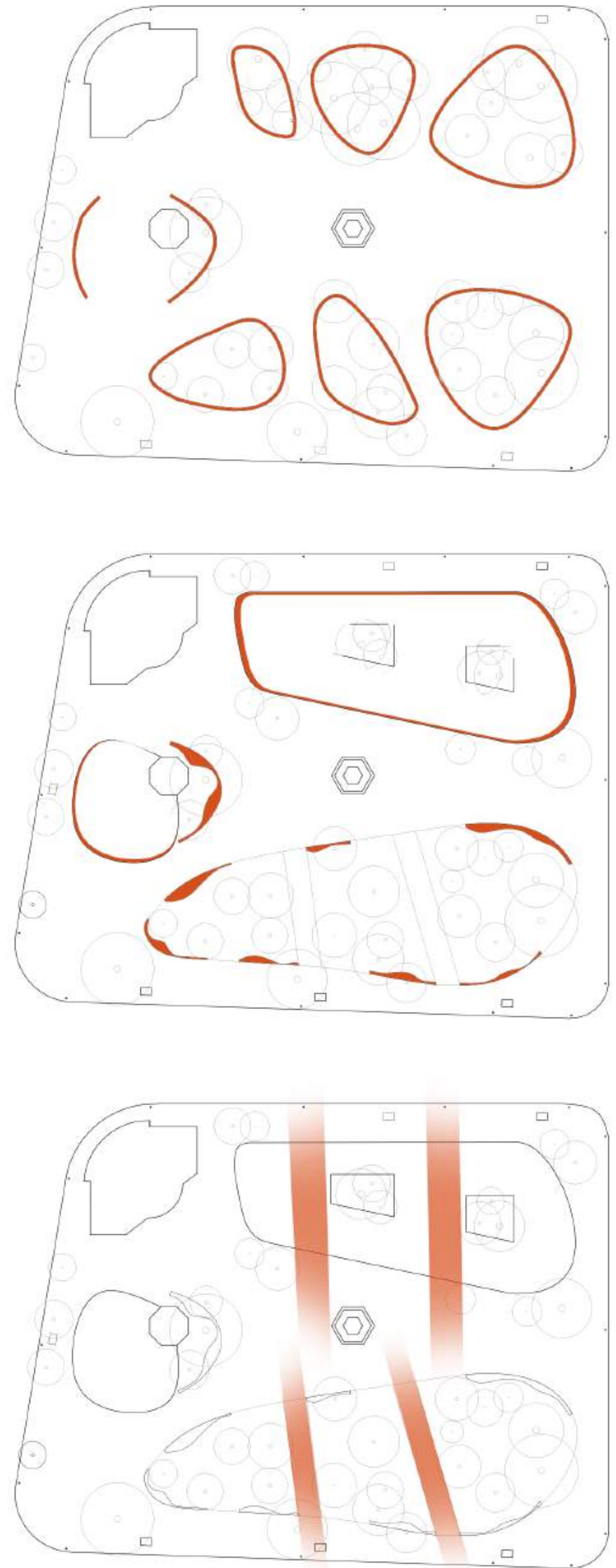


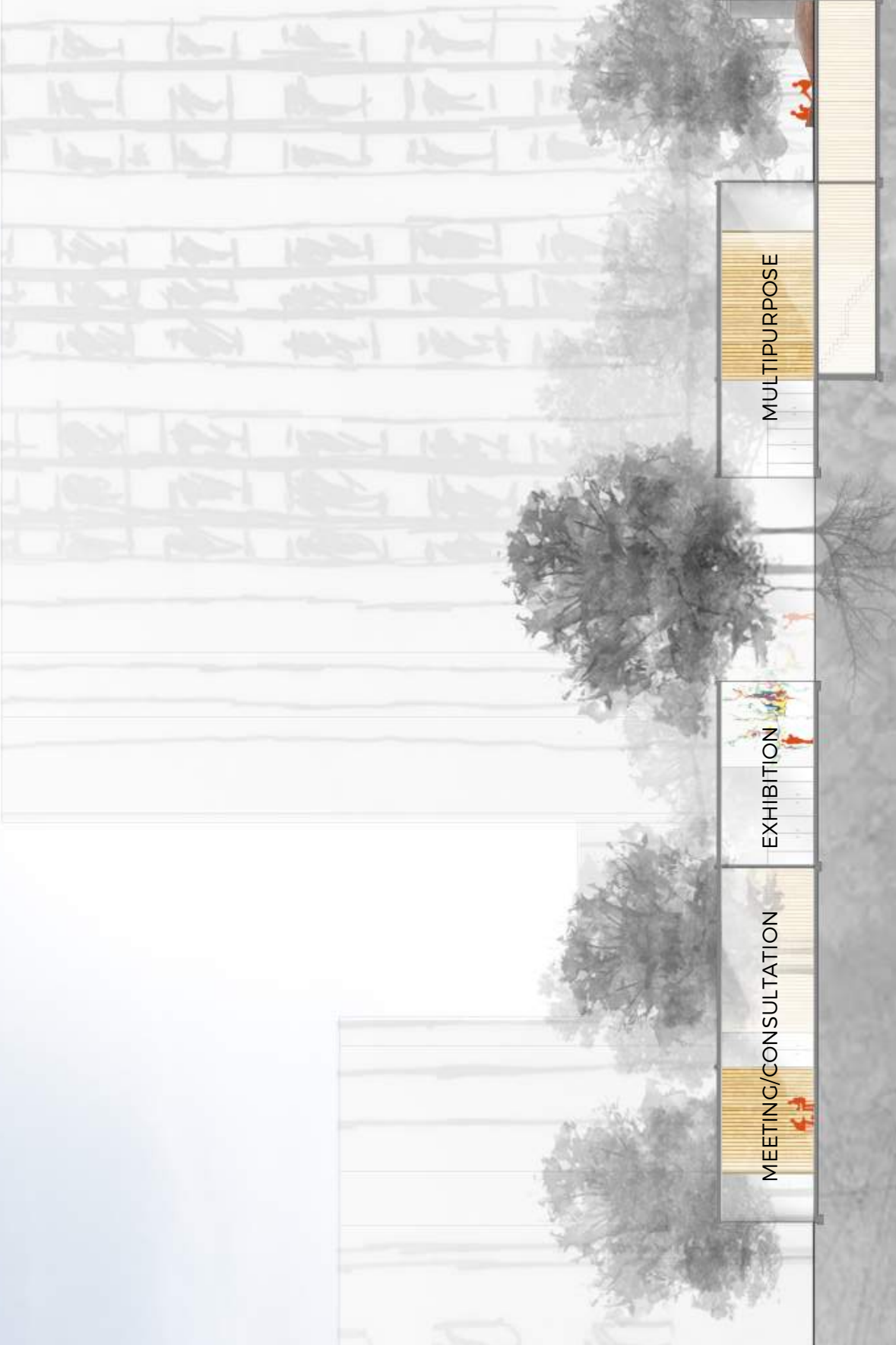




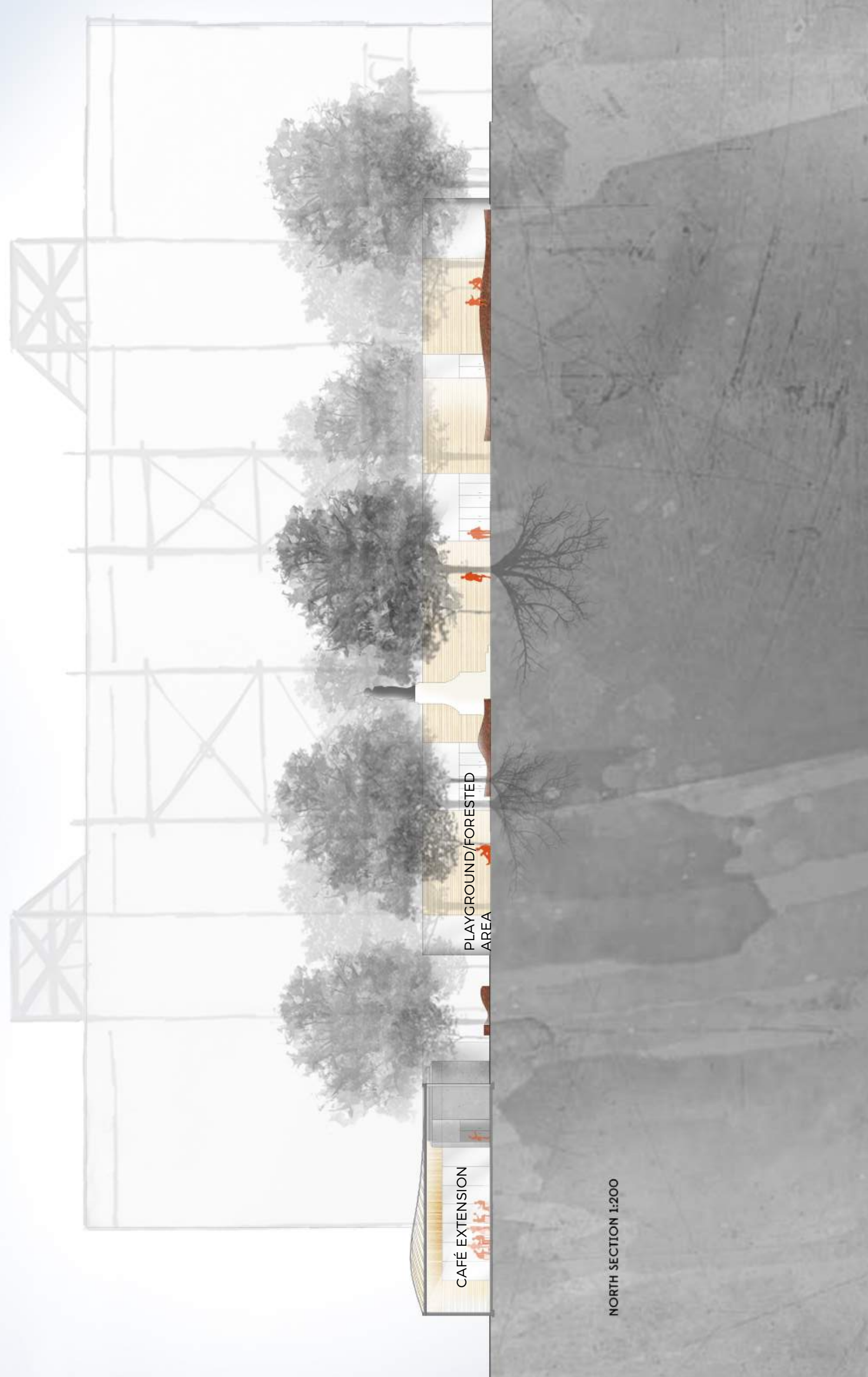




\section{a.}

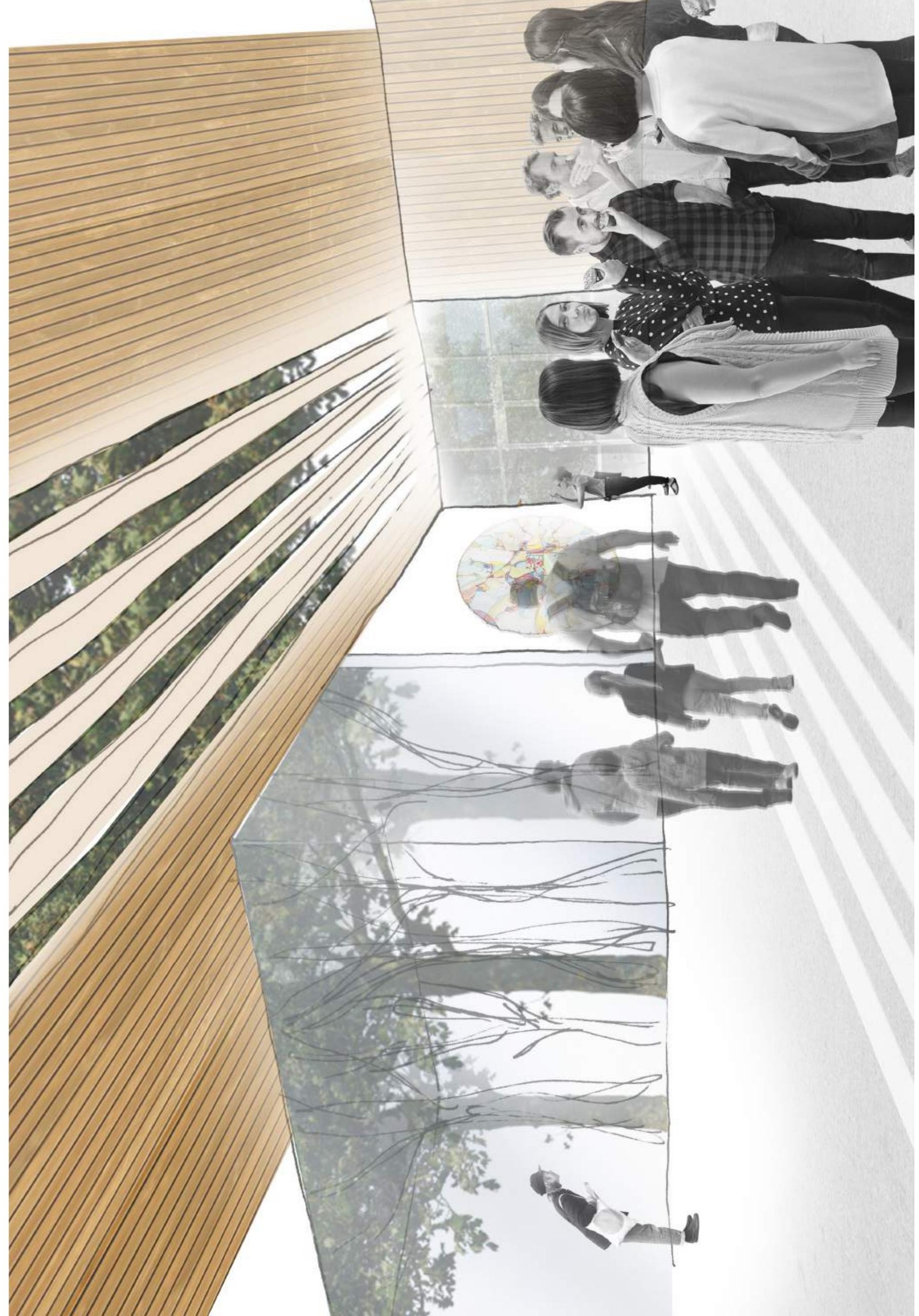


b.

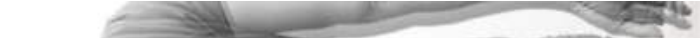
W. 3.

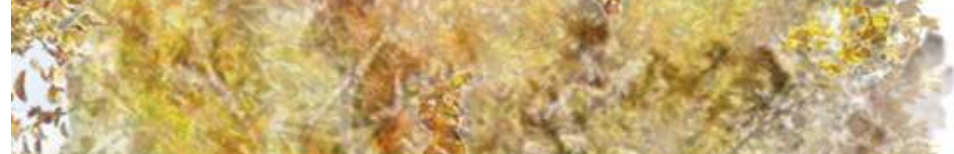
If

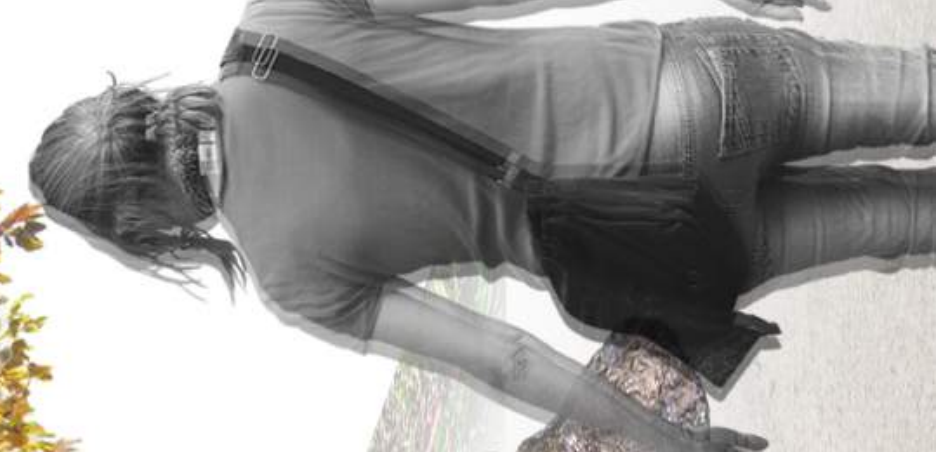
A

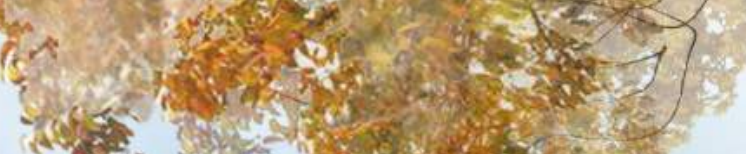

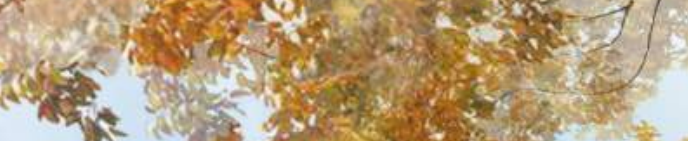
th

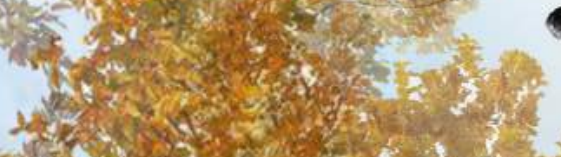

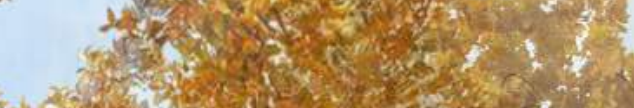

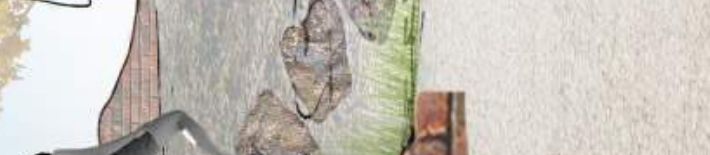

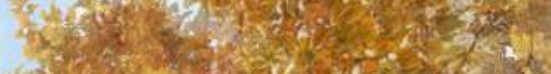

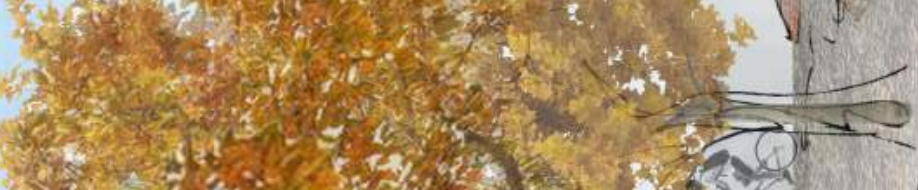

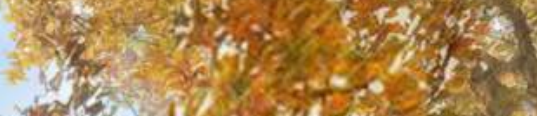

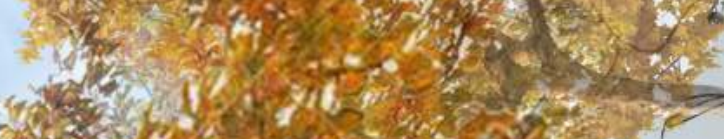

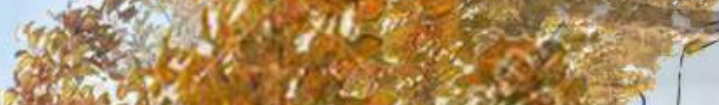
W. (2)

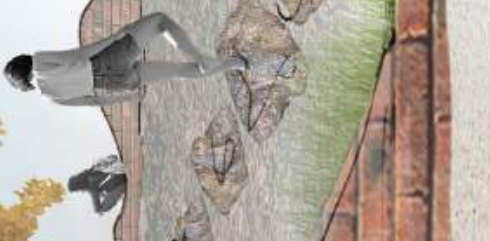

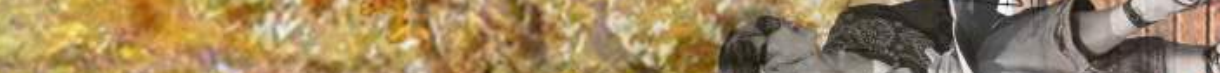
84. 
a. The first image expresses the interior view of the multipurpose space. Although this space is included in the main building, which covers an amount of space at the square, the circulation through the building allows for direct access to the square (highlighted in the diagram image, p.94). To highlight this, glass openings in the ceiling are proposed, also aiming to connect the occupants with the trees when looking up. The structures of the proposal are built with white pine. Named Ontario's official tree in 1984 , white pine was established as a valuable wood type in early Canadian history for products ranging from furniture to ship masts. ${ }^{8_{2}}$ It is considered one of the most valuable softwood lumbers because of its uniform grain and is an abundantly fast growing conifer, which makes it an important tree for reforestation. ${ }^{83}$ White pine also has a cultural significance to North American Indigenous communities. It is perceived as an important component of traditional life; pine is used in medicine, offers habitat for wildlife species, is a distinguished part of cultural landscapes and is included in many Indigenous legends. ${ }^{84}$

b. The second image expresses a view of the playground/ forested area that faces the main building. Although the space is designed to be used however the occupant chooses, there are suggested

\footnotetext{
82 “Extension Notes: Eastern White Pine”, LRC Online, Ontario, 1995, accessed 6 April 2017 http://www.Irconline.com/Extension_Notes_English/pdf/wht_pn.pdf 
paths created with hornfels stone. Which has an important significance to Montreal and to the history of the first Indigenous peoples who discovered Old Montreal. Hornfels reflects a connection with the early Indigenous people's (Lamoka) significant use of the material as tools for their hunter-gatherer lifestyle. Hornfels is a local rock from the Monteregian Hills, to which Mount Royal belongs, and is still plentiful at the mountain today. ${ }^{85}$ The bench at the front of the image is the new design proposed to replace the current benches, while aiming to respect part of their shape and placement. The idea of the curvilinear shapes (in plan) move with the trees, in elevation the benches are also curvilinear, creating moments for occupants to gather, instead of a traditional bench that sometimes holds a limited amount of space for people to sit together gather. The core concept of a gathering space is also applied to the benches (and not only the main structures), also offering landscape elements, which was important here since the proposal aims to work with the existing landscape. The shape of the benches also reflect water, connecting to the St-Lawrence River along the Old Port of Montreal, the first area of the island discovered by Indigenous groups and a main mode of transportation and transit to Montreal, historically and still today.

Repurposed red brick from the former Children's Hospital adjacent to Cabot Square is used for the material of the benches. The material highlights the association with children and caring for the youth, an important part of Indigenous life.

${ }^{85}$ Forget, Madeleine, Lauzon, Gilles, et al. Old Montreal: History through Heritage. Québec: Les Publications du Québec, 2004, 17. 
A final detail that should be mentioned for the benches is the collaboration with the square frequenters, especially the urban Indigenous community. Although the image shows brick as the proposed material, it would also be part of the project to allow the occupants to collaborate with the design of them, possibly including a mosaic, for example. This idea reflects the concept that decision making for this thesis would in reality include the input and ideas of the park stakeholders and Indigenous peoples. 
103 


\section{CONCLUSION}

The final proposal of this thesis is the result of a yearlong process seeking to understand and contribute to the growth of urban Indigenous identity in the urban context, specifically at Cabot Square. Since I come from a non-Indigenous perspective, there were many different marks of my project timeline trying to determine what is suitable for the frequenters, the site and the area. It was determined that once the methodology of 'Detach', 'Engage', and 'Conserve' was applied, which aims to fully encompass Indigenous identity in the city and the identity of Cabot Square itself, the proposal would result in a sympathetic, bold and simple design, offering an equally important program. The final proposal is essentially three elements (the Roundhouse Café extension, the main building and the playground/forested area) intervening the square, that function as three main gathering spaces creating a dialogue with Cabot Square and its heritage elements, and the core concept of community engagement here which includes not only the different communities at the park but also engagement with Cabot Square. This could further help contribute to community interactions and learning, focusing on the growth of the Indigenous community by supporting arts, culture and employment, while even facilitating familiarization with the area and the city. The research and methodology of this thesis seek to further transcend into other public areas in Montreal that have similar issues. 
A final understanding of this thesis project expresses that since the proposal's decisions were not possible to be made with the full contribution of the different communities and Indigenous peoples at the square, although majorly influenced by research and information found by and for the Indigenous community (mainly the Cabot Square Project by NETWORK), the proposal is still open and adaptable to further input and ideas. The spaces designed are solely created for the park occupants, focusing on the Indigenous frequenters, and it is now their space to occupy and chose how to use it, and help further develop it for the future. 



\section{BIBLIOGRAPHY}

Curtis, Michèle. "Thinking Outside of the Square: Cabot Square \& Place Émilie-Gamelin: Cultural Diversity in Changing Places", Carleton University, December 122016

Environics Institute. Urban Aboriginal Peoples Study: Montreal Report. Toronto: Environics Institute, 20Ir. Accessed 24 Apr 2017, http://reseaumtlnetwork.com/network-documents-and-reports/

Forget, Madeleine, Lauzon, Gilles, et al. Old Montreal: History through Heritage. Québec: Les Publications du Québec, 2004.

Galbraith, Robert. "Montreal Cabot Square Inuit Homeless Survive on the Street", 3 July 20I4, (Blog) accessed ir Dec. 2or6, http://robertgalbraith.com/

Kelly, Jeanette. "Gritty Parc Émilie-Gamelin gets glamorous makeover" CBC News, CBC News, 8 May 20г5. Accessed п Dec, 2016. http://cbcnews.ca/news/canada/montreal.

Montreal Urban Aboriginal Community Strategy Network. Final Report, Project: Learning from Cabot Square - Developing the Strategy for Community Safety and Wellbeing. Montreal: Montreal Urban Aboriginal Community Strategy Network, 2013. Accessed 3 Jan 2017, http://reseaumtlnetwork.com/network-documents-and-reports/

Newhouse, David, Peter, Evelyn. "No Strangers in These Parts" Policy Research Initiative: Aboriginal Policy Research Conference. Nov. 2002.

Pucci, Michelle, "Election Candidates Weigh in on Future of Former Montreal Children's Hospital Site", CBC Nexss, Aug 27 20r5, accessed 3 Jan 20I7, http://montrealgazette.com/news/local-news/electioncandidates-weigh-in-on-future-of-former-montreal-childrens-hospitalsite

Sealy, Peter. "Cabot Square Redux", Canadian Architect. Accessed 24 Apr 2017,.https://www.canadianarchitect.com/features/cabot-squareredux/ 
Sudhakar, Kuruvada. "What was John Cabot's relationship with the Indians?" blog post from Yahoo.com, 20I4. Accessed Apr. 3o 2017. https://answers.yahoo.com/question/index?qid=2013on of

Thompson, Susan, "Home and Loss", Media Culture Journal, Aug 2007, accessed 3 Jan 20I7, http:/journal.media-culture.org.au/ozo8/o7thompson.php

Uprety, Yadav et al., "Cultural importance of white pine (Pinus strobus L.) to the Kitcisakik Algonquin community of western Quebec, Canada", Canadian Journal of Forest Research, 26 March 2013, accessed 6 April 20I7, http://www.nrcresearchpress.com/doi/abs/ıo.ı39/cjfr-

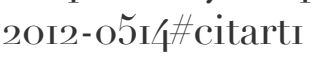

Valois, Paradis. "Place Émilie-Gamelin in Montréal: Landscape Narrative, Meaning and the Uses of Public Space". Journal of Landscape Architecture, 20I0: 5:2, 72-83. Accessed II Dec. 2016

Wilkins. "Cabot Square, Formerly Western Square." Wordpress, Montreal Gazette, 3o Nov. 2013, accessed II Dec 2016, http://rnwilkins.wordress.com/

Zhai, Binqing. "Definition and Concept of Urban Squares in View of Urban Spaces and Buildings" Bulletin of the Georgian National Academy of Sciences, 20I4: vol. 8 no.r. Accessed 9 Dec. 2or6, http://bnas.org/.

A\&E Television Networks. "John Cabot", Biography. April 282017. Accessed 3o Apr. 2017. http://www.biography.com/people/john-cabot9234057

"Fact Sheet- Urban Aboriginal Population in Canada", Urban Indigenous Peoples, Indigenous and Northern Affairs Canada, Government of Canada. Accessed 20 Apr 2017, http:/www.aadncaandc.gc.ca/eng/ıгогооог/298/ıгогоогі402

"Former Montreal Children's Hospital Officially Sold to Developer for \$25M", CBC News, 2 Dec 2or6, accessed 3 Jan 2017,

http:/www.cbc.ca/news/canada/montreal/former-montreal-children-shospital-officially-sold-to-developer-for-25m-г.387857 
"Fragmentation (sociology)", Wikipedia, accessed 3 Jan 2017, https://en.wikipedia.org/wiki/Fragmentation_(sociology)

Dictionary.com, accessed 3 Jan 2017, http://www.dictionary.com/browse/detach?s=t

Environics Institute. Urban Aboriginal Peoples Study: Montreal Report. Toronto: Environics Institute, 20II. Accessed 12 Oct 2016, http://reseaumtlnetwork.com/network-documents-and-reports/

"Extension Notes: Eastern White Pine", LRC Online, Ontario, 1995̆, accessed 6 April 2017 http://www.Irconline.com/Extension_Notes_English/pdf/wht_pn.pdf Interpretation and Presentation of Cultural Heritage Sites. ICOMOS, $6^{\text {th }}$ GA, Québec, 2008.

New Life for Historic Cities: The Historic Urban Landscape Approach Explained. UNESCO, Paris, France, 2013.

"Skwachàys Story", Skwachays, accessed 3 Jan 2017, http://skwachays.com/the-lodge/

Standards and Guidelines for the Conservation of Historic Places in Canada (2010). Canada's Historic Places. Accessed 3o Apr. 2017,

http://www.historicplaces.ca/en/pages/more-plus/contact.aspx

Wabano, accessed 3 Jan 2017, http://www.wabano.com/about/

"Ville-Marie, Montreal", Wikipedia, 5 December 2or6, accessed 3o March 20I7, https://en.wikipedia.org/wiki/Ville-Marie_Montreal 
APPENDIX

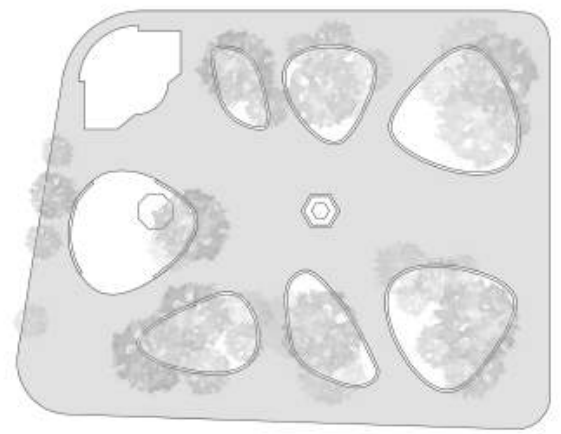

A. EXISTING GARDEN BEDS

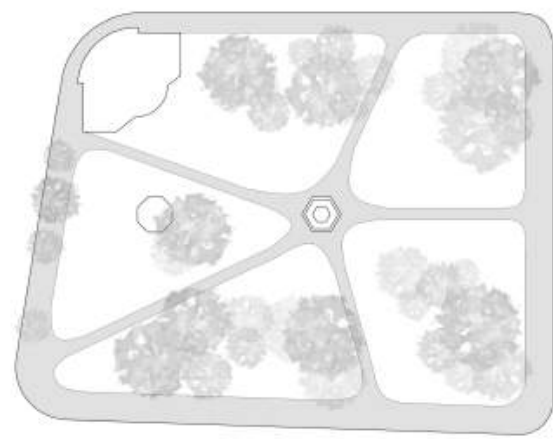

B. SPACE DEVIDED INTO PROCRAM AND NEW PATHWAYS

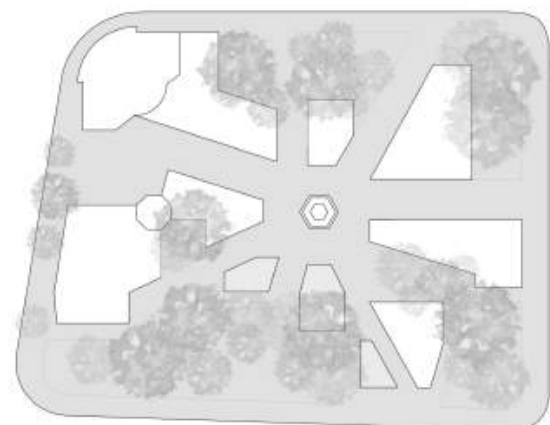

C. PATHWAY PROPOSAL 


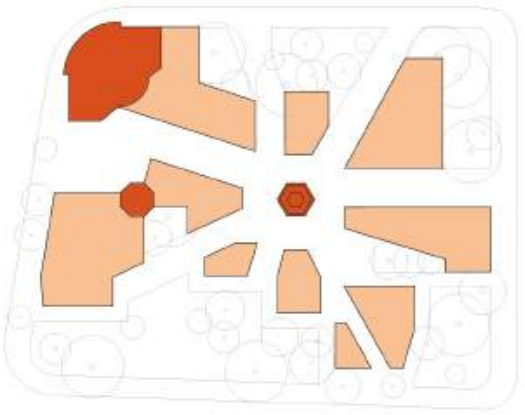

- EXISTINC BUILDINCS

- GATHERINC SPACES

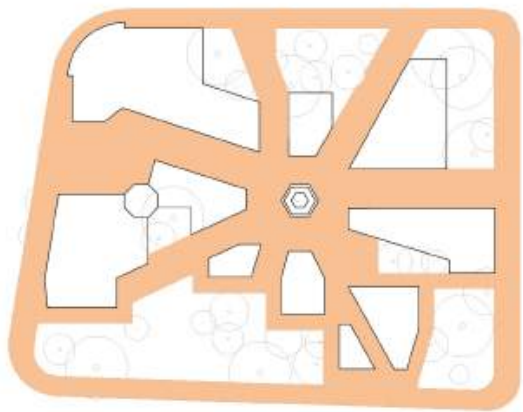

EXTERIOR SQUARE CIRCULATION

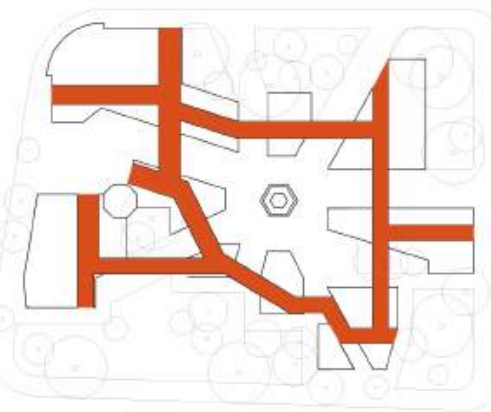

- circulation throughout spaces

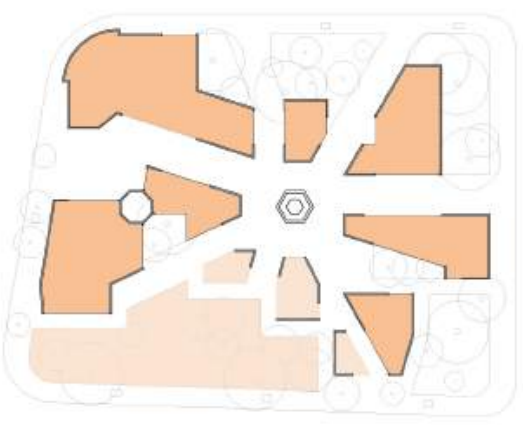

- INTERIOR SPACES
EXTERIOR SPACES

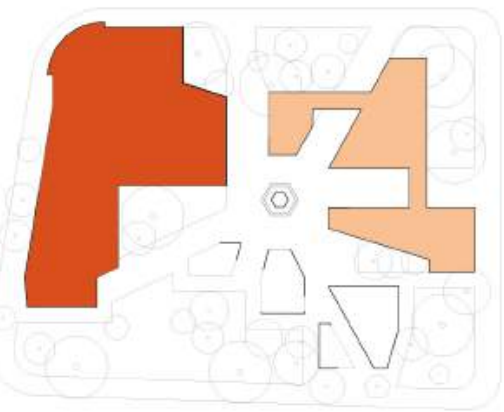

- UNDERGROUND CONNECTION

- ABOVECROUND CONNECTION 


\section{GROUNDFLOOR PLAN}

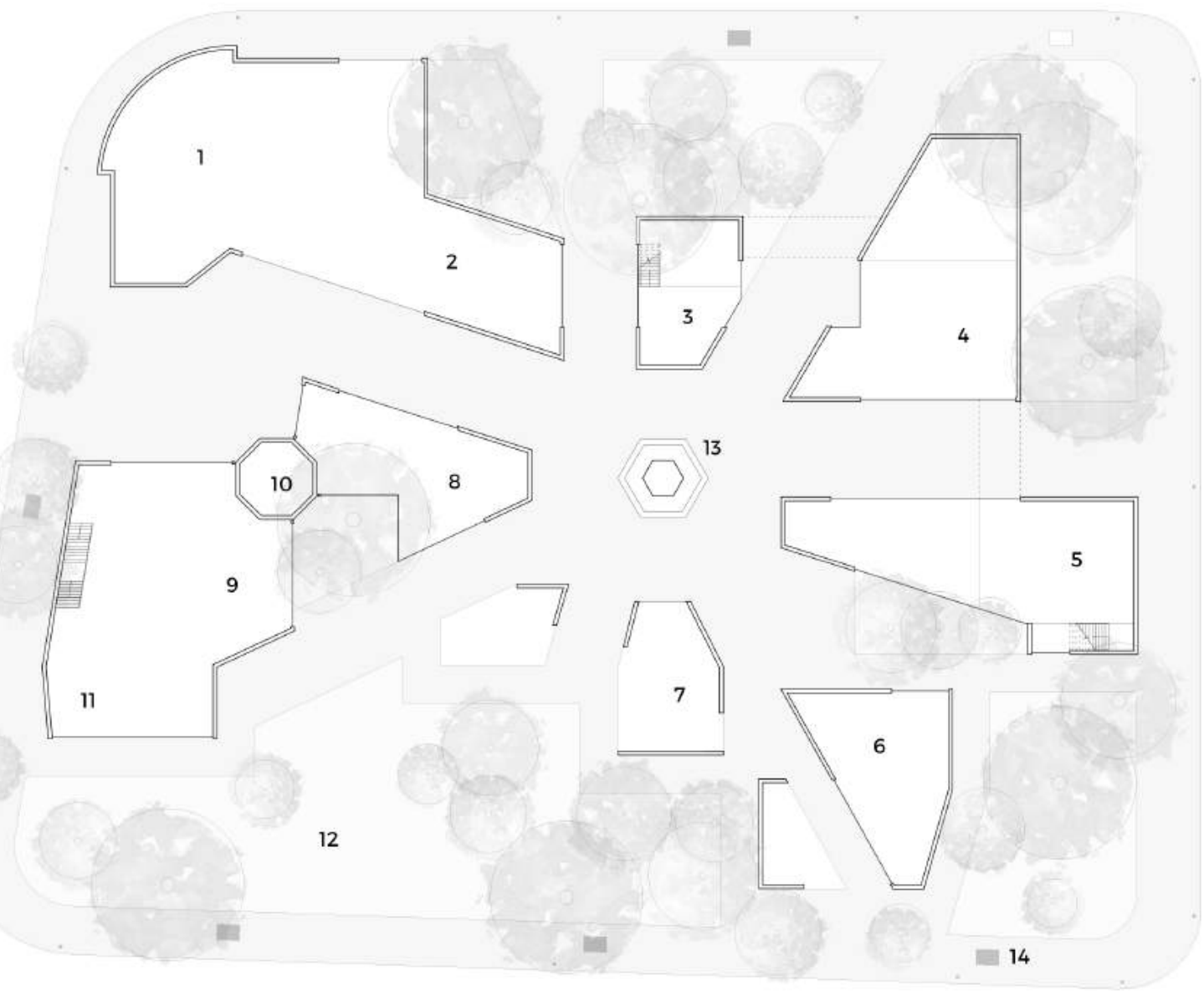

1. ATWATER METRO ENTRANCE (existing)

2. EVENT HALL/ MULTIPURPOSE

3. INDIGENOUS GALLERY BOUTIQUE

4. HELP CENTRE: RECEPTION, PRIVATE CONSULATION SPACE

5. HELP CENTRE: "LIVING ROOM" PUBLIC CONSULTATION SPACE

6. MEDITATION SPACES

7. PERFORMANCE SPACE

8. EXHIBITION SPACE

9. EXTENDED CAFÉ

10. ROUNDHOUSE CAFÉ (existing)

11. INDIGENOUS WORKSHOP SPACE 


\section{SECOND FLOOR PLAN}

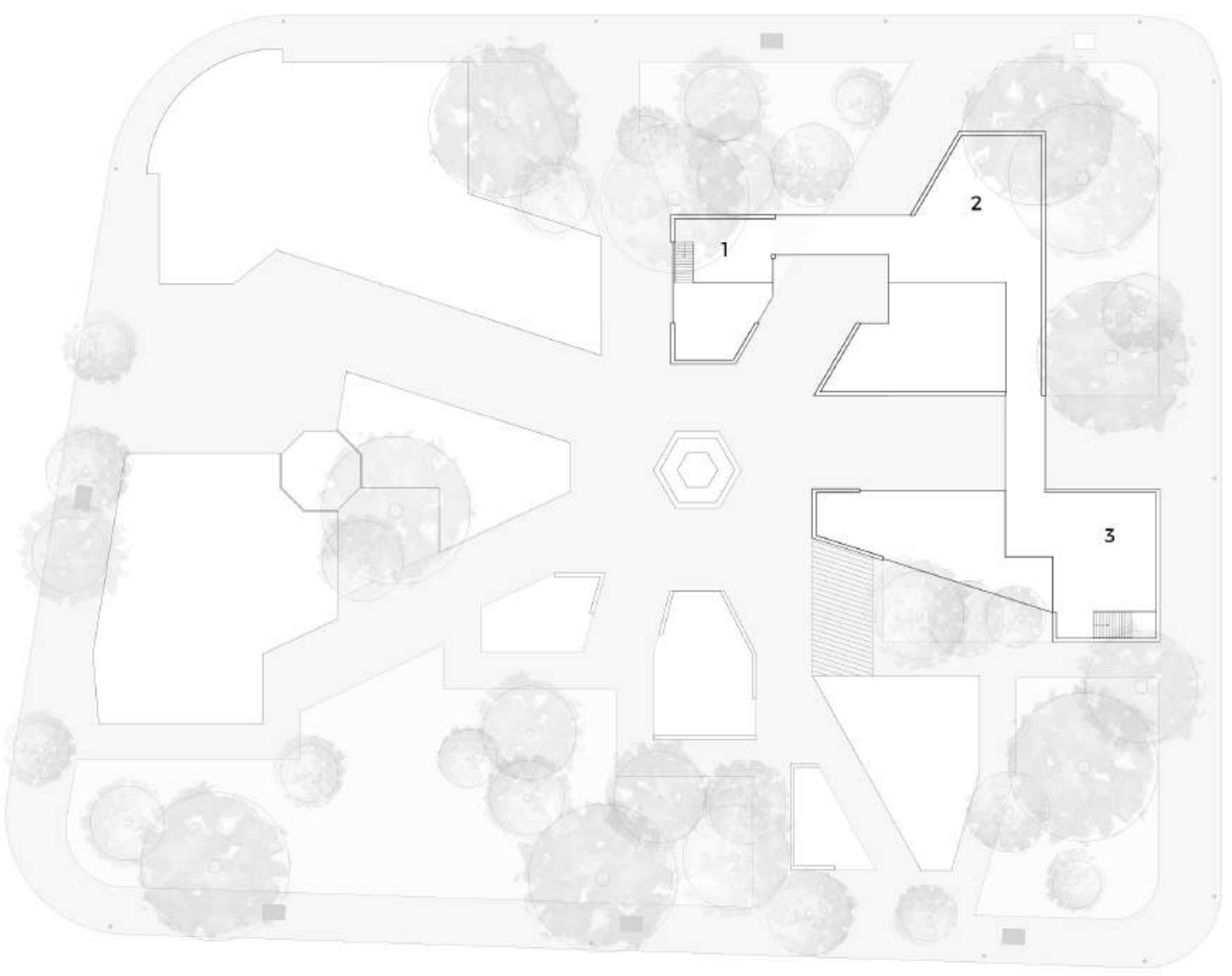

1. GALLERY: OFFICE

2. HELP CENTER: OFFICE

3. HELP CENTER: READING AND LISTENING SPACE 


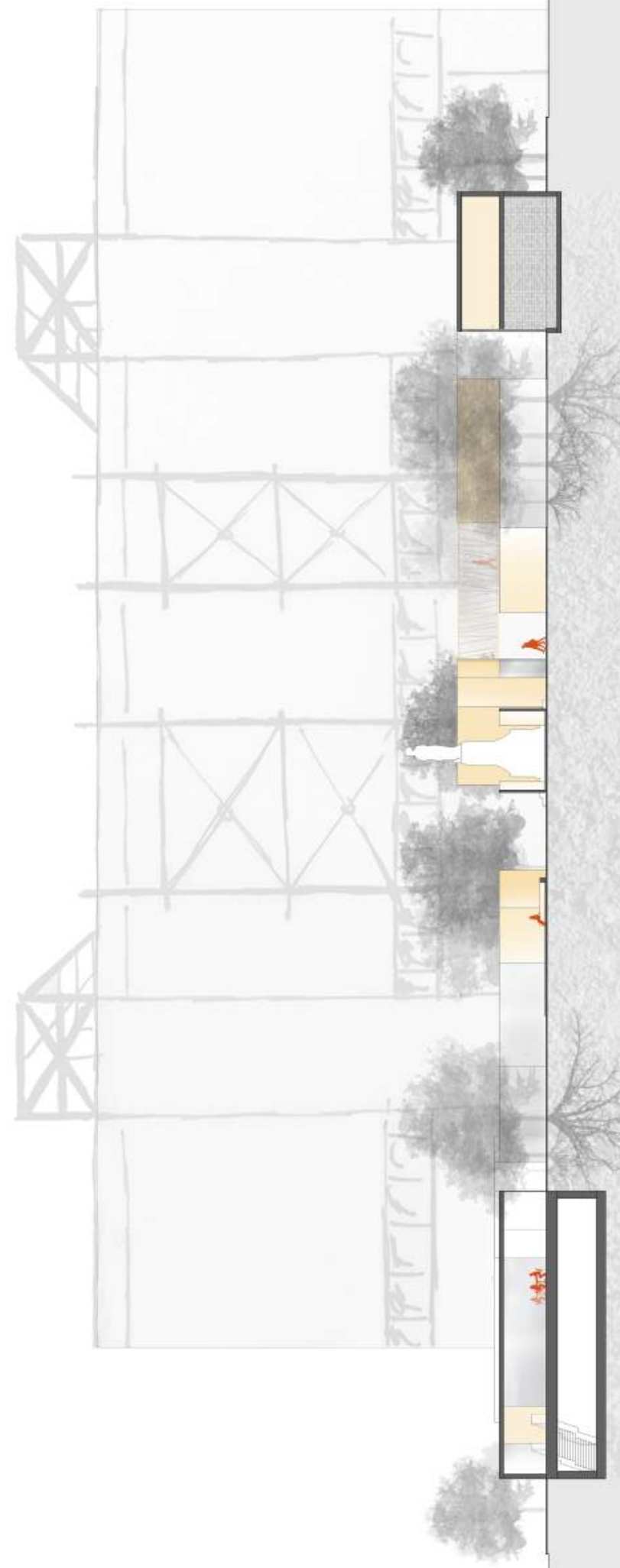




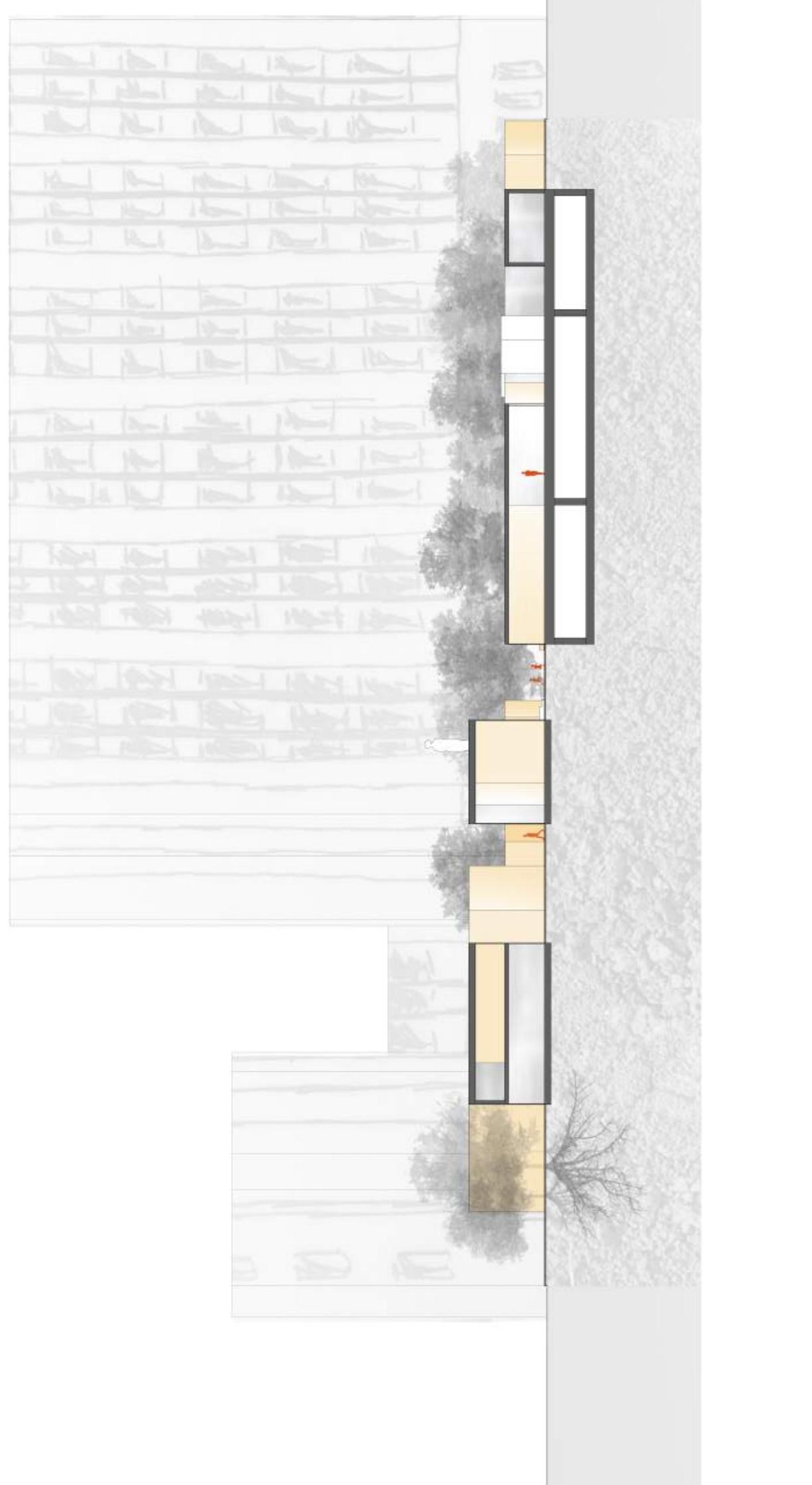




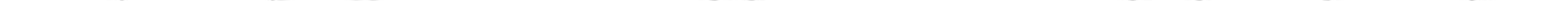


The following vignettes represent the three core approaches developed for the design methodology. The first vignette aims to reflect the notion 'Detach'; the different spaces are designed in a way that gives a sense of fragmentation and separation.

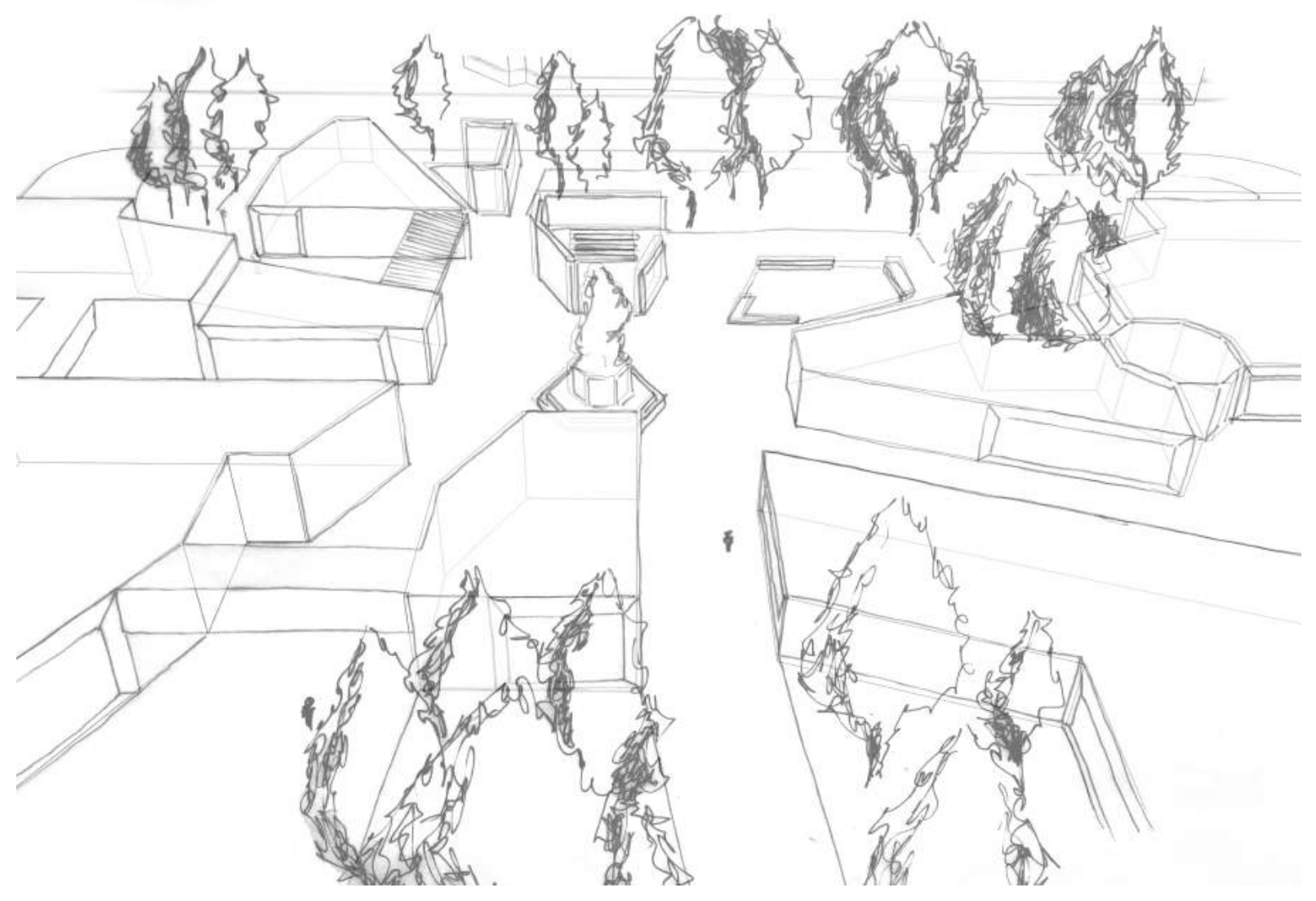


The second vignette reflects the notion 'Engage'. The windows are designed to frame the adjacent buildings (including the adjacent existing programs), intending to engage and involve occupants from the inside as well as people from the outside looking into the proposed spaces.

The trees in Cabot Square essentially shape the design and pathways. By leaving the trees as one of the main focal elements of the square, frequenters are engaged and integrated with its original context.

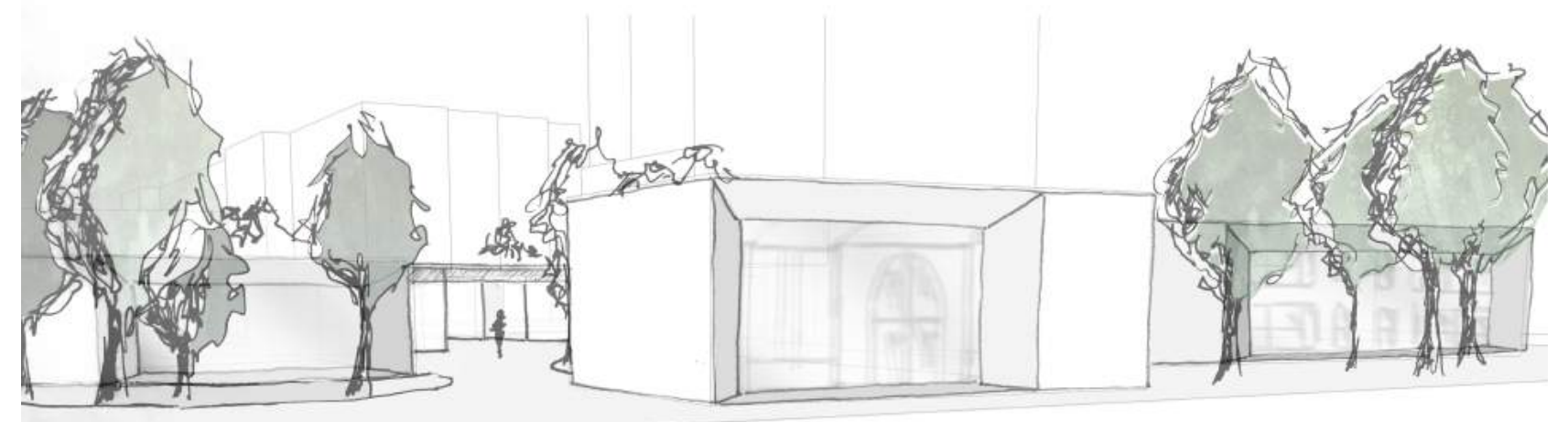


The third vignette represents the "Conserve" principle. The Rounhouse Café, the Atwater metro entrance and the monument all have historical and cultural associations established by the frequenters of the square and are completely incorporated in the design.

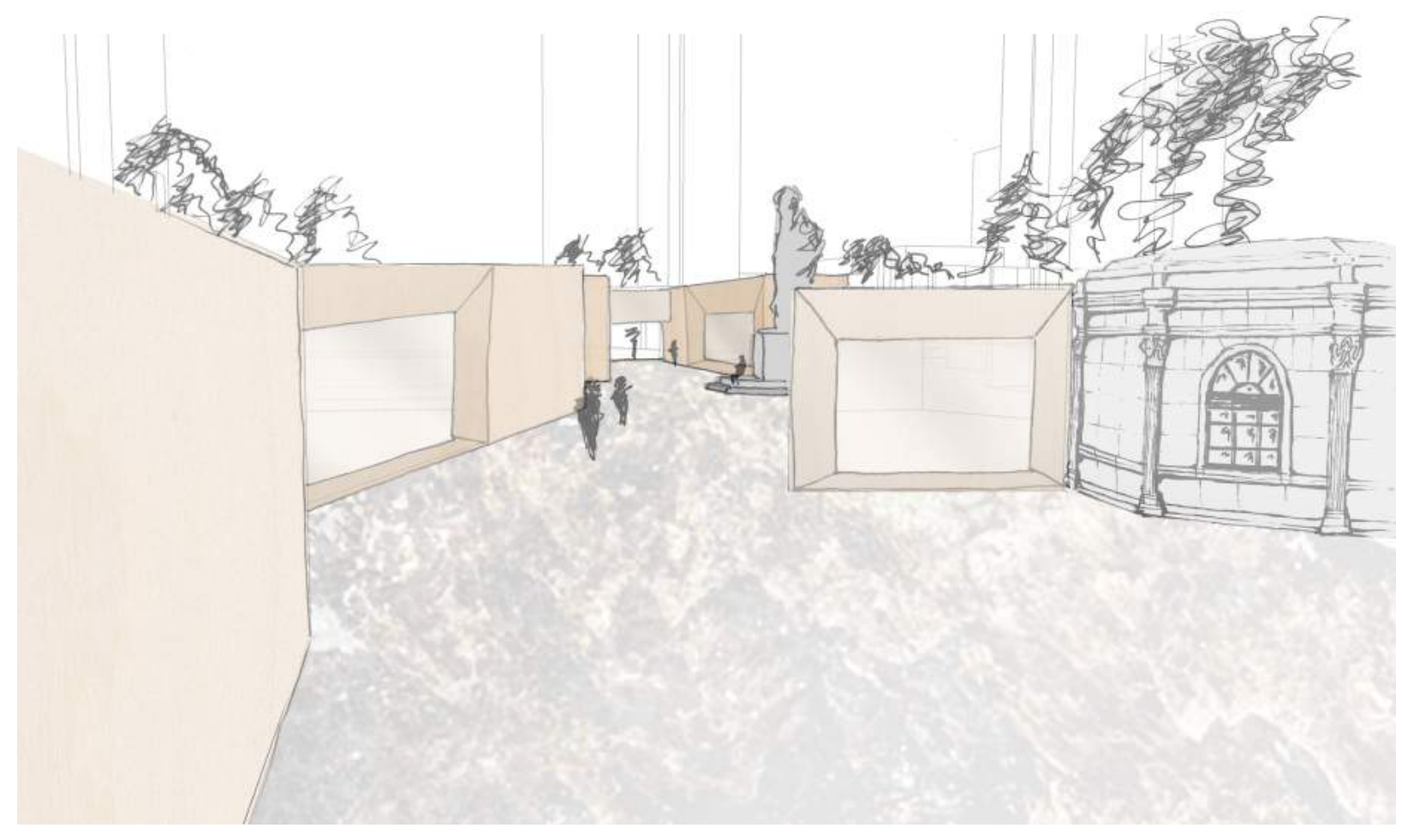

